\section{UNITED NATIONS UNIVERSITY}

\section{UNU-IAS}

Institute for the Advanced Study of Sustainability

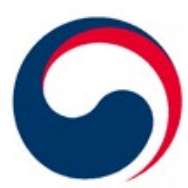

Rural Development

Administration

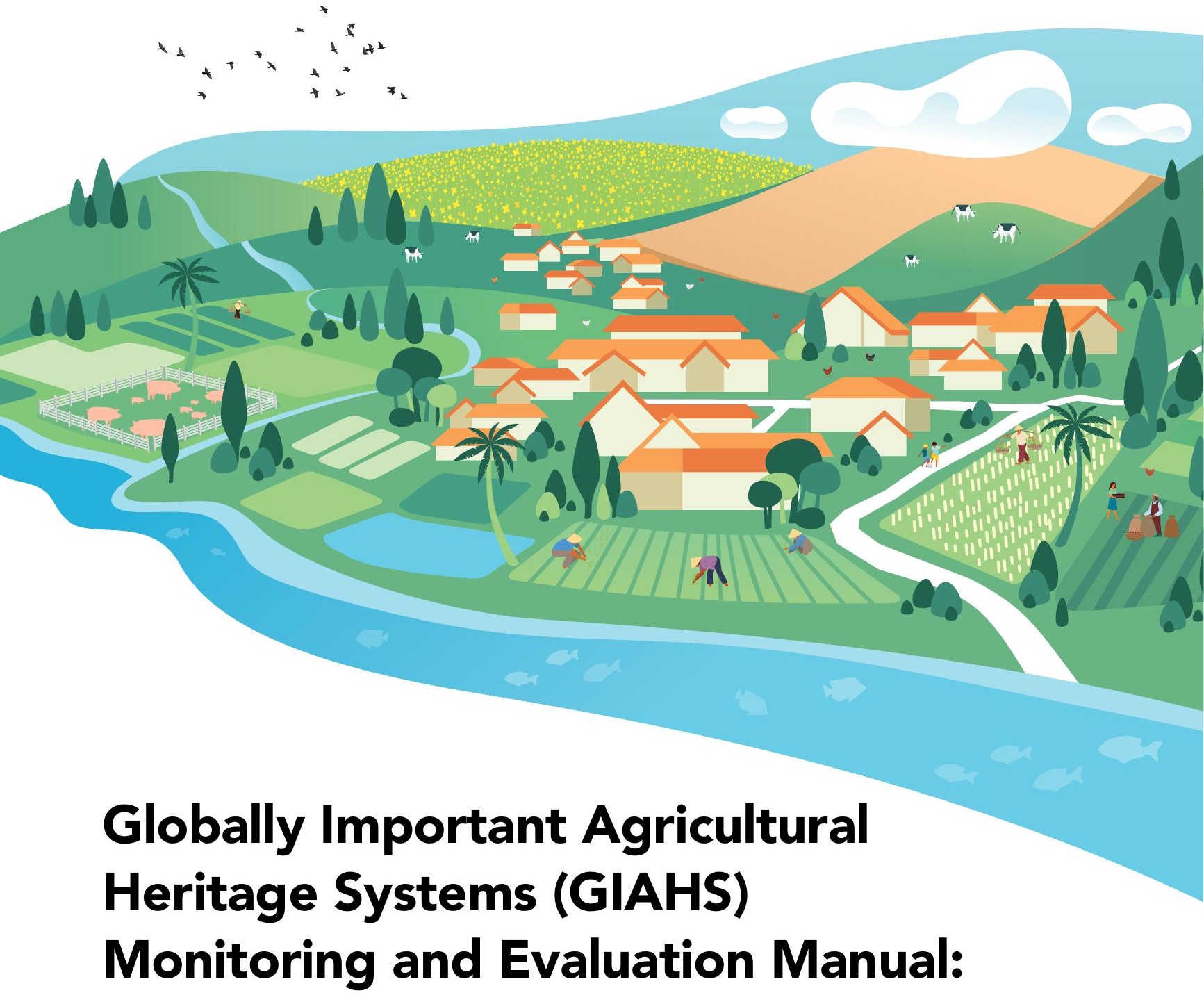

A Technical Reference

United Nations University Institute for the Advanced Study of Sustainability (UNU-IAS), in partnership with the Rural Development Administration of the Republic of Korea (RDA) 
Citation

Yiu, Evonne, Jang, Bosun, Owada, Junko, Jeong, Myeong-chul, and Hwang, Daeyong. (2022). Globally Important Agricultural Heritage Systems (GIAHS) Monitoring and Evaluation Manual:

A Technical Reference. United Nations University Institute for the Advanced Study of

Sustainability, Tokyo.

(C) United Nations University

ISBN 978-92-808-4650-8 (print version)

ISBN 978-92-808-4600-3 (e-version)

DOI

https://doi.org/10.53326/FMNS6151

\section{Authors}

Evonne Yiu (UNU-IAS), Bosun Jang (UNU-IAS), Junko Owada (Doshisha University),

Myeong-chul Jeong (RDA), Daeyong Hwang (RDA)

Corresponding authors

Evonne Yiu (yiu@unu.edu) and Bosun Jang (bosun.jang@unu.edu)

\section{Feedback and enquiries}

UNU-IAS Operating Unit Ishikawa Kanazawa (UNU-IAS OUIK) (unu-iasouik@unu.edu)

\section{Design}

Xpress Print Pte Ltd

\section{Photo credits}

(C) Damyang County (pg. 53, 81)

(c) GIAHS Ayu of the Nagara River System (pg. 15)

(c) GIAHS Takachihogo-Shiibayama Revitalization Association (pg. 5)

(c) Hadong County (pg. 43)

() Jeju Special Self-Governing Province (pg. 9)

(C) Osaki GIAHS Promotion Association (pg. 67)

(C) RDA (pg. 1)

() UNU-IAS/Evonne Yiu (pg. 8, 42, 51, 63, 73, 75)

() Wando County (pg. 18-19)

This publication is printed on recycled paper.
11 UNITED NATIONS

$\geqslant$ UNIVERSITY

UNU-IAS

Institute for the Advanced Study

of Sustainability Administration

\section{Globally Important Agricultural Heritage Systems (GIAHS) \\ Monitoring and Evaluation Manual:}

A Technical Reference 
UNITED NATIONS

UNU-IAS

Institute for the Ad
of Sustainability

\section{ias.unu.edu}

The United Nations University Institute for the Advanced Study of Sustainability (UNU-IAS) is a research and teaching institute dedicated to realising a sustainable future for people and our planet. Based in Tokyo, Japan, UNU-IAS serves the international community by producing evidence-based knowledge and solutions to inform policymaking and address priority issues for the UN system.

Through policy-oriented research and capacity development the institute drives progress in four thematic areas: governance for sustainable development, biodiversity \& society, water \& resource management, and innovation \& education.

\section{Q}

Rural Development

Administration

\section{rda.go.kr}

With its mission of achieving a 'bright future for agriculture and happy rural community' with all farmers, since its establishment in 1962, the Rural Development Administration (RDA) of the Republic of Korea has pioneered R\&D for agricultural development, guidance, and training of farmers, and training of rural leaders. An independent branch of the Ministry of Agriculture, Food and Rural Affairs (MAFRA), RDA aims to further develop and strengthen the Korean agriculture industry into a leading export industry. To that end, RDA continues to generate advanced agricultural technologies with practical applications that will benefit the farmers. Its areas of focus are basic agricultural science and technology, development of steady supply of food and value-added technology, horticultural crop production, animal science, and strategic technology development. 
- ince its launch in 2002 at the World Summit on Sustainable Development in Johannesburg, South Africa, the Globally Important Agricultural Heritage Systems (GIAHS) initiative has come a long way. Initially funded by the Global Environment Facility (GEF), it evolved into a formal programme of the Food and Agriculture Organization of the United Nations (FAO) in 2016. As of January 2022 the GIAHS programme has 62 designated sites across 22 countries, and many more applications pending.

The GIAHS programme nonetheless remains relatively young, and nested within global efforts to achieve the Sustainable Development Goals. The international community remains in the midst of recognising agricultural heritage systems and defining their timeless compatibility with the modern world of fast-paced technological advancement and socioeconomic transformation. Through the GIAHS programme we are uncovering the multi-faceted ways in which traditional methods of production and cultural practices contribute to the sustainability of humanity and the environment.

The Rural Development Administration (RDA) and the United Nations University Institute for the Advanced Study of Sustainability (UNU-IAS) have developed leading roles in GIAHS initiatives in the Republic of Korea and Japan, respectively. Since 2012, RDA has been at the forefront of efforts to identify agricultural heritage systems, conducting research and development and empowering local communities with technical support for conservation and management activities, including the recent launch of community-based participatory monitoring and evaluation (PM\&E). Its contributions have led to the establishment of the Korean Important Agricultural Heritage Systems (KIAHS) initiative, under which 16 regions have obtained KIAHS designation. Five of them have successfully received the FAO GIAHS designation, as part of the Republic of Korea's effort to promote the cultural and ecological value of agricultural heritage systems and sustain wisdom that stands the test of time - not only within the country, but also at a global scale.

The engagement of UNU-IAS in the GIAHS programme dates back to 2009, when Japan became the first developed country to prepare an application for GIAHS designation. UNU-IAS provided technical assistance to the Government of Japan and municipal governments, leading applications for "Noto's Satoyama and Satoumi" in Ishikawa Prefecture and "Sado's Satoyama in Harmony with Japanese Crested Ibis" in Niigata Prefecture. These first two GIAHS designations in 2011 have paved the way for nine more, and the establishment of the Japanese Nationally Important Agricultural Heritage Systems (J-NIAHS). UNU-IAS continues to support agricultural heritage systems across Japan, conduct studies, and provide policy recommendations. We are collaborating with governments, organisations, and research institutes across East Asia, including in the People's Republic of China, Japan, and the Republic of Korea, on information-sharing, research, and advocacy. Together with

these three countries, UNU-IAS co-founded the East Asia Research Association for Agricultural Heritage Systems (ERAHS) in 2013, and is serving as its secretariat in Japan to bridge academic knowledge with policymaking for the sustainable conservation of GIAHS.

This collaboration includes the research project, Introduction of Technologies on Characteristic Analysis and Conservation Management in Agricultural Heritage Systems, implemented in partnership between UNU-IAS and the RDA since 2018. It aims to contribute towards institutionalising monitoring and evaluation at the core of GIAHS governance and as an integral part of the process to design and update the GIAHS Action Plans for existing and aspiring GIAHS, in Japan, the Republic of Korea, and beyond. This publication is one of the key outcomes of the project.

Achieving this vision will require broader and deeper efforts; it is contingent upon partnerships across the international community, governments at the national and local levels, stakeholder bodies and social organizations, and everyday citizens who live in and benefit from agricultural heritage systems. GIAHS and their valuable contribution to society cannot last in the absence of appropriate support structures and resources.

We present this Manual with the deepest gratitude to the GIAHS community across the globe, for the milestones reached to date and its contributions to the continued progress of GIAHS. Much like the story of the GIAHS programme, it is a testament to the possibilities that partnerships can realise. It is our hope that this resource is received enthusiastically and proves instrumental to the efforts of the GIAHS community as we build a more sustainable future together.

\section{Prof. Shinobu Yume Yamaguchi \\ Director}

United Nations University Institute for the Advanced Study of Sustainability (UNU-IAS)

\section{Park Byunghong}

Rural Development Administration (RDA) of the Republic of Korea 


\section{ACKNOWLEDGEMENTS}

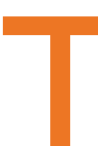

he Globally Important Agricultural Heritage System (GIAHS) Monitoring and Evaluation Manual: A Technical Reference (hereafter referred to as "the Manual") is a research output of the "Introduction of Technologies on Characteristic Analysis and Conservation Management in Agricultural Heritage Systems" project, a partnership between the Rural Development Administration (RDA) of the Government of the Republic of Korea and the United Nations University Institute for the Advanced Study of Sustainability (UNU-IAS).

The Manual is authored by Dr. Evonne Yiu and Ms. Bosun Jang from UNU-IAS, and Dr. Junko Owada from Doshida University, with technical guidance, advice, and support from Dr. Daeyong Hwang and Dr. Myeong-chul Jung from RDA. It is also built upon the invaluable advice received from the following experts in GIAHS: Dr. Nobuyuki Yagi of the University of Tokyo, Dr. Osamu Saito of the Institute for Global Environmental Strategies, Dr. Mitsuyo Toyoda of Niigata University, Dr. Hiroyaki Hayashi of the Kunisaki Peninsula Usa GIAHS Promotion Association, Dr. Wonhee Yoo from RG\&E Research Institute, Dr. Jiao Wenjun of the Chinese Academy of Sciences, Mr. Akira Nagata and Ms. Sayako Koyama of UNU-IAS.

The Manual draws extensively on existing documents, studies, and insights of experts, government officers, researchers, and stakeholders from all five GIAHS in Korea and all eleven GIAHS in Japan. They were further supplemented by a review of research and policy documents produced within and outside the auspices of the project and from the knowledge of GIAHS around the world. The authors are grateful to everyone who contributed their invaluable knowledge, time, and expertise.

UNU-IAS and RDA gratefully acknowledge the contribution of partners at all levels. They include government representatives and partner organizations of GIAHS in Korea and Japan, whose commitment to conserving GIAHS positively impacts the lives of rural communities and contribute to the sustainable development of our planet.

Our great appreciation is also offered to the girls, boys, women, men and all living in GIAHS regions who are at the forefront of conserving the generations of agricultural land, knowledge, traditions, and values. Their wisdom in and dedication to conserving GIAHS will continue to inspire the world for generations to come, so humanity may stand resilient in the face of everchanging and complex contexts.

(c) UNU-IAS and RDA, March 2022

\section{TABLE OF CONTENTS}

FOREWORD

ACKNOWLEDGEMENTS

ACRONYMS

GLOSSARY

CHAPTER 1. INTRODUCTION

Monitoring and evaluation (M\&E) of GIAHS conservation efforts

Purpose for M\&E and theory of change for GIAHS conservation

CHAPTER 2. GUIDING PRINCIPLES

Process of developing monitoring indicators

Key guiding principles

CHAPTER 3. WHAT TO MONITOR

Monitoring elements

Reporting formats

Core criteria

Enabling criteria

CHAPTER 4. HOW TO DESIGN AN M\&E PROCESS FOR GIAHS

Designing an M\&E process for GIAHS

Institutional structure

Resource mobilization

\section{CHAPTER 5. HOW TO IMPLEMENT AN M\&E PROCESS FOR GIAHS}

CHAPTER 6. HOW TO EVALUATE

The linkage between monitoring and evaluation

Purpose of evaluation

How to conduct an evaluation

Strategic and meaningful use of M\&E data and results

\section{WAY FORWARD}

ANNEX: RESEARCH PROCESS, TEMPLATES, AND TOOLS

Annex 1: Research process

Annex 2: Templates and tools

REFERENCES
63

64 


\author{
CBO Community-based organization \\ CSO Civil society organization \\ FAO Food and Agriculture Organization of the United Nations \\ GIAHS Globally Important Agricultural Heritage Systems \\ IPLC \\ KIAHS \\ KPI \\ LTK \\ MAFF \\ MAFRA \\ MIS \\ Indigenous peoples and local communities \\ M\&E \\ Korean Important Agricultural Heritage Systems \\ Key performance indicator \\ Local and traditional knowledge \\ Ministry of Agriculture, Forestry and Fisheries of Japan \\ NGO Non-governmental organization \\ NPO Non-profit organization \\ PM\&E Participatory monitoring and evaluation \\ RBM Results-based management \\ RDA Rural Development Administration of the Republic of Korea \\ SDGs Sustainable Development Goals \\ ToC Theory of change
}

UNU-IAS United Nations University Institute for the Advanced Study of Sustainability
Action Plan is the plan of conservation actions the GIAHS region commits to take after its GIAHS designation.

The Action Plan is first submitted to FAO along with its application proposal. After GIAHS designation, it is subsequently revised in a cycle of every three to

Advanced indicators are the aspirational and supplementary indicators that would be relatively difficult to gather data than basic indicators but could be taken up for more robust and comprehensive monitoring of GIAHS.

Depending on the GIAHS and its priorites, these hilcators may or may not be "advanced." There is no indicators, and pursuit of the latter should not be held contingent upon the fulfillment of the forme

Baseline is a minimum or starting fixed point of reference that is used for comparison purposes.

In the GIAHS context, it is information or data on the status of the GIAHS at the point of implementing the Action Plan.

Basic indicators are foundational indicators to ensure the integrity of the GIAHS and therefore should be factored in as many as possible.

Depending on the GIAHS and its priorities, these indicators may or may not be "basic." There is no hierarchy of importance between basic and advanced
indicators, and pursuit of the latter should not be held indicators, and pursuit of the latter should not
contingent upon the fuffillment of the former

Core criteria refer to the key five criteria for Monitoring and Evaluation of GIAHS, which mirror the GIAHS designation criteria set by FAO: food and livelihood security; agro- biodiversity; local and traditional knowledge systems; cultures, value systems, and social organizations; and landscapes and seascapes features.

The definition for each criterion is available in Chapter
3 and the FAO GIAHS website

Criteria refer to the set of eight criteria for monitoring and evaluation of GIAHS recommended by this Manual, consisting of five core and three enabling.

Each criterion is comprised of sub-criteria and basic and criteria. Each criterion is equal in importance and the priority for data collection should be determined by ndividual GIAHS region.

Enabling criteria refer to the three criteria that should be in place to ensure effective overall implementation of the monitoring and evaluation of GIAHS itself: governance, capacity development and research, partnerships and outreach.

The Manual recommends that the monitoring and evaluation of the actions of the core criteria would criteria are also assessed.

Evaluation is the assessment of the monitoring results of the actions implemented under the GIAHS Action Plan, conducted as systematically and impartially as possible by a third-party panel.

In the GIAHS context, this is a review of the monitoring results and the self-assessment report compiled by 
GIAHS managers are officers within or outside the government tasked with executing GIAHS conservation activities.

The GIAHS managers based at the GIAHS Promotion Office will likely be responsible for the overall management of GIAHS, but GIAHS managers at other related municipal governments or organizations also conservation efforts.

GIAHS Promotion Association is the governing body of the GIAHS region, usually comprised of the local governments, related ministries and agencies, producer cooperatives of agriculture, livestock, forestry and fisheries, businesses, community groups, academic institutions and other core stakeholders.

In some GIAHS, the governing body also takes the name of the local government, GIAHS Promotion This Manual collectively refers such governing bodies the 'GIAHS Promotion Association.'

GIAHS Promotion Office is the secretariat located at the governing body of the GIAHS.

mostinstances, the office is hosted by one of the municipal governments permanently or in rotation Assogition The GIAHS Promotion Office takes the ole of coordinating all conservation activities of
GIAHS, mainly in the execution of the GIAHS Action Plan and other administrative and operational tasks

IAHS region refers to both the physical area and the institutional structure, including the stakeholders related to and supporting the GIAHS.

Impacts also referred to as long-term goals, are the state that the GIAHS region envisages and aspires to achieve in the future.

Impacts can include the passing of the GIAHS to
future generations while also contributing to the future generations while also contributing to the
achievement of global aims, such as the Sustainable achievement of global aims,
Development Goals (SDGs).
Indicators are a means to an end used to measure specific quantitative and qualitative attributes to track outputs of actions and help monitor trends in the sustainability of the GIAHS region over time.

Inputs refer to the conduct of actions, interventions, and activities as laid out in the GIAHS Action Plan.

Key performance indicators (KPIs) are the combination of a selection of basic and advanced monitoring indicators, along with other indicators outside of those listed in this Manual that a GIAHS region may decide to pursue.

Local and traditional knowledge (LTK) refers to long-standing traditions, practices, wisdom, knowledge, and teachings of regional, knowledge, and teachings
indigenous or local communities. Iiterature, LTK can be a critical source of basic information for scientific research, conservation, and resource management. In the GIAHS context, it includes farming practices, ingenious adaptive technology an biota, land, water which have supported agriculturat. forestry and/or fishery activities.

Management information system (MIS) refers to a process used for coordination, control, analysis, and visualization of information in an organization. In this Manual, MIS is mainly referred to as an initial
system of central collection and maintenance of
monitoring data.

Monitoring is the continuous collection of data and information for a set of criteria and indicators appropriate to the GIAHS region for regular tracking and comparison of the outputs and outcomes of actions implemented under the GIAHS Action Plan against its targets and goals.

This Manual recommends that monitoring be
Monitoring and evaluation (M\&E) is a process of continual gathering of information and assessment of the results in order to determine the progress towards pre-specified goals and highlight positive or negative unintended effects, with the intention to bring about positive change and impact for the sustainability of the GIAHS region.

Older persons, also referred to as aging population, refer to persons aged 60 or above as defined by the United Nations.

However, the age range and definitions vary across
contexts and are subjected to specification by contexts and are subjected to sp
individual GIAHS countries and regions.

Outcomes are the changes observed or achieved by the inputs, measured by using the results of the outputs matched against the targets that were set out to achieve the desired changes. Given this sequence, outcomes speak to a higher
level of results, such as efficiency, efficacy, and effectiveness, that occur due to the outputs.

Outputs refer to the tangible and intangible products or results created by the actions taken under the GIAHS Action Plan towards intended outcomes.

As the first level of results, outputs do not directly measure the impact or value of the inputs (actions
but can help monitor progress towards outcomes.

Participatory M\&E (PM\&E) is a process through which stakeholders at various levels engage in monitoring or evaluating a particular project, programme, or policy, share control over the content, the process and the results of the monitoring and evaluation (M\&E) activity, and engage in taking or identifying corrective actions.
Qualitative listing (OL) refers to reporting format that lists the items, activities, initiatives, and/or events measured under an indicator.

The Manual recommends that the total count also be
provided where possible. This reporting format can be used for indicators that aim to measure the number

and types of actions taken towards an outcome.

Qualitative reporting (QR) refers to the reporting format that describes the activities, initiatives, events and/or efforts measured under an indicator.

It does not need tocontain numbers nor equate efforts 列 accounts of the action, as well as the capacity of making of key actors. Anecdotal accounts of the leve and perception can also be captured under $\mathrm{OR}$.

Quantitative statistics (OS) refers to the reporting format that provides numbers related to the actions taken. Statistics, financial data, and headcounts of participants take the form of OS.

Sub-criteria are the key components of each of the eight criteria proposed in this Manual.

One or more indicators can be applied to measure the conservation status of a sub-criterion, which in
turn helps determine the status of the corresponding criterion.

Theory of change (ToC) is a comprehensive description of how desired social change is expected to happen in a particular context.

ToC serves as a framework for an outcome-based and process-oriented approach to programme design, providing a guiding framework for critical thinking in designing, implementing, and analyzing the complex chang

Youth is defined as persons between the ages of 15 and 24 years by the United Nations.

However, the age range and definitions vary acros individual GIAHS countries and regions. 
OBJECTIVES AND INTENDED AUDIENCE OF THIS MANUAL

This Manual aims to support the management and governance of GIAHS through specific steps it can take to monitor and evaluate the actions taken to conserve the GIAHS. It hopes to serve as a technical reference on constructing a systematic process for monitoring and evaluation (M\&E) of the conservation actions implemented under the GIAHS Action Plan, mainly for GIAHS designated regions and also other communities interested in applying for a GIAHS designation. The Manual also aims to reinforce the importance and usefulness of having an M\&E process as a crucial part of the GIAHS Action Plan implementation.

In this regard, this Manual targets a variety of audiences, chiefly among them:

- Governments and entities governing GIAHS regions, in particular, officers and

- Governments interested in applying for GIAHS designation to understand how to plan for M\&E;

- GIAHS stakeholders interested in understanding and tracking GIAHS activities and their effectiveness;

Researchers and students undertaking M\&E studies; and

Others interested in promoting sustainable development of agricultural heritage systems.

This document provides guidelines for the designing and implementing a M\&E process technical reference for those interested in assessing the status of outputs and outcomes of the conservation activities carried out under the GIAHS Action Plan. While the experiences of GIAHS in Korea and Japan served as the in source of information in developing and societal contexts of both developing and developed countries and is meant to contribute to all current and aspiring GIAHS communities around the world.

To that end, the Manual opens with an overview of the current state and need for M\&E of GIAHS and explains the role played purpose and core principles of M\&E of GIAHS (Chapter 2), followed by a detailed explanation of the proposed criteria and indicators for monitoring GIAHS (Chapter 3). The Manual maps out a holistic, systematic process to design and implement an M\&E process for use of M\&E findings towards improvement and of the indicators are based on rounds of verification by experts and stakeholders, they vary in feasibility and needs across GIAHS regions. It is not the intention of the authors of regions, but to provide a resource they can use to make important decisions.

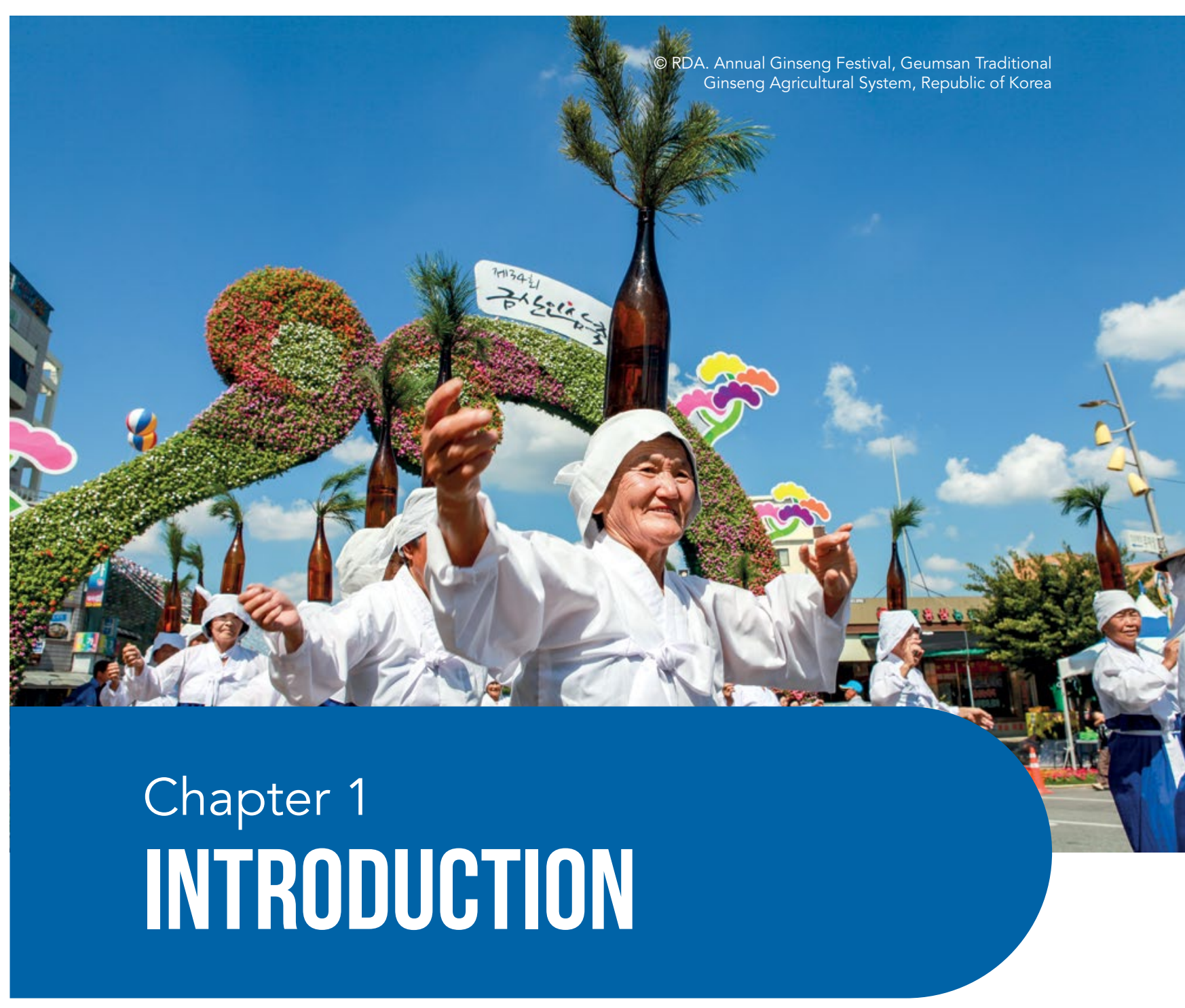


This chapter aims to lay a foundational understanding of monitoring and evaluation (M\&E) in the context of GIAHS. Key concepts that are integral to the rest of the Manual, such as the purpose of M\&E and the theory of change (ToC) of GIAHS, are also introduced.

\section{MONITORING AND \\ EVALUATION OF GIAHS \\ CONSERVATION EFFORTS}

The FAO defines GIAHS as "remarkable landuse systems and landscapes which are rich in globally significant biological diversity evolving from the co-adaptation of a community with its environment and its needs and aspirations for sustainable development (FAO, 2005). These traditional agricultural systems are time-tested testaments of our ancestral wisdom and fruits of the efforts made by the current generation in living in harmony with nature. GIAHS are living and evolving heritages that require dynamic conservation efforts. Periodical M\&E is necessary to understand and track the progress of these dynamic interventions, as well as to make timely improvements in response to changes and shocks.

While 2022 will mark two decades of GIAHS inception as an initiative in 2002, it has been only five years since it became a FAO regular programme. As a relatively new programme, it relies heavily on individual GIAHS to define M\&E needs and carry out M\&E activities; specific guidance or mandate on M\&E from FAO is pending. FAO (2021) encourages GIAHS regions to perform the following M\&E activities. Ministry of Agriculture, Food and Rural Affairs

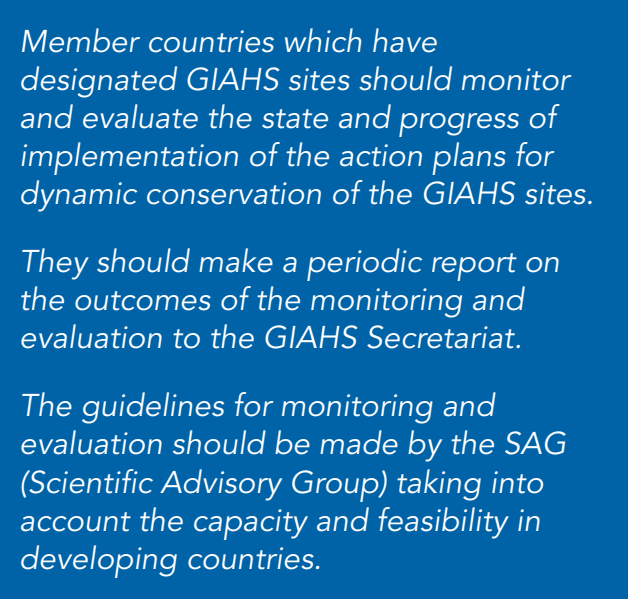

Countries are taking the initiative to implement M\&E using their own standards and processes. In Japan, the Ministry of Agriculture, Forestry and Fisheries (MAFF) administers M\&E once in two years for those GIAHS regions approaching the M\&E cycle of every five years, whereby a third-party expert committee, established by the Japanese ministry, the GIAHS Experts Meeting, will provide advice to the self-assessment reports submitted by each GIAHS region. A summary report of the Expert Meeting advice for Japan GIAHS will then be shared with the GIAHS Secretariat of FAO for their inforr , the (MAFRA) has been conducting M\&E since 2018 for each GIAHS region every two years, which the GIAHS Preparatory Committee assesses. In China, with the most designated GIAHS to date, every GIAHS region is required to submit an annual monitoring report to the Ministry of Agriculture and Rural Affairs (MARA) and will be evaluated by the Center of International Cooperation Service every three years.
However, reporting of M\&E results to FAO is not compulsory; the administration and reporting of M\&E results are left to the discretion of governments governing each GIAHS. For instance, Japan shares high-level summaries of monitoring results of each Japanese GIAHS region with $\mathrm{FAO}$ as a voluntary coordination effort, not out of obligation.

Hence, the current status of GIAHS M\&E reveals a gap. There is a lack of a systematic process for follow-up and accountability to determine the commitment and faithfulness in implementing activities, assessing impact and identifying areas of improvement after GIAHS designation. This may be due to the lack of knowledge in guiding the design and implementation of GIAHS M\&E.

In response, this Manual offers technical guidance on how to design and implement an effective M\&E process to support GIAHS managers and governments interested in applying to GIAHS in the future. It defines the important role that M\&E plays in the management of GIAHS and the core steps that a GIAHS manager can take to design and implement a full cycle of M\&E process. The Manual follows the M\&E standards set out by the United Nations, which promotes a results-based management (RBM) M\&E that is sufficiently holistic and systematic to verify the actions and their impacts (UNDP, 2011).

\section{PURPOSE FOR M\&E AND}

\section{THEORY OF CHANGE FOR GIAHS} CONSERVATION

\section{Purpose for M\&E}

The role of M\&E is multi-functional. It is essential as a measurement of the performance of GIAHS Action Plan actions and understanding the state of GIAHS conservation to ensure the sustainable development, integrity, and continuity of the GIAHS. M\&E is also helpful in supporting results assessment and its use for decision making, providing timely information to support operational and strategic management requirements, trigger learning, elicit participation and buy-in from key stakeholders, and delivering response for adaptation (FAO, 2012). M\&E is also a policy obligation and due diligence of the governments of all levels involved in GIAHS to periodically report to residents and taxpayers of the outcomes of the conservation activities. More importantly, transparent and open access feedback processes of the M\&E results will also help sustain the interest and commitment of residents and other actors. The challenges and problems revealed and highlighted through the M\&E will also provide opportunities for improvement, either as ideas for new business opportunities or heightening attention for a dwindling local custom or tradition.

Theory of change for GIAHS conservation

A theory of change (ToC) is proposed for the effective implementation of the conservation actionscommitted under the GIAHS Action Plan, through the systematic design and assessment of the inputs, outputs, and outcomes channeled towards the vision in attaining the long-term goals and impacts (see Figure 1-1). ToC provides an outcomes-based and process-oriented approach to designing a programme, serving as a guiding framework for designing, implementing, and analyzing the complex systems of interventions to bring about social change (Vogel, 2012; van Es, Guijt and Vogel, 2015). The ToC in Figure 1-1 demonstrates a high-level logical map across actions, outputs, and outcomes that lead to desired goals and impacts for GIAHS. Integrated into this logical map is a systematic process of planning, designing, implementing, and assessing the impact of actions that are defined in the GIAHS Action Plan, which are based on a set of reasonable assumptions informed by learnings from the past or research and enabling preconditions. 
ASSUMPTIONS

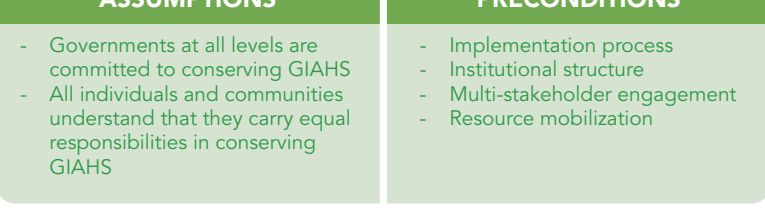

PLANNING
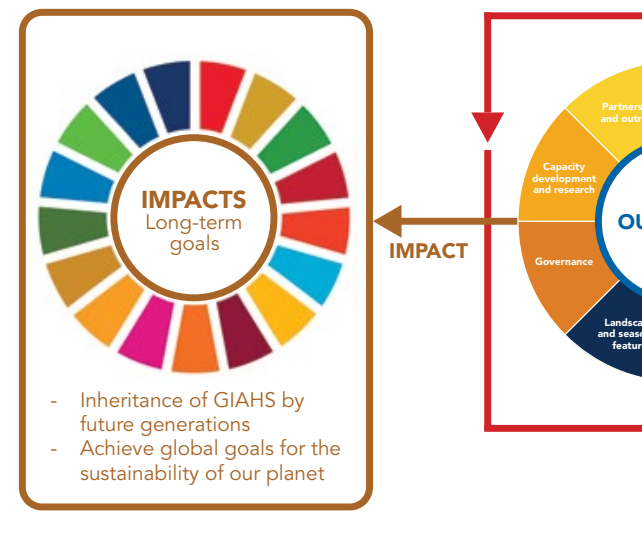

The GIAHS M\&E is implemented based on the assumptions that governments at all levels are equally committed to conserving their GIAHS. All communities, individuals, and stakeholders have equal opportunities to be involved, voice their views and share the responsibility of conserving GIAHS. The conduct of M\&E is set on preconditions that are already in place, including (1) the implementation process including methodologies and procedures, (2) the institutional structure of the main body of $M \& E$ execution and other necessary institutional support, (3) multi-stakeholders engaged in participatory processes, and (4) resources needed, including human resources and funding, are mobilized and sufficient. The inputs will be the conduct of actions as laid out in the GIAHS Action Plan, and the outputs (tangible and intangible) as a product and result of these efforts will be recorded, tabulated, and interpreted against the indicators set out to measure the outcomes

around eight perspectives (or the eight criteria proposed by this Manual), through an M\&E process. Feedback from the M\&E will then provide the basis and information for timely revisions for adaptation to sudden shocks and changes, and also to improve the Action Plan. By ensuring that the outcomes go through this constant, periodical, systematic, timely, and robust check, the GIAHS is more likely to be on the pathway to attain its intended impacts (or long-term goals). The impacts or goals can include passing on the GIAHS to future generations while also contributing to the achievement of global goals, such as the

The ToC in Figure 1-1 also highlights the role of the M\&E process as a critical component and continuous cycle embedded in the Action Plan workstream to check on performance, ensure integrity and provide basis for revisions. This exercise of defining pathways for change through using the ToC framing helps clarify the actions requ realistic wa a ToC should be articulated to establish a shared understanding of the purpose and value of GIAHS, which in turn will help to justify the establishment of its supporting systems, including an M\&E process. The ToC should be designed through consultations with the Chairperson of the GIAHS Promotion Association and the heads of government of related municipalities. All stakeholders should also be consulted when making the GIAHS Action Plan or revising the new Action Plan through future scenario planning meetings conducted. Figure 1-2 illustrates a sample detailed ToC of a GIAHS region, with M\&E playing a key role in tracking the progress of inputs, outputs, outcomes, and impacts.

I GIAS MONTORNG AND EMAUATON WANUAL:ATECHNTCL RETERENCE 
RATIONALE / THE NEED FOR GIAHS: The intricate relationship between humans and their territory are subjected to vulnerabilities introduced by compounding factors within and external to the community. Aging of farming population coordination in governance, research, conservation, and outreach efforts have emerged as key threats to the GIAHS

ASSUMPTIONS: Governments at all levels are committed to conserving GIAHS and have pursued the designation for that purpose. Communities living in GIAHS and individuals visiting the region understand that conserving

\section{INPUTS}

\section{(ACTIONS OF GIAHS ACTION PLAN)}

- (C) Generate employment through cultivation of younger workforce and strengthening of related industries such as tourism, technology,

- (C2) Enrich agro-biodiversity of GIAHS by

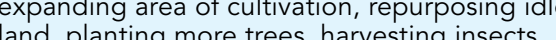

- (C3) Foster transfer of traditional knowledge and practice through support of artisans and specialists; exchange among experts and residents; and deliberate documentation and recordkeeping through photos, films,

(C4) Empower local residents, governing bodies, and key stakeholders of GIAHS as forerunners of conservation through ongoing information sharing, meaningful engagement in decision-
making, participatory monitoring, and technical guidance.

- (C7) Support through policy, economic and workforce of GIAHS, so that they are able to produce sufficient volume of food using traditional techniques to sustain livelihoods and their wellbeing

- (C8) Invest in outreach activities, such as educational initiatives, volunteer programs, and online messaging through social media and websites. and workers, including youth and retire

that upholds the lifestyle, values, and wellbeing of its communities and their natural environment. Identifying and 作 but also the wider humanity whose very sustenance depends on its relationship with nature.

PRECONDITIONS: An implementation process for the GIAHS Action Plan is already taking place or is planned to take place in the near future. The necessary institutional structures are in place and functioning to - ensure that the local governance bodies, local residents, and other external actors. Adequate financial and human resources are secured to support all such operations.

\section{OUTCOMES}

(C1) Physical land area of production is

increased.

(C1) Agricultural income from producers and industries related to the GIAHS

(C1) Products from GIAHS certified and validated by the GIAHS Promotion Association, then properly branded,
marketed, and distributed for public consumption

- (C1) Jobs created to attract new farmers older persons, to farming and related industries such as tounism, technology,

(C5) Revived areas of idled land agricultural waste, and enriching the biodiversity within GIAHS

- (C7) The conduct of research studies the findings through formal platforms (e.g., conferences, journals, newspaper articles, announcements via mass media,
etc.) and informal channels (e g. organizations, community groups and networks, one-off public events, etc.)

- (C8) The conduct of outreach activities, events, and training with clear learning goals and key messages for the target
- (C1, C2, C6) Economic policies, regulations on land and water use, protection of small farmers against corporate interests, climate changes and risk management, etc., are implemented.

- $(C 1, C 4)$ Employment is increased, particularly among young people, and they
region for at least five years.

- $(C 1, C 6)$ Agricultural products that comply with the certification system are sold. The in stabilized. Income of GIAHS populations from these sales has increased.

sity is enhanced as detected by scientific surveys.

- (C3, C4) Next-generation of artisans, craftsmen specialists, and laborers enroll and complete pursuing careers in agricultural heritages.

- (C8) Growing interest and awareness in GIAHS (C8) Growing interest and awareness in GIAHS
has led to a positive attitude within the public

(C4, C8) Farmers and local residents demonstrate pride in their agricultural heritage.

\section{MPACTS}

\section{(LONG-TERM GOALS)}

\section{GIAHS regional level}

(C1) The population of youths increase needs are met by increase in job prospects, educational opportunities, social support, an

- (C1) Farmers and local residents testify to mproved wellbeing and reduced anxiety disappearing.

- (C2, C5) The agro-ecological environment and natural resources are sustainably used and resilience against climate pressures and

ecological disturbances is enhanced.

( $(C 3, C 4, C 7)$ Inheritance of GIAHS by future generations is secured through the cultivation of

(C6) Economic incentives for businesses are no opening of new markets, including tourism.

\section{Global level}

Contribute to all 17 SDGs, particularly 2 Zero hunger), 12 (Respons palte pro 15 (Life on land).

- The relationship between humanity and nature grows resilient, the planet's sustainability is secured, and the wisdom of GIAHS is
MONITORING AND EVALUATION (M\&E): Regular M\&E of inputs, outputs, and outcomes is necessary to obtain feedback, improvise and make timely responses to the needs and circumstances that arise. It will be based on
assessing a set of key performance indicators (KPIs) selected from eight criteria: five core criteria required by FAO for
GIAHS designation - 1) food and livelihood security; 2) agro-biodiversity; 3) local and traditional knowledge systems; 4) cultures, value systems and social organizations; and 5) landscapes and seascapes features - and 


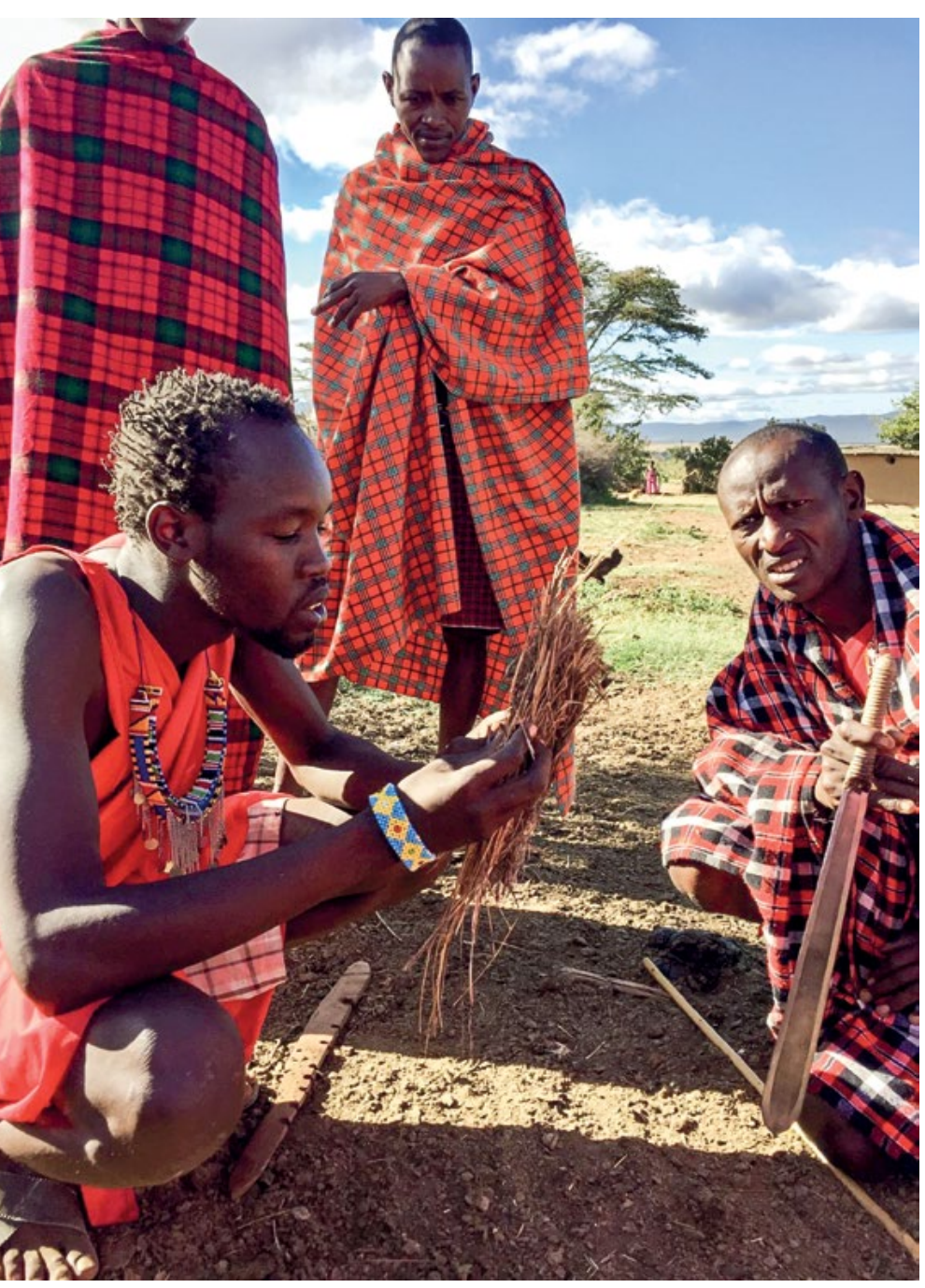

() UNU-IAS/Evonne Yiu.

Starting a fire using tradition
Pastoralist Heritage, Kenya

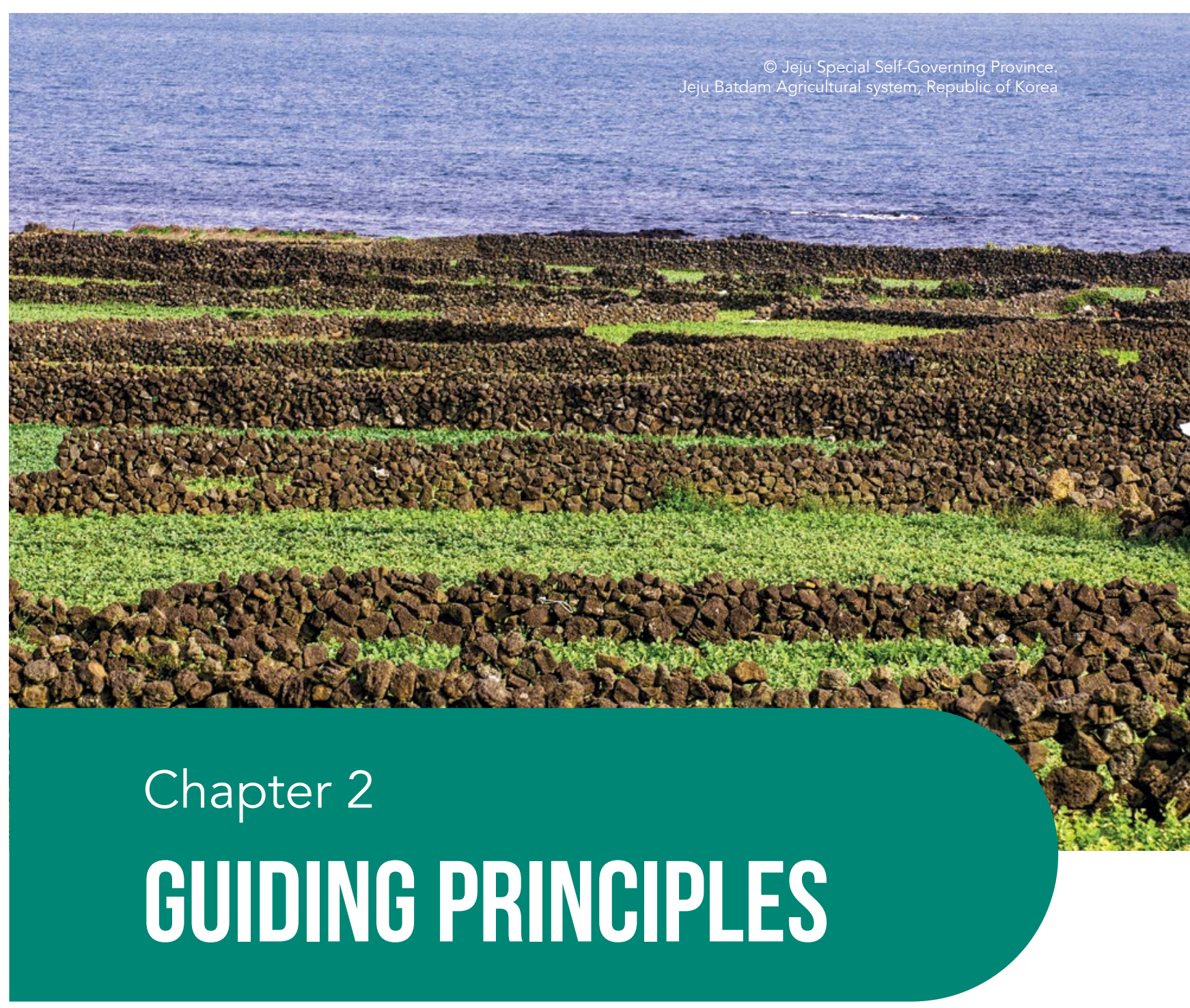


monitoring GIAHS, and defines the key principles applied throughout that process. These principles are intended to also guide GIAHS managers in applying the criteria and indicators in Chapter 3.

\section{PROCESS OF DEVELOPING MONITORING INDICATORS}

UNU-IAS and RDA conducted two main activities to arrive at the monitoring indicators and this Manual. We first reviewed literature, GIAHS proposals and Action Plans, as well as held interviews and workshop discussions with GIAHS managers and relevant experts. Notable documents include Enhancing Sustainability in Traditional Agriculture: Indicators for Monitoring the Conservation of Globally Important Agricultural Heritage Systems (GIAHS) in Japan by UNU-IAS (Reyes et al., 2020) and Guidebook on Community-based Participatory Monitoring and Activities for Sustainable GIAHS Conservation by RDA (2021), both of which are the UNU-IAS and RDA joint project outputs that have undergone a thorough validation process with stakeholders and experts, in addition to a comprehensive review of GIAHS proposals and Action Plans of Japan and Korea.

UNU-IAS and RDA also administered a survey and two consultation workshops with GIAHS officers and researchers in Japan and Korea to assess the relevance and feasibility of a preliminary set of 84 indicators. Respondents from both countries overlapped much in the indicators they identified to be 'too advanced,' particularly around measuring changes in agrobiodiversity, transfer of traditional technical knowledge, economic support through policy, adaptation measures against environmental crises, and community-level initiatives. The survey also showed that, although the awareness of Sustainable Development Goals (SDGs) was much higher and related activities more vibrant among Japan GIAHS, participants from both countries agreed that SDGs provide a viable platform for raising public awareness of GIAHS and its value to society.

The research and validation process arriving at the set of criteria and indicators of this Manual is summarized in Annex 1.

\section{KEY GUIDING PRINCIPLES}

As in any undertaking, principles provide a common anchor and foundation for operationalizing an idea, plan, and strategy. Intended to help define the purpose of M\&E of GIAHS - each of which is complex and diverse in population, activities, environment, and challenges - and set those engaged in the process on the right path for a meaningful outcome, we have determined the following to be core principles for the M\&E process of GIAHS.

The selection does not represent exclusion of other important principles. Here, we focus on highlighting the basic, critical elements of M\&E of GIAHS that have emerged organically through the abovementioned process.

Equity

According to their respective needs, equity or fairness of treatment of all concerned populations may include equal treatment or treatment that is different but considered equivalent in terms of rights, benefits, obligations, and opportunities (UNEG, 2014). For GIAHS, this principle applies to all individuals residing within the region, with a special focus on women and youth as custodians and beneficiaries of biodiversity and natural resources conservation (FAO, 2014). It also applies to indigenous peoples and local

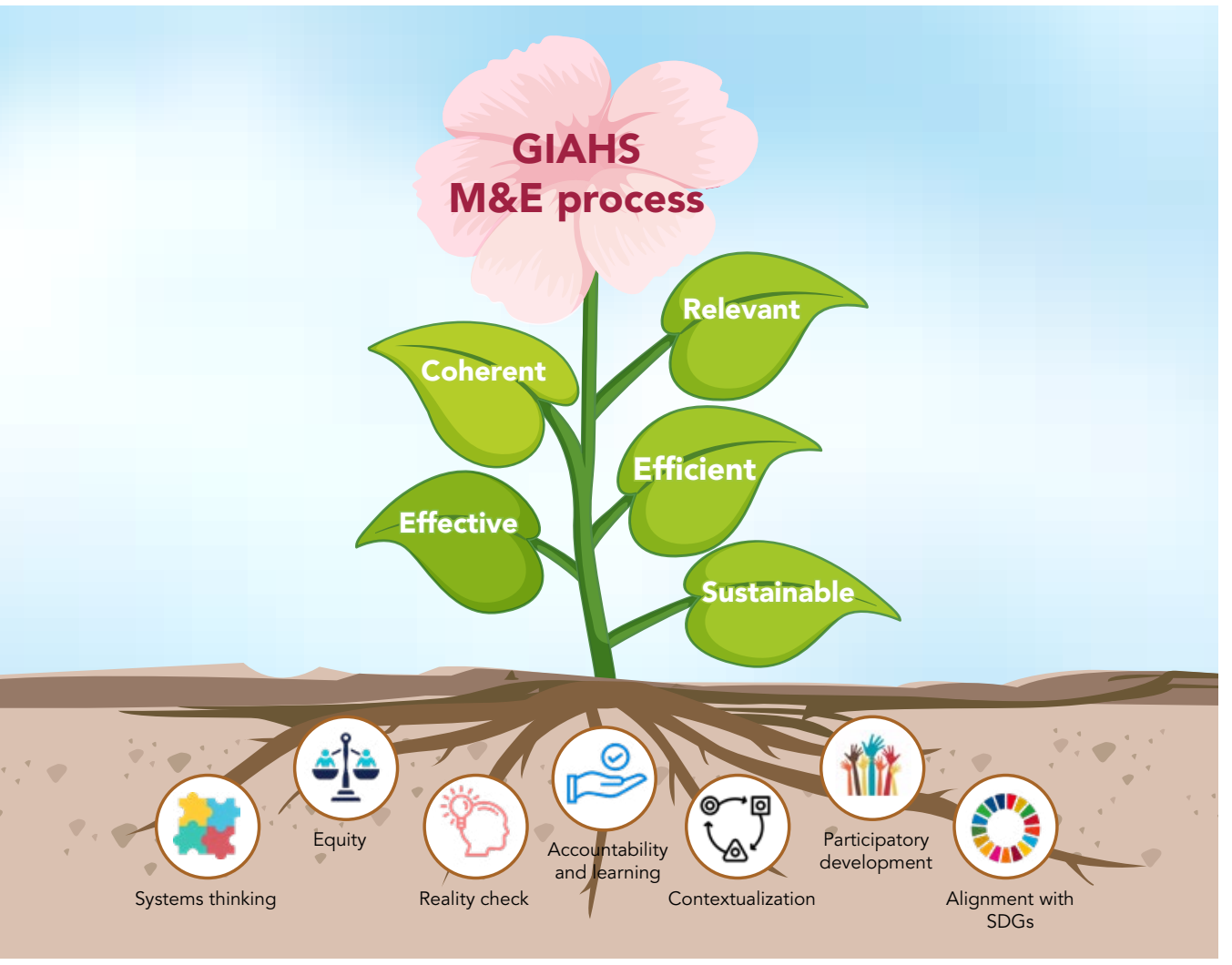

communities (IPLCs) who are fundamentally reliant on the environment and natural resources for their daily existence, making them specialists in agriculture-related activities and local environmental management practices (FAO, 2009). Monitoring can play a significant role in supporting pro-equity approaches by (1) engaging deliberate effort to reach out to key groups in the data collection process, within the context of their place in the national fabric, agricultural policy, and operations of GIAHS, and (2) drawing conclusions from monitoring activities in ways that proactively presents positive and negative implications on vulnerable groups and seek to advise on measures in support of those target groups (Wagner, 2004).
In developing the proposed M\&E process of this Manual, we envisioned it being applied to achieve equity in GIAHS regions and their activities. Consequently, there are indicators specifically for tracking the participation of vulnerable groups in production (e.g., Indicators B5. population of youth, A2 young and new farmers, and A20. participation of women, youths, indigenous peoples, and other vulnerable groups), participation in programmes (e.g., Indicators B13. groups conserving traditional agricultural techniques, A17. training programmes and schemes on traditional agricultural practices targeting aspiring or new farmers, and B26. formal and informal community entities maintaining landscapes and seascapes), and activities 
for or support towards such groups (e.g., Indicators A19. social organizations supporting GIAHS and A26. farmers and agricultural area receiving financial support).

\section{Accountability and learning}

The global trend in M\&E is to set it up to serve dual functions of accountability and learning. M\&E for accountability commonly focuses on 'upward accountability' to the government or the funding agency to demonstrate that contracted work has been conducted in compliance with agreed standards or to report on results against targets or plans. "Downward accountability" focuses on making transparent accounts and plans to the primary stakeholders and beneficiaries. M\&E for learning, on the other hand, requires continuous and conscious involvement of stakeholders in collaborative sharing of views, perspectives, and ideas. In a functioning M\&E system, these two functions should complement one another (Wongtschowski et al, 2016). The GIAHS M\&E criteria and indicators are also intended to serve both functions; for instance, the administration of agro-biodiversity surveys can meet reporting requirements and trigger reflections on new challenges and potential solutions. The exact mechanisms of operationalization will be determined by each GIAHS region and its governing bodies.

\section{Participatory development}

Participatory development is "an attempt to compensate for or overcome the limitations of the top-down development approach by adopting a bottom-up development approach [that]... involves taking the needs and opinions of local residents into account as much as possible in the formulation and implementation" of policies, programmes, or projects (JICA Research Institute, 1998). It enables people to acquire the skills needed to implement and coordinate the management of projects themselves and thus reap more of its returns. While recognized as one of the key challenges of operationalizing GIAHS, participatory development is simultaneously a core principle and a strategic vision for the programme (FAO, 2005). As such, the M\&E process aims to support conscious efforts to track participation of local residents and stakeholders of GIAHS in its core industries, activities, and participation of women, youths, indigenous peoples, and other vulnerable groups) and that the processes they uphold are participatory (e.g., Indicator A23. participatory monitoring with community and B28, monitoring results reported or shared with the public).

Systems thinking

In conducting M\&E for GIAHS, one must recognize the complexity it presents and apply systems thinking to analyze GIAHS as a whole, not in compartments or actions. In complex settings, the results of activities are difficult to predict due to dynamic contexts or unclear cause-and-effect relationships within the system (USAID, 2021). The complexity warrants both performance and context monitoring; the data that is collected must reveal whether implementation of GIAHS actions is on track and whether expected results are being achieved, as well as information about conditions and external factors relevant to the implementation. It goes beyond just monitoring specific actions, but analyse holistically and interpret rhe outcomes in its entirety. Factors to take in mind include potential of unintended positive and negative consequences, alternative variables and causes, and non-linear changes that may be imposed by risks such as plant encroachment or climate change. Ignoring them can undermine effective decision-making for the entire system (USAID, 2021).

Reality check

One purpose of this Manual is to guide its users to prevent mistakes that are commonly made in developing the M\&E process. They include (1) over-engineering with too many indicators while lacking a clear purpose or means of use; and (2) over-aggregating data with composite indices and weighting schemes that may conceal important information (ILO, 2015). Hence, we started out with existing indicators identified in official documents, such as the GIAHS application proposals and Action Plans and the research outcomes based on these documents (MAFRA, 2016; Reyes et al., 2020; RDA, 2021). A preliminary set of criteria and indicators was further refined through a series of reviews between UNU-IAS and RDA, including administering feasibility surveys with GIAHS experts and monitoring officers ${ }^{1}$ and consultation workshops. ${ }^{2}$ This process helped assess the practicality and feasibility of the indicators, weighing the possibility for data collection and timely reporting, considering common challenges faced during data collection, and balancing between "must have" information and "nice to have" information. The indicators proposed in this Manual offer a starting point that is reflective of the reality on the ground and practicality in application.

\section{Contextualization}

Each GIAHS features unique products, means of livelihood, knowledge systems, cultural practices, landscapes and seascapes, and governance systems. Best practices and vulnerabilities vary across sites and call for tailored approaches and solutions. Accordingly, the M\&E criteria and indicators herein consist of those that are universally applicable (e.g., agricultural income, types of species, and cultural activities) and those that are intended to serve as aspirational examples (e.g., PR activities through mass media, training on new agricultural technologies). Selecting and adapting the criteria and indicators for one's own context and needs - that is, in alignment with their country-specific (or GIAHS regionspecific) frameworks, strategies, and plans will increase their relevance and support from the GIAHS stakeholders, thereby translating information from monitoring into action. It is also important to note that contextualization should not be used to lower standards, but to maintain the objectives by articulating the standards that fit the context.

Alignment with Sustainable Development Goals (SDGs)

The criteria and indicators of this Manual are developed with expectations for users to contextualize to their GIAHS-specific needs, as well as align with the long-term social economic, and environmental outcomes articulated by the SDGs set out by the United Nations. GIAHS, after all, is a designation granted by FAO, a UN agency. For instance, from surveys conducted for this Manual, Korean and Japanese GIAHS managers and experts testified to strong alignment between GIAHS activities with SDGs, particularly SDG 2 (Zero hunger) and SDG 15 (Life on land).

It is also important to reiterate the importance of equitable access to and participation of women, youths, IPLCs, and other vulnerable groups of society, such as people with disabilities, in GIAHS. While linkages to SDG 5 (Gender equality) and SDG 10 (Reduced inequalities)) had not emerged explicitly as areas of concerns of GIAHS regions, they serve as an undercurrent, cross-cutting theme across all criteria, sub-criteria, and indicators. 
In recent years, an increasing number of local governments in Japan have reported anchoring their broader municipality, town, and district plans and goals to SDGs. This trend is in response to the national Future City Initiative, which was launched in 2011 as part of reconstruction efforts in the aftermath of the 2011 Great East Japan Earthquake (Japan for Sustainability, 2019; Ministry of Foreign Affairs of Japan, 2012). As of 2020,39.7\% of prefectural and municipality governments reported actively promoting SDGs in their plans and strategies, with an aim to reach $60 \%$ by 2024 (Regional Revitalization Promotion Office, 2021). The Ministry of Agriculture, Forestry and Fisheries (MAFF) has also in its recent reporting on the evaluation of multi-functional grants ${ }^{3}$ defined linkages between categorie of grant activities and outputs with SDGs to which they contribute (MAFF, 2020).

GIAHS regions in Japan, too, have reported increased awareness of SDGs and activities aimed at achieving those goals. In two surveys conducted by the Manual between 2019 and 2021, all eleven GIAHS regions in Japan reported to have plans or be implementing activities that help fulfill commitments to a wide range of SDGs, as shown in Figure 2-2. No changes are detected for SDGs 2 and 15 between the two years. Even though FAO designation of five of the 11 GIAHS predated the adoption of SDGs in 2015, given the core objective of GIAHS, the linkage to SDGs 2 (Zero hunger) and 15 (Life on land) have remained unaffected and

Figure 2-2 | Japanese GIAHS reporting to pursue SDGs in their activities, 2019 and 2021 ( N=11)

$$
\begin{aligned}
& 2019 \\
& \text { SDG 1. No poverty } \\
& \text { SDG 2. Zero hunger } \\
& \text { SDG 3. Good health and wellbeing } \\
& \text { SDG 4. Quality education } \\
& \text { SDG 5. Gender equality } \\
& \text { SDG 6. Clean water and sanitation } \\
& \text { SDG 7. Affordable and clean energy } \\
& \text { SDG 8. Decent work and economic growth } \\
& \text { SDG 9. Industry, innovation and infrastructure } \\
& \text { SDG 10. Reduced inequalities } \\
& \text { SDG 11. Sustainable cities and communities } \\
& \text { SDG 12. Responsible consumption and production } \\
& \text { SDG 13. Climate action } \\
& \text { SDG 14. Life below water } \\
& \text { SDG 15. Life on land }
\end{aligned}
$$

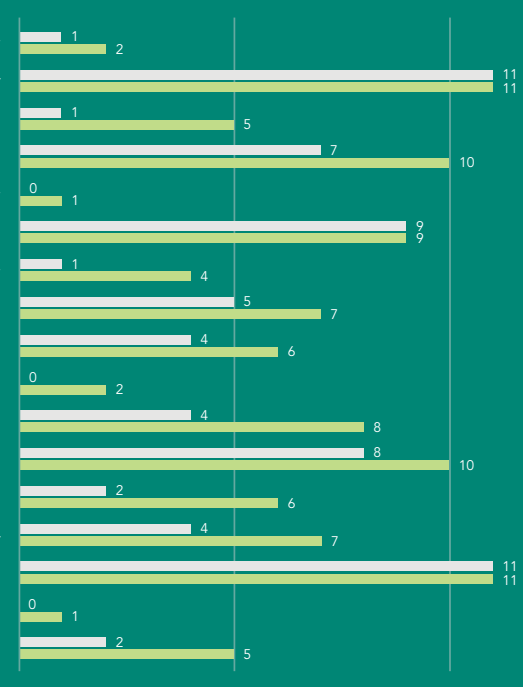

Multi-functional payment grants "support regional joint activities carried out by groups organized by farmers so that include: (1) farm and maintenance grant: (2) resource improvement grant (joint activity to improve the quality of local resources); and (3) resource improvement grant (activity to extend the life of the facility). For more information, see MAFF's official website at: https://www.maff.go.jp///nousin/kanri/tamen siharai.htm.

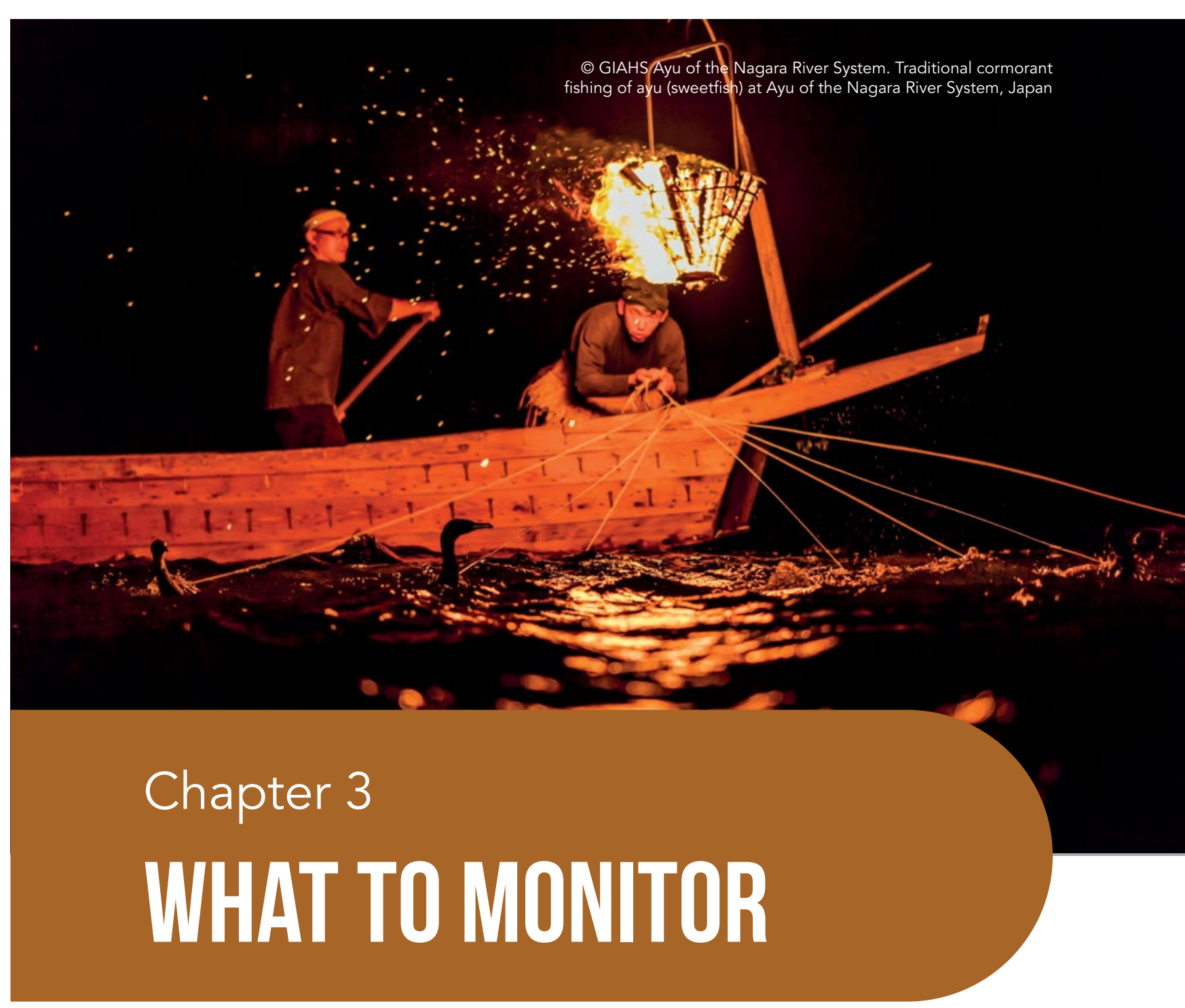


The Manual proposes eight M\&E criteria, whereby each criterion (C) comprises a set of sub-criteria (SC) and corresponding indicators. An indicator measures an output or a group of outputs - e.g., GIAHS products branded and certified, GIAHS region's agricultural income, or training programmes conducted - as a milestone towards a desired outcome. To this end, each input (action) is assigned a target, such as an increase of GIAHS certified products by 20 percent met, total agricultural income maintained, or 100 new farmers trained. The output(s) will be matched against the target to determine whether the target has been achieved - that is, to arrive at the outcome. Monitoring helps determine the progress against these targets. Monitoring is the continuous collection of data and information for a set of criteria and indicators for regular tracking and comparison of the outputs and outcomes of activities implemented under the GI AHS Action Plan against its expected outcomes. All elements of the ToC - inputs, outputs, and outcomes - are then holistically reviewed and evaluated (see Chapter 6 for more details on evaluation).

\section{MONITORING ELEMENTS}

\section{Criteria and sub-criteria}

Since GIAHS are designated based on the key five criteria - (1) food and livelihood security; (2) agro-biodiversity; (3) local and traditional knowledge systems; (4) cultures, value systems, and social organizations; and (5) landscapes and seascapes features. - the conservation of these five aspects are vital and should be considered as the core criteria to ensure the integrity of the GIAHS. However, the management and conservation of GIAHS go beyond just maintaining the key features, and have to take into account operational aspects of the management. Therefore, the Manual also proposes three enabling criteria - Governance, Capacity development and research, Partnerships and outreach - for those GIAHS regions ready to upscale their conservation efforts, enhance the effectiveness and ensure a more robust, meaningful monitoring and evaluation exercise. Hence the Manual proposes eight criteria for GIAHS M\&E, GIAHS regions can choose to include all criteria or only those which may apply. Corresponding to each criterion (C) are sub-criteria (SC) that makes up the criterion (see Figure 3-1).

\section{Indicators}

Indicators are a means to an end used to measure specific quantitative and qualitative attributes to track outputs of activities and help monitor trends in the sustainability of the GIAHS region over time. Indicators should, wherever possible, be Specific, Measurable, Achievable, Relevant, and Time-bound (SMART) (UNDP, 2009). Other characteristics to consider when selecting the appropriate indicator could include (1) validity; (2) precise and specific meaning; (3) practical, affordable, and simple; (4) reliability; (5) sensitivity; (6) clear direction; (7) utility, and (8) owned (modified from the canadian international development agency, cited in GIZ, 2011). This Manual's indicators take guidance from and generally follow the FAO CountrySTAT Food and Agriculture Data indicators (FAO, 2013), but are modified to relate to the GIAHS context.

The indicators for monitoring GIAHS are categorized into two levels: (1) basic indicators are foundational indicators to

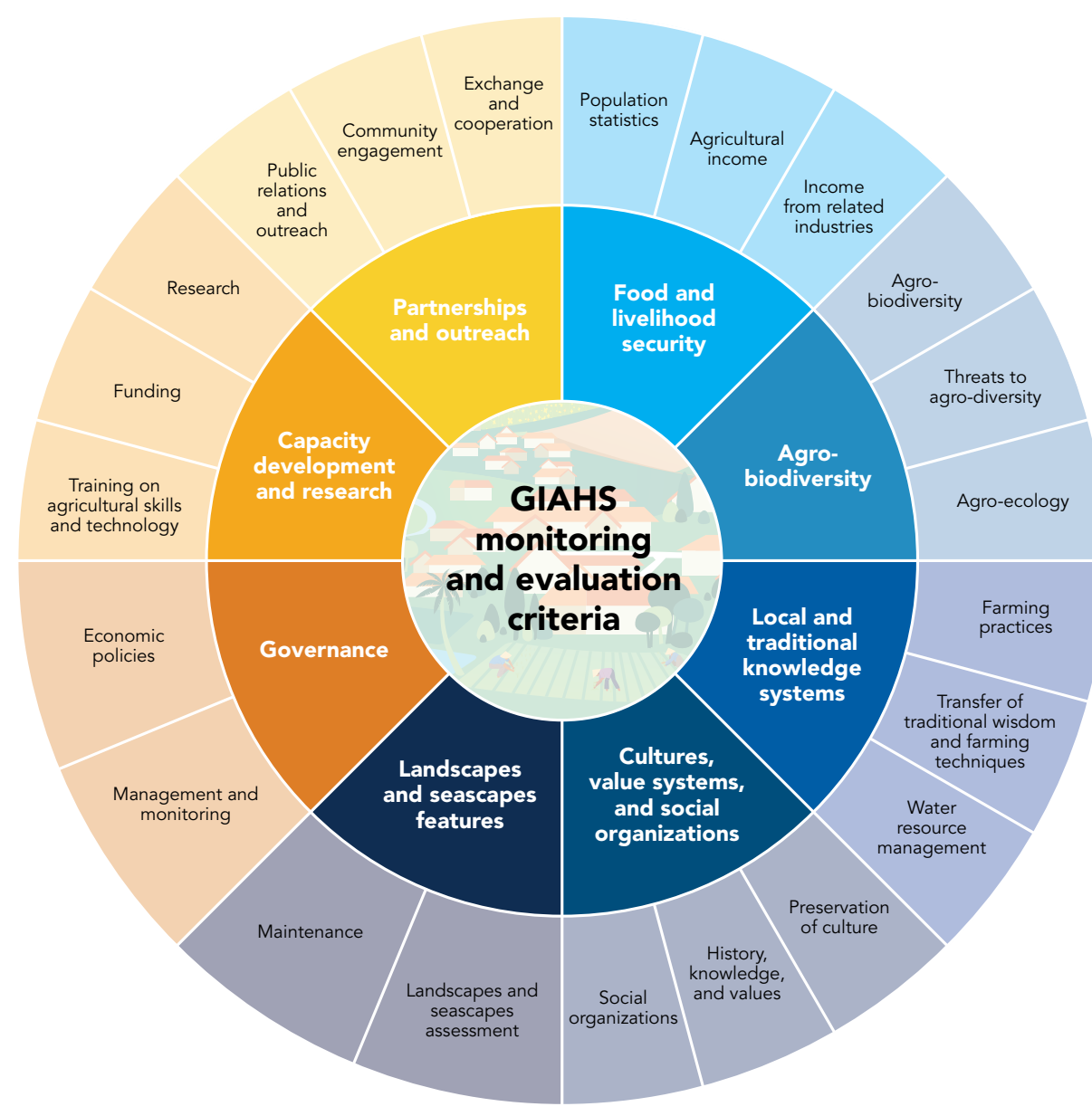

ensure the integrity of the GIAHS that should be factored in as many as possible, and (2) advanced indicators are the aspirational and supplementary indicators that would be relatively difficult to gather data than basic indicators, but could be taken up for more robust and comprehensive monitoring of GIAHS. The indicators are derived from the preliminary indicators that have gone under a feasibility check with GIAHS managers in Japan and Korea (see Annex 1 for details. from those indicators which had perceived feasibility among an average of 50 percent and more respondents from Japan and Korea. The advanced indicators consist of those with an average response below 50 percent but are retained for their importance and modified to increase data collection feasibility and practicality.

As mentioned in Chapter 2, one of the principles underpinning the proposed set of indicators is contextualization and selecting and tailoring them to the specific needs of a GIAHS, whose demographics, practices, and needs vary 
across regions. The Manual recognizes that the needs and conservation of a GIAHS may extent beyond those of the proposed indicators and may entail other indicators relevant to their context. Thus, the combination of a selection of basic and advanced monitoring indicators,

along with other indicators outside of those listed in this Manual that a GIAHS may decide to pursue, will hereafter be referred collectively to as 'key performance indicators' (KPIs) (see Figure 3-2).
Within the process of designing a GIAHS M\&E process (elaborated in Chapter 4), the selection of KPls enables GIAHS managers to translate one's strategic goals and vision into concrete actions that can be measured by indicators. It is also a critical step - and one of the earliest — in the designing of the M\&E process that will inform data collection methods, tools, and approaches to institutional learning.

The Manual proposes the following list of criteria, sub-criteria, and indicators for GIAHS M\&E (see Table 3-1):

Figure 3-2 | Key performance indicators for GIAHS M\&E

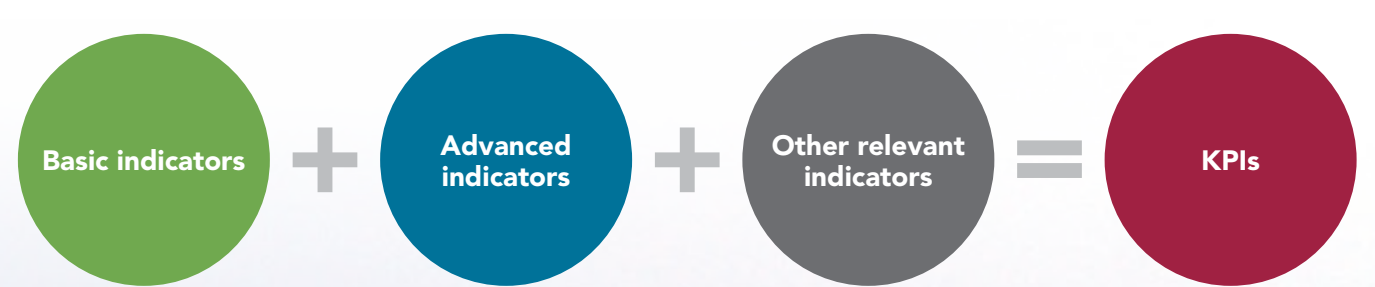




\begin{tabular}{|c|c|c|}
\hline \multicolumn{3}{|l|}{ CORE CRITERIA } \\
\hline SUB-CRITERIA & BASIC & ADVANCED \\
\hline \multicolumn{3}{|l|}{ C1. Food and livelihood security } \\
\hline SC1. Population statistics & $\begin{array}{l}\text { B1. Farming entities managing GIAHS } ₫ \\
\text { B2. Number of farmers } \circledast \\
\text { B3. Agricultural heritage regional population @ } \\
\text { B4. Number of aging population (at retirement and beyond) } \\
\text { B5. Population of youth } @\end{array}$ & $\begin{array}{l}\text { A1. Primary industry labor population } \circledast \\
\text { A2. Young and new farmers }\end{array}$ \\
\hline SC2. Agricultural income & $\begin{array}{l}\text { B6. Production quantity @ } \\
\text { B7. Agricultural area @ }\end{array}$ & $\begin{array}{l}\text { A3. Agricultural income of GIAHS region @ } \\
\text { A4. Income sources @ } \\
\text { A5. Agricultural sales @ }\end{array}$ \\
\hline SC3. Income from related industries & B8. Development and utilization of GIAHS-related tourism programmes & $\begin{array}{l}\text { A6. Income from related industries } @ \\
\text { A7. Development of green, blue, and sustainable tourism } \\
\text { A8. Tourism infrastructure and facilities }\end{array}$ \\
\hline \multicolumn{3}{|l|}{ C2. Agro-biodiversity } \\
\hline SC4. Agro-biodiversity & B9. Biodiversity survey on key species @ & $\begin{array}{l}\text { A9. Genetic diversity @ } \\
\text { A10. Indigenous varieties @ } \\
\text { A11. Crop/livestock/marine species and varieties @@ }\end{array}$ \\
\hline SC5. Threats to agro-biodiversity & B10. Reports on animal and plant encroachment $@$ & $\begin{array}{l}\text { A12. Threatened species @ } \\
\text { A13. Agricultural damage caused by animal and plant encroachment } @ \circledast\end{array}$ \\
\hline SC6. Agro-ecology & $\begin{array}{l}\text { B11. Agro-ecological zones @ } \\
\text { B12. Agro-ecology conservation and improvement }\end{array}$ & $\begin{array}{l}\text { A14. Disaster restoration, reduction, and resilience measures } \\
\text { A15. Climate adaptation practices and mitigation measures }\end{array}$ \\
\hline \multicolumn{3}{|l|}{ C3. Local and traditional knowledge systems } \\
\hline SC7. Farming practices & B13. Groups conserving traditional agricultural techniques (3) & A16. Farming practices (i) \\
\hline $\begin{array}{l}\text { SC8. Transfer of traditional wisdom and farming } \\
\text { techniques }\end{array}$ & $\begin{array}{l}\text { B14. Nurturing of human resource and supporting of actors } \\
\text { B15. Knowledge recording and documentation @ } \\
\text { B16. Training workshop and seminars for farmers @® }\end{array}$ & A17. Training programs and schemes on traditional agricultural practices targeting aspiring or new farmers @® \\
\hline SC9. Water resource management & B17. Water reserves and irrigation management & \\
\hline \multicolumn{3}{|c|}{ C4. Cultures, value systems, and social organizations } \\
\hline SC10. Preservation of culture & $\begin{array}{l}\text { B18. Religious, spiritual, and cultural practices and activities } \\
\text { B19. Crafts and tools @ } \\
\text { B20. Local food culture and traditional cuisines @@ }\end{array}$ & A18. Cultural assets and monuments (i) \\
\hline SC11. History, knowledge, and values & $\begin{array}{l}\text { B21. Historical records of cultural practices @@ } \\
\text { B22. Folk beliefs and folklores @@ }\end{array}$ & \\
\hline SC12. Social organizations & B23. Groups sharing of labor and resources (a) & $\begin{array}{l}\text { A19. Social organizations supporting GIAHS @ } \\
\text { A20. Participation of women, youths, indigenous peoples, and other vulnerable groups @) }\end{array}$ \\
\hline \multicolumn{3}{|l|}{ C5. Landscapes and seascapes features } \\
\hline SC13. Landscapes and seascapes assessment & B24. Map of GIAHS area @ & A21. Land and sea use @ \\
\hline SC14. Maintenance & $\begin{array}{l}\text { B25. Unmanaged/poorly maintained area and related challenges } \\
\text { B26. Formal and informal community entities maintaining landscapes and } \\
\text { seascapes }\end{array}$ & A22. Ecosystems and watershed management plans \\
\hline
\end{tabular}




\section{ENABLING CRITERIA}

\begin{tabular}{|c|c|c|}
\hline SUB-CRITERIA & BASIC & ADVANCED \\
\hline \multicolumn{3}{|l|}{ C6. Governance } \\
\hline SC15. Management and monitoring & $\begin{array}{l}\text { B27. Monitoring, evaluation, and revision cycle of Action Plan } \\
\text { B28. Monitoring results reported or shared with the public } \\
\text { B29. Institutional structure for monitoring and evaluation }\end{array}$ & $\begin{array}{l}\text { A23. Participatory monitoring with community } \\
\text { A24. Database for GIAHS-related information gathering and maintenance }\end{array}$ \\
\hline SC16. Economic policies & $\begin{array}{l}\text { B30. GIAHS products branded and certified @ } 9 \\
\text { B31. GIAHS-related products @) }\end{array}$ & $\begin{array}{l}\text { A25. Policies and regulations related to GIAHS @® } \\
\text { A26. Farmers and agricultural area receiving financial support } 9 \\
\text { A27. Support to community for shared resource management, maintenance, and operation } \\
\text { A28. Channels for direct sales and marketing @@ } \\
\text { A29. Supply chain management }\end{array}$ \\
\hline \multicolumn{3}{|c|}{ C7. Capacity development and research } \\
\hline $\begin{array}{l}\text { SC17. Training on agricultural skills } \\
\text { and technology }\end{array}$ & $\begin{array}{l}\text { B32. People who received training in agricultural skills and technology } \\
\text { (?) }\end{array}$ & \\
\hline SC18. Funding & B33. Funding dedicated to maintaining GIAHS @ (1) & \\
\hline SC19. Research & B34. Research outputs @ & A30. Ongoing research that supports maintenance and improvement of GIAHS and livelihood (-) \\
\hline \multicolumn{3}{|l|}{ C8. Partnerships and outreach } \\
\hline SC20. Public relations and outreach & $\begin{array}{l}\text { B35. Sharing, education, and promotion of agricultural culture @@ } \\
\text { B36. Promotion and advocacy through media, including social media } \\
\text { @)@ }\end{array}$ & \\
\hline SC21. Community engagement & $\begin{array}{l}\text { B37. Formation and activities of resident governance bodies @@ } \\
\text { B38. Local organizations related to GIAHS and expansion of its activities } \\
\text { (1) }\end{array}$ & A31. Volunteer programmes @@ \\
\hline SC21. Exchange and cooperation & $\begin{array}{l}\text { B39. Partnerships within and/or among GIAHS sites and with different } \\
\text { sectors @@ } \\
\text { B40. Cooperation between residents and GIAHS administration groups/ } \\
\text { experts @@ } \\
\text { B41. Conferences, expert convenings, exhibitions, and events }\end{array}$ & \\
\hline
\end{tabular}




\section{REPORTING FORMATS}

The reporting of the indicator results can be categorized into three types: quantitative statistics (QS), qualitative listing (QL), and qualitative reporting (QR) (see Table 3-2). Not all criteria can be measured quantitively and that qualitative documentation will also enhance the M\&E process by giving a holistic assessment of the multiple values. GIAHS

Table 3-2 | Indicators reporting types: QS, QL, and QR

\begin{tabular}{|c|c|c|}
\hline REPORTING TYPE & DESCRIPTION & EXAMPLE \\
\hline $\begin{array}{l}\text { QUANTITATIVE } \\
\text { STATISTICS (OS) }\end{array}$ & $\begin{array}{l}\text { Data obtained for a QS indicator should be in } \\
\text { the form of numbers, obtained from existing } \\
\text { statistical data such as census, government } \\
\text { administrative data and reports, or new data } \\
\text { obtained through primary or secondary data } \\
\text { collection. The data from OS indicators should, } \\
\text { as far as possible, be recorded annually in } \\
\text { numeric terms to monitor trends. }\end{array}$ & $\begin{array}{l}\text { A3. Agricultural income of } \\
\text { GIAHS region: } \$ 10 \text { million/year } \\
\text { A13. Agricultural damage } \\
\text { caused by animal and plant } \\
\text { encroachment: } \$ 500,000 \text { loss in } \\
\text { sales for } 2020, \$ 680,000 \text { loss in } \\
\text { sales for 2021. }\end{array}$ \\
\hline $\begin{array}{l}\text { QUALITATIVE } \\
\text { LISTING (QL) }\end{array}$ & $\begin{array}{l}\text { Data obtained for a QL indicator should list the } \\
\text { items, activities, initiatives, and events and give } \\
\text { the total count where possible. The data can be } \\
\text { obtained from existing data, but often requires } \\
\text { the monitoring officer to make a conscientious } \\
\text { effort to keep a regular record of the items/ } \\
\text { efforts diligently. The data from } Q L \text { indicators } \\
\text { should, as far as possible, be recorded annually } \\
\text { to monitor trends. }\end{array}$ & $\begin{array}{l}\text { B1. Farming entities } \\
\text { managing GIAHS: } 10 \text { entities } \\
\text { (farmer cooperative, fishery } \\
\text { cooperative, livestock } \\
\text { association, etc.) }\end{array}$ \\
\hline $\begin{array}{l}\text { QUALITATIVE } \\
\text { REPORTING (QR) }\end{array}$ & $\begin{array}{l}\text { Data obtained for a QR indicator should describe } \\
\text { the activities, initiatives, events and/or efforts, but } \\
\text { need not contain numbers or equate efforts in } \\
\text { terms of numerical value. The report could include } \\
\text { normative accounts of efforts implemented, } \\
\text { as well as the capacity of actors involved, level } \\
\text { of participation and decision making of key } \\
\text { actors, and anecdotal evidence of the level of } \\
\text { satisfaction, changes in knowledge and attitudes. } \\
\text { The data from QR indicators can be obtained } \\
\text { by monitoring officer(s) through observational } \\
\text { notes, focus groups, key informant interviews, } \\
\text { questionnaires, case studies, and other data } \\
\text { collection methods. The data from QR indicators } \\
\text { should, as far as possible, be recorded annually to } \\
\text { monitor trends and attitudes. }\end{array}$ & $\begin{array}{l}\text { A7. Development of green, } \\
\text { blue and sustainable tourism: } \\
\text { An agro-tourism promotion } \\
\text { policy/campaign for GIAHS } \\
\text { was launched in } 2019 \text { in } \\
\text { cooperation with local farmers } \\
\text { to draw tourists to the GIAHS. } \\
\text { As a result, tourist numbers } \\
\text { increased and more farmers } \\
\text { have expressed their interest to } \\
\text { run farmer inns. }\end{array}$ \\
\hline
\end{tabular}

\section{CORE CRITERIA}

regions can choose the most suitable way of assessment and reporting, as they continue to aspire to more complex ways of data keeping in future. Information should be aggregated and disaggregated at the appropriate administrative level (e.g., GIAHS regional level, municipal level, village level, etc.)
The criteria for GIAHS monitoring are categorized into core and enabling criteria. The core criteria, its sub-criteria, and corresponding indicators consist of those that will help to track status, changes, developments, and needs of GIAHS. They also correspond to the five key FAO criteria for FAO designation: (1) food and livelihood security; (2) agrobiodiversity; (3) local and traditional knowledge systems; (4) culture, value systems, and social organizations; and (5) landscapes and seascapes features. Since the GIAHS region is designated based on these core criteria, it is critical to uphold, maintain and improve the status of all of these criteria to ensure its integrity and credibility as a GIAHS.

C1. Food and livelihood security

The agricultural system contributes directly to the food and livelihood security of local communities. This includes providing through a wide variety of agricultural types, such as self-sufficient and semi-subsistence agriculture, where provisioning and exchanges take place among local communities, which contribute to rural economies (FAO, 2021). The Manual proposes the following sub-criteria and indicators to monitor actions implemented for this criterion:

\section{SC1. Population statistics}

Demographic information of the population residing in GIAHS and workforce of the primary sector statistic. Note that it should not only limit to agriculture data, but also include all primary sectors such as forestry, livestock, and fisheries. The indicators to measure this subcriterion could include the following:

(1) B1. Farming entities managing GIAHS : List farming groups or cooperatives, local or regional, who are directly involved in the farming production of GIAHS
(2) B2. Number of farmers : Provide the number of full-time and part-time farmers earning agricultural income.

(2) B3. Agricultural heritage regional population : Provide annual records of the number of the entire population residing in the GIAHS region.

(2) B4. Number of aging population (at retirement and beyond) : Provide number and/or proportion of the population of the GIAHS region who are above the retirement age relative to the entire population of the GIAHS region (Indicator B3) (or above the retirement age, where applicable). Retirement age may vary across contexts.

(2) B5. Population of youth : Provide number or proportion of youth population of the GIAHS (or below the youth age cut-off, where applicable) relative to the entire population of the GIAHS region (Indicator B3). Definition and age range of "youth" may differ across contexts.

(2) A1. Primary industry labor population : Provide number of individuals working in primary industries, including agriculture, forestry, livestock, fisheries, or other major sectors relevant to the GIAHS

(3) A2. Young and new farmers : Provide number of young and new incoming farmers or proportion compared to total farmer population. Individuals who had abandoned farming and returned to the profession are also captured under this indicator.

\section{SC2. Agricultural income}

The income and revenue earned or derived from agricultural products (including forestry, livestock, fisheries, and other primary sectors), as well as production volume and area. The indicators to measure this sub-criterion could include the following:

- B6. Production quantity : Provide amount of annual production quantity in terms of 


\section{Linkages between C1 GIAHS indicators and SDGs}

The indicator for this criterion and sub-criteria could contribute to the achievement of the following SDGs:

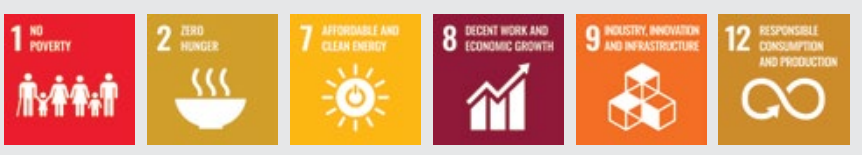

The statistics of GIAHS population, including youth, and income and production from agriculture and related industries can support tracking of poverty levels (SDG 1) and food security (SDG 2), as well as distribution of economic growth and employment (SDG 8). Well managed forestries can support affordable and sustainable energy sources (SDG7). Tourism and related infrastructural and facilities development within GIAHS, particularly the development of green, blue, and sustainable tourism in GIAHS regions, is also an integral part of building resilient infrastructure and fostering sustainable industrialization (SDG 9), while ensuring responsible consumption and production patterns (SDG 12)

weight of agricultural products, according to key products and also the total volume.

(2) B7. Agricultural Area : Provide total land production area (or water/sea area for fisheries) responsible for the production quantity in Indicator B6. It includes arable land and permanent crops, permanent meadows, and pastures production.

(3) A3. Agricultural income of GIAHS site : Provide amount of total annual agricultural income earned or revenue derived from the sources that include agriculture land, farming land, etc., and from agricultural sales in Indicator A5.

(21) A4. Income sources : List GIAHS related primary industries and income sources, such as farming, forestry, livestock, fisheries, etc.

(2) A5. Agricultural sales: Provide amount of sales of agricultural products grown, raised or harvested in the GIAHS related farmlands, or certified and uncertified crops/products.

\section{SC3. Income from related industries}

The income and revenue earned or derived from non-agricultural sectors that are important complementary sectors supporting the GIAHS, such as tourism, food manufacturing, restaurant businesses, traditional arts and crafts making, etc. The indicators to measure this sub-criterion could include the following:

(2B B8. Development and utilization of GIAHS-related tourism programmes : Report on developments of plans, programmes, initiatives, or events that promote awareness of GIAHS through agro-tourism that directly benefit the farmers and residents.

(2) (1) A6. Income from related industries : Provide amount of total income earned from or list income sources from GIAHS-related industries.

(2R A7. Development of green, blue and sustainable tourism : Report on developments of plans, programmes, initiatives or events promoting tourism experiences that are sustainable for the local environment, culture and economy.
(2R A8. Tourism infrastructure and facilities: Report on construction or renovation of infrastructure and facilities that facilitate GIAHS tourism, such as roads, rest-stops, viewing towers, etc

C2. Agro-biodiversity

Agricultural biodiversity or agro-biodiversity, as defined by FAO, is the variety of animals, plants and micro-organisms that are used directly or indirectly for food and agriculture, including crops, livestock, forestry and fisheries. The GIAHS region should be endowed with globally significant biodiversity and genetic resources for food and agriculture (e.g., endemic, domesticated, rare, endangered species of crops and animals) (FAO, 2021). ${ }^{4}$

Also included under C2 is environmental resilience. The resilience of the agricultural

\section{Linkages between C2 GIAHS indicators and SDGs}

The indicator for this criterion and sub-criteria could contribute to the achievement of the following SDGs:

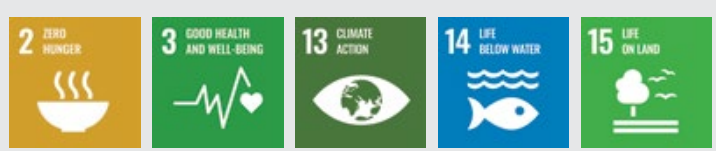

Indicators on agro-biodiversity, its species and varieties, and threats to their survival directly link to food security (SDG 2) and human wellbeing (SDG 3). By systematically tracking the health of agro-ecological zones and biodiversity of GIAHS regions, including the mechanisms of its seascapes and landscapes to withstand risks from climate change and disasters, GIAHS monitoring can support society's progress towards fight against climate change (SDG 13), challenges imposed to life below waters (SDG 14) and on land (SDG 15).

FAO defines agro-biodiversity as "the variety and variability of animals, plants and micro-organisms that are used directly or indirectly for food and agriculture, including crops, livestock, forestry and fisheries. It comprises the diversity and those in the wider environment that support agro-ecosystems (agricultural, pastoral, forest and aquatic) as well as the diversity of the agro-ecosystems" (FAO, 2021). 


\section{SC4. Agro-biodiversity}

The variety of animals, plants, and microorganisms that are used directly or indirectly for food and agriculture, including crops, livestock, forestry, and fisheries. The indicators to measure this sub-criterion could include the following:

(21) (2R B9. Biodiversity survey on key species : List or report on the administration of biodiversity survey on key species, which could include crop, fish, and livestock species and other living creatures determined to be important to the agro-ecology of the GIAHS region.

(21) A9. Genetic diversity : List genetic resources (i.e., plants/crops, animals, aquatic resources, forests, micro-organisms, and invertebrates) that are produced and harvested or kept by local farmers, seedbanks, or research institutions.

(1) A10. Indigenous varieties : List traditional and indigenous varieties produced, harvested, or seeds kept by farmers in seedbanks or research institutions.

(1) 악 A11. Crop/livestock/marine species and varieties : List or describe crop, livestock, and marine species and varieties that are being produced, sold, and/or consumed within the GIAHS region. This also captures changes to crop, livestock and marine species and varieties cultivated, as well as the reasons for the changes.

\section{SC5. Threats to agro-biodiversity}

Threats on agro-biodiversity may include but are not limited to climate change, scarcity of land and water, development, invasive species encroachment, disease or abandoned cultivation due to underuse, etc. This subcriterion intends to identify threatened species and the major threat of encroachment. The indicators to measure this sub-criterion could include the following:
(2) (2.8) B10. Reports on animal and plant encroachment : Provide number of incidents caused by animal and plant encroachment, or report trends of such encroachment. This should include incidents reported under Indicator A13.

(12) A12. Threatened species : List native threatened and unthreatened - and species of animals and plants that are agricultural products or living creatures that reside in the agro-ecology of the GIAHS region. To the extent possible, give particular attention to threatened species by specifying the threats and possible causes of the threats.

(6) A13. Agricultural damage caused by animal and plant encroachment : Provide statistics or report scale of damages in terms of the number of casualties of humans, animals, and plants, as well as economic loss and disruption in social and livelihood activities that are caused by animal and plant encroachment on farmlands, forests and water spaces, or the trend of such damage.

\section{SC6. Agro-ecology}

While agro-ecology generally refers to the science of applying ecological concepts and principles to manage interactions between plants, animals, humans, and the environment for food security and nutrition, this sub-criterion also encompasses the ecological environment of the GIAHS region and measures taken to conserve and enhance its resilience. The indicators to measure this sub-criterion could include the following:

(a) B11. Agro-ecological zones: Provide map or list the types of agro-ecological zones, which are homogenous and contiguous areas with similar soil, land, and climate characteristics.

(2R B12. Agro-ecology conservation and improvement : Report on projects, programmes, and activities implemented for agro-ecology conservation and improvement.
(2) A14. Disaster restoration, reduction, and resilience measures : Report on disaster incidences and plans, programmes, research, and activities taken to reduce, restore and enhance ecological resilience in response to the disaster incidences.

(2R A15. Climate adaptation practices and mitigation measures : Report on damages caused by climate change impacts and the research, programmes, projects, initiatives, and activities conducted for climate adaptation and mitigation, including cultivation of adaptive crops, land-use adaptation measures, farming practices that reduce greenhouse emissions, etc.

C3. Local and traditional knowledge systems

GIAHS should maintain local and invaluable traditional knowledge and practices, ingenious adaptive technology, and management systems of natural resources, including biota, land, and water, which have supported agricultural, forestry and/or fishery activities (FAO, 2021). The Manual proposes the following sub-criteria and indicators to monitor actions implemented for this criterion:

\section{SC7. Farming practices}

One of the key characteristics of GIAHS is the traditional farming practices kept alive for hundreds and, in some instances, thousands of years, that have not only provided food and means of livelihood, but also sustained agrobiodiversity, cultural values, and landscapes and seascapes of the region. Traditional and evolving farming practices and formal and informal groups dedicated to conserving those farming practices deem critical to sustaining and improving GIAHS. The indicators to measure this sub-criterion could include the following:
(11) B13. Groups conserving traditional agricultural techniques : List groups conserving traditional agricultural techniques and farming practices (detailed information on farming practices to be tracked via Indicator A16, if available). They include formalized promotional associations, local non-governmental organizations, and research institutes, as well as informal social organizations such as local youth groups and support groups.

(1) A16. Farming practices : List types of traditional, evolving, and emerging farming practices. They include technological advances such as mobile applications and equipment that support the enhancement of the traditional technique operated by hand.

\section{SC8. Transfer of traditional wisdom and}

\section{farming techniques}

Understanding, documenting, and transferring the wisdom and the value of the farming techniques used in GIAHS is critical to conserving the system. Across various platforms and means, from simple recordkeeping of farming practices to schematic training programmes, it is important that they strategically and systematically target intended populations, as well as track their progress and impact. Target populations, in the case of GIAHS, consist of actors related to the system, including current and aspiring farmers. The indicators to measure this sub-criterion could include the following:

(자 B14. Nurturing of human resource and supporting of actors : Report activities, programmes, and schemes aimed to cultivate cohorts of human resources and support actors related to GIAHS. They include administrators and officers in the local government, GIAHS promotional associations, NGOs, and research institutes. This indicator deliberately excludes the engagement of farmers, which is tracked by Indicators B16 and A17. 


\section{Linkage between C3 GIAHS indicators and SDGs}

The indicator for this criterion and sub-criteria could contribute to the achievement of the following SDGs:

4 U|

Conservation of traditional agricultural techniques and existing practices, including water resources management, and transfer of knowledge rely heavily on education initiatives for current and future generations (SDG 4) and equitable participation of girls and boys and men and women in all processes (SDG 5). The knowledge transfer and preservation of that knowledge in GIAHS are deliberate actions to sustain clean water (SDG 6), life below water (SDG 14), and life on land (SDG 15) as a continuation of its practices that have always protected the environment and as part of the systems' collective effort to mitigate modern day climate change (SDG 13).
(1) (2) B15. Knowledge recording and documentation : List materials that record traditional farming techniques and document the details of the know-how to enable transferring of the technical knowledge across organizations and generations. This entails a wide range of written and multi-media materials, including government archives, library collections, storybooks, research outputs, and films. Initiatives captured under GIAHS' capacity to perform B15.

(1) B B16. Training workshop and seminars for farmers : List or report training workshops and seminars for existing, new, and aspiring farmers, both one-off events, such as consultation workshops and information sessions, and comprehensive intervention programmes implemented . This indicator differs from Indicator A17 in that the training workshops and seminars concern new techniques, technological advances, and social innovations designed to supplement existing traditional farming practices. Indicators B14, B16, and A17 rely heavily on a
(2R B17. Water reserves and irrigation management : Report the status of programmes, measures, or activities for water reserves and irrigation management. The indicator should speak to the direct linkage between water resource management and agriculture, as well as the social and economic role it plays within the GIAHS community. Irrigation and drainage schemes represent prominent public works in the rural spaces and, by that nature, provide a logical vehicle for employment and livelihood (World Bank, 2020).

C4. Cultures, value systems, and social organizations

Cultural identity and sense of place are embedded in and belong to specific agricultural sites. Social organizations, value systems, and cultural practices associated with resource management and food production may ensure conservation of and promote equity in the use and access to natural resources. Such social organizations and practices may take the form of customary laws and practices as well as ceremonial, religious on traditional agricultural practices targeting
aspiring or new farmers : List or report training programmes and schemes, such as short-term academic courses or long-term intervention programmes, aimed to transfer traditional agricultural practices to aspiring or new farmers. It differs from Indicator B16 in its focus on traditional techniques and related institutional knowledge.

\section{SC9. Water resource management}

The management of water sources and irrigation channels, such as water ponds and reservoirs, is critical to the conservation of GIAHS and the survival of humanity at large. Population growth, urbanization, and climate change are anticipated to drive increased competition for water resources, with a particular impact on agriculture - and more acutely so in water-stressed regions (World Bank, 2020). Accordingly, it is important to measure this subcriterion through the following indicator: following SDGs: and/or spiritual experiences (FAO, 2021). The Manual proposes the following sub-criteria and indicators to monitor actions implemented for this criterion:

\section{SC10. Preservation of culture}

Conserving the identity of a GIAHS starts with preserving its culture associated with the local agricultural practices. A GIAHS region's religious and spiritual beliefs and rituals; cultural activities; arts found in crafts, tools, monuments, and other cultural assets; and traditional cuisines and unique food culture together constitute its identity which, unless deliberately documented and preserved, may lose its place in the collective sense of identity. The indicators to measure this sub-criterion could include the following:

(12) B18. Religious, spiritual, and cultural practices and activities : List religious, such as rituals, festivals, community activities, and the arts including games, songs, music, dances, poetry, and theater. spiritual, and cultural practices and activities,

\section{Linkages between C4 GIAHS indicators and SDGs}

The indicator for this criterion and sub-criteria could contribute to the achievement of the

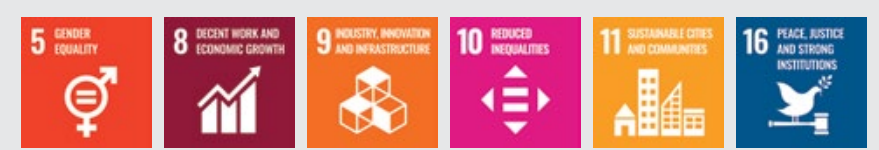

Preservation of all aspects of culture with deep historical roots, as well as support provided to social organizations and populations such as women, youths, indigenous peoples, and other vulnerable social groups of the GIAHS region support global aims to reach equitable distribution of social, political, and economic opportunities (SDGs 5 and 8) and reduced inequalities (SDG 10). Conscious development of industries and innovation (SDG 9) and cities and communities (SDG 11) occur with closely knitted societies bonded by shared values and culture. These aims cannot be achieved without partnerships at various levels (SDG 17). 
(2) B19. Crafts and tools : List crafts and tools, including those used in farming, cultural activities, and daily lives, such as pottery, traditional clothings, musical instruments. etc.

(2) 사 B20. Local food culture and traditional cuisines : List or describe local food culture and unique traditional cuisines that use local ingredients harvested via traditional farming techniques by residents working on the lands and seas of the region.

(21) A18. Cultural assets and monuments : List cultural assets and monuments, such as architecture built in celebration of local deities; statues and structures meant to extend guardianship, protection, and judgment between good and evil; and represent popular beliefs or legendary stories. While similar to Indicators B18, B19, and B20 in the type of information required, cultural assets and monuments are less likely directly linked to the residents' livelihoods but important to the community's agrarian history and identity.

\section{SC11. History, knowledge and values}

History, traditional knowledge, and societal values of GIAHS have transcended across generations to shape its identity. In the age of plethora of publicly accessible information and platforms that host them, keeping an official, systematic record of history, cultural practices, folk beliefs, and folklores and how they help understand today's society has increased in importance. To this end, the indicators to measure this subcriterion could include the following:

(2) 살 B21. Historical records of cultural practices : List or describe historical records of cultural practices, including administrative records, references in classic literature, and oral history and its relation to today's beliefs, perceptions, and practices.

(11) @ B22. Folk beliefs and folklores : List or describefolk beliefs and folklores that inform the conventional wisdom, points of view, interpretation of human-made and natural phenomena, and cultural practices of today's communities of GIAHS.

\section{SC12. Social organizations}

FAO (2021) defines "social organization" as individuals, families, groups, or communities that play a key role in the agricultural systems' organization and dynamic conservation. It further acknowledges the critical role that local social organizations play in balancing environmental and socio-economic objectives, creating enhancing resilience, and reproducing all elements and processes critical to the functioning of the agricultural systems. The indicators to measure this sub-criterion could include the following:

(21) (28) B23. Groups sharing of labor and resources: List and describe formal and informal groups sharing agricultural labor and resources, such as resident associations and informal farming groups who provide services to the collective body, ensure equitable access to resources, and distribute labor.

(14) A19. Social organizations supporting GIAHS : List social organizations supporting GIAHS, such as NGOs, promotional associations, cooperatives, museums, artisan groups and guilds, educational organizations, and advocacy groups, set out to conserve part or the whole of GIAHS.

(1) 자) A20. Participation of women, youths, indigenous peoples, and other vulnerable groups : List or describe status of participation of social groups and minorities engaged in agricultural professions, chiefly but not limited to women, youths, and indigenous peoples.

C5. Landscapes and seascapes features

GIAHS regions should represent landscapes or seascapes that have been developed over time through the interaction between humans and the environment,. Their form, shape, and ecological interlinkages are characterized by its long historical persistence and a strong connection with the local socio-economic systems that produced them. Their stability, or slow evolution, is the evidence of integration of food production, the environment and culture in a given area or region. They may have the mive sych as landuse mosaics, water and coastal management systems (FAO, 2021). The Manual proposes the following sub-criteria and indicators to monitor actions implemented for this criterion:

SC13. Landscapes and seascapes assessment The purpose of a landscapes and seascapes assessment is to check on the status of the landscape, seascape, and waterscapes, which could include information on landform, geology, soil, vegetation cover, drainage patterns, built development, land uses, sea uses (fishing grounds, aquaculture, marine protected areas, etc.) and related infrastructure. The indicators to measure this sub-criterion could include the following:

(a) B24. Map of GIAHS area : Provide map of GIAHS area, including farmlands, forest, watershed area, residential area, and other areas related to GIAHS with the region.

\section{Linkages between C5 GIAHS indicators and SDGs}

The indicator for this criterion and sub-criteria could contribute to the achievement of the following SDGs:

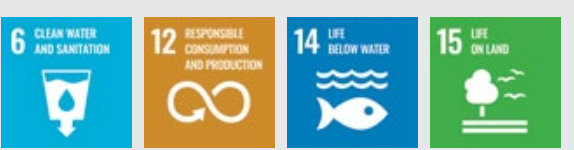

Water essential for irrigation is secured through holistic plans for managing ecosystems and watershed, thereby also supporting provision of clean water sources (SDG 6).Sustainable land and sea use and management support SDGs related to life below water (SDG 14), life on land (SDG 15), and people's consumption and production reliant on nature (SDG 12). 


\section{ENABLING CRITERIA}

In addition to the abovementioned five core criteria related to FAO GIAHS designation which all GIAHS designations are based upon, the Manual recommends GIAHS regions to also include the following enabling criteria Governance (C6), Capacity development and research (C7), and Partnerships and outreach (C8) - to enhance the effectiveness and ensure a more robust and meaningful M\&E process. GIAHS regions can choose to include all the additional criteria or only those which may apply.

C6. Governance

Conservation and effective utilization of valuable agricultural heritage resources critically rely on a management system with appropriate measures to revitalize rural areas and maintain their way of life (Yiu et al., 2016). The complexity of such natural resources, however, requires sophisticated governance systems (Krister et al., 2008). The sustainability of GIAHS is contingent upon the commitment of the government. Hence, the indicators delineated in this criterion focus on policies and strategic plans that the local government spearheaded in liaison with the national government.

\section{Linkages between C6 GIAHS indicators and SDGs}

The indicator for this criterion and sub-criteria could contribute to the achievement of the following SDGs:

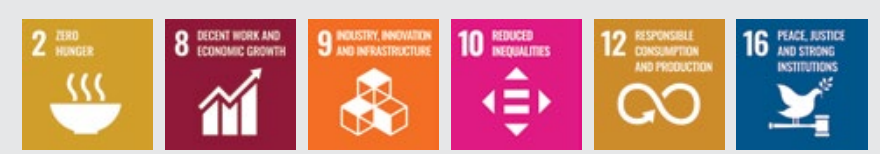

While governance services all SDGs, the indicators most explicitly focus on strengthening institutions (SDG 16) and economic policies targeting GIAHS producers, their support groups, and governance of the commodification process. The policies aim to ensuring food security (SDG 2), economic development (SDG 8), resilient industrial development (SDG 9), reduced inequalities (SDG 10), and responsible cycle of consumption and production (SDG 12).
B28. Monitoring results reported or shared with the public: Report on mechanisms or mediums through which monitoring results are reported or shared with the public and feedback is received. This can include announcements through mass media, town hall meetings at the community level, conferences, and online dissemination.

(1) 18 B29. Institutional structure for Bist or report on the status of institutional structure put in place for M\&E, such as personnel working on GIAHS monitoring, key stakeholders, institution commissioned to conduct monitoring (if applicable), and participating entities.

(2R A23. Participatory monitoring with community : Report on the status of participatory monitoring with community, including technical guidance, resources for PM\&E, and facilitation of participation.

(AR A24. Database for GIAHS-related information gathering and maintenance : Report on the development of the database for GIAHS-related information gathering and maintenance. Databases dedicated to key activities of GIAHS, such as certification of agricultural products, crop and indigenous varieties, water use systems, biodiversity, landscapes and seascapes, human resources, and cultural elements (e.g., food, historical records, religious practices, etc.) can be centrally managed through a comprehensive management information system (MIS). Information can also be in the form of video footages for aesthetically recording of scenery, practices, events, knowledge, and opinions of GIAHS community.

\section{SC16. Economic policies}

Economic policies rolled out and implemented by national or local governments to boost sales of GIAHS products and financial assistance given to GIAHS farmers. The indicators to measure this sub-criterion could include the following:
(2) (11) B30. GIAHS products branded and certified : Provide number or list of products branded and certified as supporting GIAHS conservation under official schemes.

(2) (1) B31. GIAHS-related products : Provide number or list of products that are not officially branded or certified, but are produced in and related to GIAHS, including fresh produce, processed foods, and craft items. Products captured under this indicator do not include those reported under Indicator B30.

(1) 사 A25. Policies and regulations related to GIAHS : List or report on the policies and regulations related to the GIAHS economy, or on the development of such policies and regulations.

(3) A26. A26. Farmers and agricultural area receiving financial support: Provide statistics or report the number of farmers receiving and area of agricultural land subject to financia support or subsidies related to GIAHS, or on the development of such schemes.

QR A27. Support to community for shared resource management, maintenance, and operation : Report on support extended to community organizations for shared resource management, maintenance, and operation,

(11) 아 A28. Channels for direct sales and marketing : List or report on the development of channels for direct sales and marketing of certified and branded (Indicator B30) and GIAHS-related products (Indicator B31).

(2) A29. Supply chain management : Report on the status of supply chain management concerning production, processing, distribution, and consumption of certified and branded (Indicator B30) and GIAHS-related products (Indicator B31). 
Conserving GIAHS requires multi-stakeholder participation in many facets, including helping to promote an understanding and the importance of agricultural systems, as well as transferring traditional knowledge to future generations (Reyes et al., 2020). Such "knowledge governance" or "structures, agents, and cultures shaping the overlapping networks of actors, organizations, and institutional arrangements conducive to the reproduction and transformation of knowledge" (Manuel-Navarrete \& Gallopín, 2011), encompasses ongoing capacity development of not only the farmer, but also the wider public from all generations. To this end, research that cultivates scientific and cultural literacy and concern for the sustainability of GIAHS will help address the novel challenges that many GIAHS face today. It is important to note that governance is an evolving, historical process (Manuel-Navarrete \& Gallopín, 2011) that requires financial backing for its educational and research activities, whose learnings should be shared with interested groups in a timely fashion. The Manual proposes the following sub-criteria and indicators to monitor actions implemented for this criterion:

\section{Linkages between C7 GIAHS indicators and SDGs}

The indicator for this criterion and its sub-criteria could contribute to the achievement of the following SDGs:

\section{U1i \& 4 is}

Capacity development indicators speak directly to education of people trained on agricultural skills and technology (SDG 4), ongoing innovation through research and partnerships that enable such innovations (SDG 9 and 17), and creation of strong institutions through secured funding that provides the necessary human resources and social services (SDG 16). activities are fundamental to effective GIAHS conservation. An indicator to measure this subcriterion could include the following:

(2) B33. Funding dedicated to maintaining GIAHS : Provide statistics or list amount and sources of funding dedicated to maintaining GIAHS to cover personnel costs, operational expenses, financial support for economic schemes and social services, and commissioning expenses for monitoring, evaluation and/or special studies.

\section{SC19. Research}

Research paves the road to functioning knowledge governance and affords exploration of possibilities that can contribute to enhanced agricultural productivity, public education and awareness of GIAHS, resilience against risks, and mobilization of resources. Research encompasses assessments, surveys, academic studies, and $R \& D$ efforts. The indicators to measure this subcriterion could include the following:

(21) B34. Research outputs : List research outputs, such as academic papers, dissemination events and presentations, and reports and materials from R\&D or academic research projects.

(1) (2) A30. Ongoing research that supports maintenance and improvement of GIAHS and livelihood : List or describe ongoing research that contributes to maintaining and improving GIAHS and residents' livelihood such as evaluation studies, environmental assessments, field surveys, and pilot testing of new inventions and agricultural varieties.

C8. Partnerships and outreach

Given the complexity of GIAHS, the local community, farmers and "masters" of the heritage system alone cannot conserve and protect the GIAHS. Investments in multi-stakeholder processes that invite the participation of governments, technical experts, private enterprises, social organizations, and the wider public are needed for the long-term sustainability of GIAHS (Min et al., 2016). To this end, public partnerships, outreach, and advocacy efforts at the local, national, and international levels via in-person and remote delivery platforms and messaging technologies available, practical, and feasible for the context can be considered. The Manual proposes the following sub-criteria and indicators to monitor actions implemented for this criterion:

\section{SC20. Public relations and outreach}

Conservation of GIAHS relies heavily on advocacy of its existence and value to society, as well as promotion of activities occurring within the region (e.g., festivals, museum exhibits) or in support of the region (e.g., marketing of GIAHS-branded products). Raising the public's knowledge, awareness, and interest in what a GIAHS region has to offer can boost local economies, as well as the confidence and pride of the local people. Hence, the indicators to measure this subcriterion could include the following:

(1) (2B B35. Sharing, education, and promotion of agricultural culture : List or describe content and status of initiatives and actions such as information sessions, education workshops, and side events at conferences aimed at increasing knowledge, awareness, interest, and appreciation for agricultural culture of GIAHS. This indicator differs from Indicator B36 in its intended audience (targeted vs. anyone exposed to the content) and depth of engagement (organized events vs. postings on public places and online).

(1) 살 B36. Promotion and advocacy through media, including social media : List or describe content and status of initiatives and actions conducted via mass media aimed at increasing knowledge, awareness, and interest in GIAHS. This will monitor for quick, light-touch reach through succinct public service announcements 


\section{Linkages between C8 GIAHS indicators and SDGs}

The indicator for this criterion and its sub-criteria could contribute to the achievement of the following SDGs:

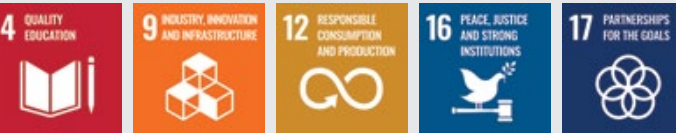

Partnerships and outreach indicators focus on the practice of exchanging information, fostering education and promoting GIAHS and its culture across various stakeholders and interest group (SDG 4). The formation of such partnerships (SDG 17) and strengthened institutions (SDG 16) can stimulate of innovation (SDG 9) and promote collective search for responsible consumption and production (SDG 12).

and publicity about GIAHS conservation, including promotion of GIAHS and its products on social media, advertisements, articles, posters, etc. More in-depth, targeted advocacy efforts are intended to be tracked separately through Indicator B35.

\section{SC21. Community engagement}

In addition to the engagement of the wider public, direct support to the GIAHS residents and urban-rural exchange through local-level community engagement extends the social protection and economic security they need against the challenges that many GIAHS regions face today. The indicators to measure this sub-criterion could include the following:

(21) 앙 B37. Formation and activities of resident Bist or describe activities carried out by resident governance bodies such as associations of industry laborers and informal groups that keep abreast of the latest information and share it, ensure adequate resources, facilitate equitable access to those resources, maintain accountability, and provide support and orientation for new residents.
(2) (2R B38. Local organizations related to GIAHS and expansion of its activities: List or describe local organizations working to strengthen the overall health of GIAHS and scale of its activities. They include organizations designing and implementing technical support programmes, in alignment with the interests of the abovementioned resident government bodies.

(1) (28) A31. Volunteer programmes : List or describe volunteer programs that serve the interests and pursuits of the GIAHS. Volunteer programmes can include one-time events and regular participation in activities at community centers and public institutions supporting GIAHS.

\section{SC22. Exchange and cooperation}

Exchange of knowledge, latest research findings, experiences and cooperation among experts, coordination across GIAHS supporting entities, and interaction between residents and experts facilitate ongoing support to and enhancement of GIAHS. Such partnerships are encouraged at all levels - local, regional, national, and international - on formal and informal bases. The indicators to measure this sub-criterion could include the following:
(1) (28 B39. Partnerships within and/or among GIAHS sites and with different sectors : List or describe activities of partnerships within and/or among GIAHS regions, and that with different sectors, such as education, tourism, commercial, etc.

(11)장 B40. Cooperation between residents and GIAHS administration groups/experts : List or describe activities and events that facilitate cooperation between residents and GIAHS administration groups and experts, such as longterm leaders in governance bodies, government officers who provide administrative and technical support, and researchers.
(11) B41. Conferences, expert convenings, exhibitions, and events : List conferences, expert convenings, exhibitions, and events at which information about GIAHS, its best practices and challenges, innovations, and solutions are discussed, debated, and refined.

All above-mentioned Criteria and sub-criteria relate to areas that contribute to all 17 SDGs. The linkages between them are summarized in Figure 3-3. 





This chapter describes how to design for the M\&E process, including the recommended action steps, institutional structure, stakeholder engagement, and resource mobilization.

The process presented herein embodies a RBM approach, which focuses on the achievement of desired results - outputs, outcomes, or highlevel goals or long-term impact — throughout the cycle of planning, implementation, and reporting. In the life cycle of RBM, "M\&E provide invaluable information for decisionmaking and lessons learned for the future" (UNDG, 2011). In the context of GIAHS, the "results" in RBM are equivalent to the goals the GIAHS region has set out to achieve in its Action Plan and the purpose of M\&E to inform - that is, to validate, evaluate, refine, and, as necessary, reinvent — the Action Plan.

Subsequent sections elaborate on each step of designing an M\&E process for GIAHS. They are intended to provide overall guidance and underscore key considerations for each step, with the expectation that specifics will inevitably vary across GIAHS regions. For instance, the sequence and scope of each of the steps will be determined by the GIAHS region per capacity, resources, context, and needs.

The Manual assumes the presence of a shared perceived value of M\&E in conserving and improving GIAHS, as well as the security of political and financial commitment to M\&E for the system. While it factors in the commonly documented challenges of GIAHS, such as reduction in the population of farmers and implications of climate change, the Manual does not advise on unpredictable special circumstances such as natural disasters, economic crises, political upheaval, etc.

\section{DESIGNING AN M\&E PROCESS} FOR GIAHS

The design phase focuses on constructing the foundations required for operationalization of an M\&E process. It includes building a team dedicated to carrying out M\&E responsibilities within the GIAHS region; defining the scope of the process by identifying clear objectives and desired outputs and activities that will be monitored in relation to those objectives; selecting KPIs and associated targets and means of verification; building a MIS for organized data management and institutional memory and determining the M\&E cycle that best informs GIAHS operations and Action Plans.

$$
\text { 1. Convene an M\&E team }
$$

Before kicking off the M\&E process, a GIAHS should form a dedicated M\&E team. The team may reside within the lead governing body, such as the GIAHS Promotion Office, or an independent team hosted outside the governing body. Regardless of institutional affiliation or residency, the M\&E team should consist of at least three people: a chairperson with institutional knowledge and political capital to represent the team at key meetings and dialogues; an M\&E specialist possessing technical knowledge and experience in managing and conducting M\&E activities; and a key stakeholder of the region, such as an officer from a supporting organization or a resident, aware of GIAHS regulations and its implications on residents.

The need for other specific expertise may emerge across time; for instance, depending on the needs, the M\&E team might consider hiring a resident expert on a particular topic, such as water resource management, agricultural technology, or cultural studies. In addition to or as an alternative to a resident expert, working group(s) could be formed for thematic and/or ad hoc consultations. Such valuable resource persons could also be shared across multiple GIAHS regions for efficiency and knowledge sharing.
Members of the M\&E team and its extensions, such as members of working groups and committees, should be representative of the populations they serve. Balance across gender, age, race and ethnicity, and industries should be considered in alignment with basic principles of equity. It is also a viable mechanism for ensuring quality in data collection, interpretation of findings, and distillation of learnings and implications for different groups within GIAHS. The M\&E team can be formed before or expanded after defining the scope of the M\&E process, depending on the expertise required and circumstances of the GIAHS region.

2. Define the scope of M\&E process

The scope of an M\&E process can be defined in a variety of ways. The sheer geographic size of a GIAHS and the types of agricultural production, agro-biodiversity, history and traditional culture, landscapes and seascapes, demographics, and core industries undoubtedly affect the calculus. Regardless of these factors, the scope of an M\&E process can comprise of the following:

\section{- An articulated theory of change (ToC)}

An ariculated theory of change (ToC) the needs of GIAHS; strategies, actions, outputs, and outcomes; desired targets or goals; and reasonable assumptions informed by learnings from the past or research serving as a foundation of the M\&E process. This exercise of defining a pathway for change helps clarify purpose and value of GIAHS and defines the actions required to achieve goals in a realistic way. Thus, in scoping a GIAHS M\&E process, a ToC of the GIAHS Action Plan should also be articulated to establish a shared understanding of the purpose and value of GIAHS with various stakewholders, which in turn will help to justify the establishment of its supporting systems, including an M\&E process (see Figures 1-1 and 1-2 for samples of ToC

- A strategic GIAHS Action Plan that clearly stipulates its actions designed to meet targets based on envisioned to meet targets based on envisioned
outputs and outcomes in order to achieve long-term goals (impacts). Already a requirement of GIAHS designation application to FAO, every GIAHS region has and should be implementing GIAHS conservation actions committed under their Action Plan. While some Action Plans are revised every few years, others have slight adjustments made as and when required. ${ }^{5}$ The Action Plan is developed in collaboration with key stakeholders of the GIAHS region, to articulate its vision for the future and design strategies for bringing that vision to fruition through a comprehensive "GIAHS programme." Action Plans are intended to be a living document and thus have to be subjected to regular reassessment and updates. Building on the conceptual grounding established by the ToC (see Figure 1-2), the Action Plan helps define for an M\&E process and the scope of GIAHS activities that it must track. This process naturally enables mapping of the type of information required and available to feed the Action Plan, thereby guiding the M\&E to target better the information it seeks to know about its actions.

- Existing information from reliable resources should be built upon for efficient scoping and conducting of an M\&E process. Sources can include research outputs; 
biodiversity surveys; meeting minutes; news articles; films, media footages and documentation of cultural activities and of landscapes and seascapes; informal reporting such as blog posts and online market promotions; and anecdotal evidence from community members on the changes that have occurred overtime, etc. Learning from a quick scan of existing information, adapting their approaches, and scaffolding their latest discoveries offers a "good enough" starting point. For instance, from speaking to people who have collected data within GIAHS (for monitoring or for other purposes), one may be able to navigate efficient ways to request government data on certified products, anticipate challenges in gathering information on productivity and sales due to the residents' sensitivity around income-related matters, etc.

A few additional considerations may help in scoping out an M\&E process. They include but are by no means limited to:

- Building relationships: Because of the communal lifestyle of GIAHS, operating within it requires building relationships with residents, establishing well-natured working rapport with key stakeholders, and navigating long-established formal and informal networks. Implementing a practice of M\&E within GIAHS requires the investment of time and skills to leverage those relationships.

- Establishing clear expectations: GIAHS is a system in which selected outcomes (e.g., agricultural sales from branded products) may be realized fairly quickly, while others (e.g., ecological changes in landscapes and seascapes, impacts of a new agricultural policy, outcomes of a course on agricultural technologies) will take some time to come to fruition in an observable way. No GIAHS region should expect to detect changes upon every monitoring exercise but should set realistic expectations according to circumstances on the ground.

\section{Determining the level of coordination} across GIAHS regionse It is an established across GIAHS regions: It is an established practice for institutions or systems to share M\&E personnel, tools, and measurement approaches, should it make sense and should they choose to do so. It may naturally emerge from cross-pollination of ideas across GIAHS and the reality of implementing a "GIAHS programme" with limited resources. Should a GIAHS region reach out to another GIAHS region to discuss best practices, challenges, and potential ways to coordinate around those challenges, as well as tools and standards, it challenges, as well as tools and standards, it
is encouraged that they do so in the design phase to help define the M\&E scope.

3. Decide on M\&E elements

The next step is to select and set the M\&E elements. This encompasses selecting the KPIs to assess progress in commitments delineated in the Action Plan, setting realistic targets and goals for GIAHS, establishing baselines, and thinking through the means of verification or sources of information. The ToC and the Action Plan are key resources for this step, helping to ground the rationale for selecting KPIs and establishing targets to which the GIAHS will be held accountable.

- Selecting indicators: $\ln$ Chapter 3 of this Manual is the list of basic and advanced indicators for monitoring GIAHS across eight criteria. A selection of those, combined with other indicators that may deem important and relevant to the GIAHS region will make up the KPIs (see Figure 3-2). It is also important to consider the linkages between the KPls and the priorities set by the national agricultural policies, prefectural or provincial plans, municipality goals, and the GIAHS contribution to long-term sustainability, as guided by the SDGs and other global priorities. By aligning the KPIs with other strategic visions in which the GIAHS must operate, this step in designing an M\&E process ensures that GIAHS is positioned within the broader context as a relevant, compatible part of society and committed to its performance.

- Setting targets: The targets should be specific to the actions (inputs) and set around each criterion. The targets should be measurable, and in most instances, directly related to an indicator. The targets are used directly to determine outcomes; the output created by an action (input) will be matched against its target to determine what outcome(s) has been derived. However, whether quantitative or qualitative, targets are dependent on the capacities and resources of the GIAHS, and therefore, this Manual does not intend to suggest specific targets or standards. Nonetheless, targets should specify a particular value or state that an indicator should ideally reach by a specific date in the future (UNDP, 2017).

- Setting goals: To ensure that actions laid out in the Action Plan leads to the desired impacts, GIAHS region should set long-term goals that could realistically be achieved in stages through first reaching corresponding short-term and mid-term goals. Goals and targets should be feasible, achievable, and consistent with local and/or national strategic plan, or any other updated and agreed country targets. However, if the setting of GIAHS specific goals is difficult, GIAHS regions can first broadly set their goals around the SDGs. This Manual proposes as a reference which SDGs could be achieved under the respective eight criteria (see Figure 3-3). The achievement of goals (impacts) is determined through the overall assessment of the outcomes gathered.

- Determining baselines: A baseline is a minimum or starting fixed point of reference that is used for comparison purposes. It acts as a reference point against which progress or achievements can be assessed (UNDG, 2017). In the GIAHS context, it is the data and information on the status of the GIAHS at the point of implementing the Action Plan. Baseline data can be based on information in the GIAHS proposal or constructed by collecting new data. Baselines are necessary to understand the changes that have taken place and therefore should be established at the beginning of GIAHS Action Plan implementation, prior to the first monitoring exercise. If there is no existing information or data to set the baseline, the results after the first year of monitoring should be used to establish the baselines. Establishing and gathering information for baselines will help the GIAHS M\&E team and stakeholders think through what means of verification should be used and what the action is intended to measure, so it also will serve as a prerun of the actual monitoring.

- Determining the means of verification Means of verification refer to sources from persons, beneficiaries, or organizations in which information will be gathered to inform initial baselines and measure the results (UNDP, 2011). Examples can include governments, ministries or agencies, civil society organizations (CSOs), community-based organizations (CBOs), institutions, volunteer 
organizations, etc. It can also include methods, such as yearly reporting, surveys, and testimonials. Beneficiaries or rights-holders should be enabled to participate in the process of monitoring results that concern and affect their lives

In deciding the scope of an M\&E process, it is useful to identify easy entry points for starting M\&E activities. It is likely that a GIAHS may not be able to conduct monitoring for all KPls in the first year of launching an M\&E process, nor have all baselines or means of verification. Approaching these elements in phases is advised over not monitoring at all. One may start with indicators which may already have targets set by the local government and clearly defined means of verification. Reliable, easyto-access entry points for GIAHS M\&E, such as information on tourism revenue, agrobiodiversity survey results, and list of social organizations that promote GIAHS and their activities most likely already exist.
4. Build a Management Information System (MIS)

In the design phase, it is important to define protocols and means of managing all the information that will be generated via M\&E activities, commonly referred to as a MIS. In a small, premature system, the MIS may consist of spreadsheets that people manually enter data. In a more sophisticated, mature design, the MIS may be a database located on a server with backend mechanisms for organizations to feed data through a common online portal or even process real-time data on a mobile phone to inform decision-making. The maturity of the GIAHS MIS is not as important as having an agreed-upon mechanism and processes for centrally gathering and storing the information.

MIS is a tool that can undoubtedly provide convenience to the users of the information, but most importantly, it is a tool for maintaining and growing institutional knowledge.
Selecting KPIs for GIAHS participatory monitoring: Korea

While this Manual does not include indicators on quality of life, RDA (2021), as part of its community-based participatory monitoring of GIAHS, plans to track 'efforts to improve the living environment in GIAHS region' and 'efforts to improve access to social services for disadvantaged individuals' by tracking a

The ultimate beneficiaries of a GIAHS are its ordinary residents. Macro-level information such as population statistics, conditions of landscapes, and implementation of economic incentives indeed provide a sense of the health of a GIAHS. However it does not help portray what and how ordinary people perceive the state of their own lives. For instance, OECD's (2011) well-being index includes indicators for material living conditions (income and wealth, jobs and earnings, housing) and quality of life (health status, work-life balance, education and skills, civic engagement and governance, social connections, environmental quality, personal security, and subjective well-being). Should these elements deem important for GIAHS, indicators that help monitor progress in the residents' well-being should be included in the selection of KPIs - as RDA has done for GIAHS in Korea.
5. Determine an M\&E cycle

Data collection for M\&E, where possible and to the extent possible, should occur annually in order for the data to be meaningful for GIAHS managers and stakeholders. The annual data collection will enable GIAHS regions to grasp the progress toward the targets set for the KPIs, and also to take timely and immediate actions in responding to challenges. Stakeholder dialogues for mid-term checks, consultation with residents, and feedback from municipal authorities and relevant experts are recommended. Some assessments that, by nature of their subjects, require more time for analyses or long-term observations (e.g., environmental surveys, perception surveys, etc.) can be aligned to the terminal year of the Action Plan (i.e., year three for Korea, years four/five for Japan).

The M\&E duration will depend on the size of the GIAHS region and the coordination amongst municipalities involved, but the conduct of the full M\&E cycle will be almost the same as the implementation duration of the Action Plan; tracking actions through periodical collection and compilation of KPls data, selfassessment, third-party evaluation, reflection, feedback, and revision of new Action Plan. Each of these steps in the implementation of an M\&E cycle is elaborated in the next section.

\section{INSTITUTIONAL STRUCTURE}

Prior to transitioning to the implementation of an M\&E process in the next chapter, it is worthwhile to discuss the institutional structure required for effective implementation. Stakeholders mapping will be helpful to identify willing actors to be delegated with roles and responsibilities. The key entities of the M\&E institutional structure could include the following:
- GIAHS Promotion Office is responsible for the overall operation and management of the GIAHS conservation activities. They include the administrative duties of holding council meetings; formation, implementation, and revision of the Action Plan; conducting M\&E; and collaborating with experts and stakeholders. As mentioned above, the GIAHS Promotion Office spearheads the M\&E design process by forming a dedicated M\&E team. Whether the team resides within the GIAHS Promotion Office or elsewhere, it operates under the auspices of the GIAHS Promotion Office.

- Government agencies refer to various levels of government that engage in the
management and conversation activities of GIAHS as hosts of the system. The national government (e.g., MAFRA in Korea and MAFF in Japan) and the prefectural/provincial and municipal governments coordinated in seeking GIAHS designations should continue to participate in policy dialogues and operations concerning GIAHS. In the case of Japan, government officers of the hosting municipality often lead the M\&E process, conducting data collection themselves. In the case of Korea, MAFRA commissions an external research agency to conduct monitoring studies and lead the M\&E process, with support and coordination from local governments.

M\&E team, as aforementioned, should consist of at least a chairperson, an M\&E specialist, and a key stakeholder of the region aware of GIAHS regulations and its implications. It is established and commissioned by the GIAHS Promotion Office to manage and conduct the M\&E process, including coordinating with all actors that form the M\&E institutional structure. 
- Working groups are formed and tasked to oversee thematic issues or projects - e.g., certified branding of agricultural products, promotion of green tourism and farm lodging, administration of biodiversity surveys and environmental assessments, etc. - so as to more effectively channe the expertise and resources to facilitate the M\&E process. The diversity of initiatives, schemes, and activities in the Action Plan are made possible by the wide range of expertise the members of the working groups contribute.

- Producers comprise the key constituents of GIAHS and are the direct stakeholders within the system. They include mainly (1) primary sector workforce engaged in agriculture, forestry, and fisheries and (2) other secondary industries related to GIAHS, such as food operators.

- Local residents refer to a wide range of actors, broadly categorized into (1) champion residents, or formal and informal community leaders with wide reach and networks, which they leverage to mobilize community support; and (2) supporting individuals and groups, such as consumers, volunteers, and entities such as businesses participating in the GIAHS economic activities, local NGOs operating volunteer environmental revitalization programmes, and local schools that teach about GIAHS. For selected KPIs, such as attitudinal shifts and promotion activities on social media, producers and local residents are the goto sources of information for GIAHS M\&E. Under the framework of participatory M\&E (PM\&E), they lead M\&E activities, from data collection to evaluation of the results and revision of the Action Plan.

The wide range and complex network of stakeholders should not be correlated with the scope of the M\&E process. It is not the intention of this Manual, by explaining the comprehensiveness of the process, to discourage GIAHS from pursuing a meaningful, systematic M\&E, but to provide an accurate picture of the possibilities. As mentioned earlier in this chapter, one should feel comfortable starting small from strategic entry points, and the more one has because of a wide cast of stakeholders, the higher the chance of accessing valuable information.

Challenges do abound, however, even in the existence of an established institutional structure. GIAHS managers in Korea and Japan have shared challenges in accumulating institutional knowledge through standardized M\&E due to regular job rotations, which occur every two years in Korea and every three to four years in Japan. New leadership and new managers often lead to changes in priorities, which may affect the priorities around the type of information gathered through M\&E and interpretation of the results. In Korea, M\&E is outsourced to third-party research agencies by MAFRA. The agencies have now been cultivated into GIAHS specialists and hold strong relationships with local GIAHS residents, who are often engaged in the M\&E process at the data collection, evaluation, and other Action Plan stages. On the other hand, government agencies who host the GIAHS remain largely administrative in their engagement with local residents, and their rapport is not as close as those demonstrated by third-party coordinators, who are often researchers. Thus in some instances, third-party "outsiders" can serve as better coordinators and catalysts to bring together different actors within the community.

\section{RESOURCE MOBILIZATION}

While the options and mechanisms for mobilizing resources for $M \& E$ should not differ from that of those efforts taken for securing resources for the implementation of the GIAHS Action Plan, M\&E is often still not recognized as an important part of the overall implementation of the GIAHS Action Plan. As a result, resources are often not budgeted or secured for the M\&E process. It is critical to plan for the resources needed for effective implementation of M\&E, as well as utilize M\&E results in effective ways towards the generation of resources.

Funding

Funding is essential to maintain GIAHS designation and drive Action Plans, including conducting M\&E. In some countries, including Korea and the China, GIAHS regions are funded by national subsidies for the inceptive years of designation. Most others, like Japan, need to secure their own funding for sustaining for their GIAHS and are usually selffunded by the host municipal governments of the GIAHS region. In developing settings, such

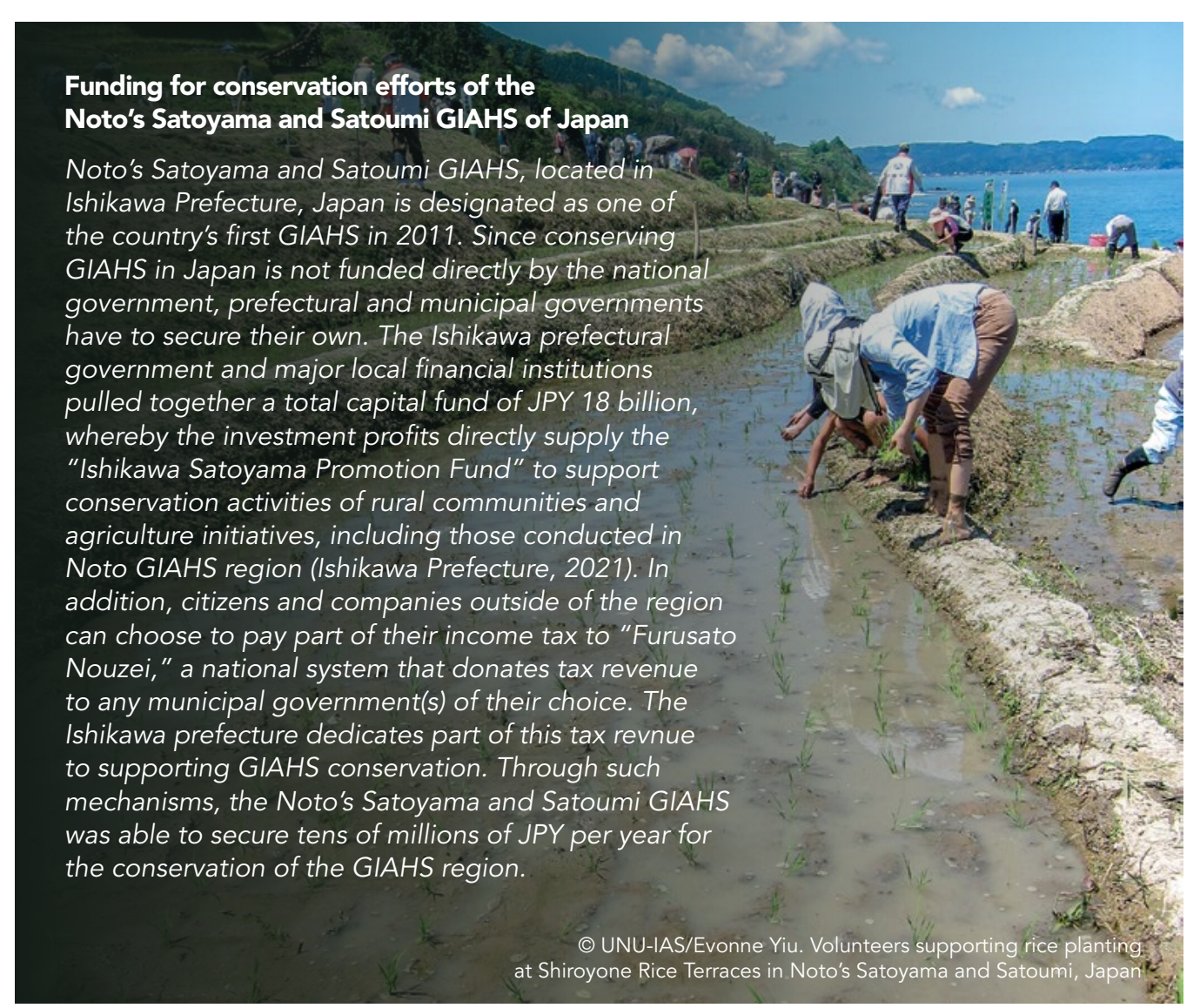

resources may be provided by the government, the international community, or a combination of both. The international community need to continuous garner and help provide funding for M\&E activities for developing countries. However, ways for cost-effective implementation of M\&E also need to be considered for the limited funds to be put to meaningful use.

Effective use of M\&E data through public dissemination for awareness-raising and advocacy may inspire creative mechanisms to better support GIAHS. Municipal governments need not rely only on their tax revenue or donation but should be proactive to generate conservation funds through establishing schemes for GIAHS product certification or attracting capital COinvestments of GIAHS related industries and co- 
funding of conservation activities. Proceeds and revenue from these schemes should as far as possible benefit the resident GIAHS community and its businesses.

Human resources

Where resources for outsourcing or hiring additional personnel for M\&E are not available, M\&E responsibilities often fall on the officers who serve as GIAHS managers of the GIAHS Promotion Office who are in charge of the overall activities of GIAHS conservation. However, as mentioned above, most of these government officers often hold rotational positions on a two-to-three-year term. In such instances, these GIAHS managers on rotation may not be able to be involved full cycle of the GIAHS Action Plan implementation, which in some countries takes about five years. Moreover, designing the M\&E scope and assessing the data received on the KPls to put together the self-assessment report requires expert knowledge, and the management of the M\&E itself and coordination with a wide range of stakeholders also require institutional knowledge.

For more effective M\&E, GIAHS Promotion Offices should consider either assigning GIAHS managers to hold a position on longer terms, or commissioning the conduct of M\&E to civil society organizations (CSOs) or non-profit organizations (NPOs) who are permanently active in the local community. The members of local CSOs and NPOs are usually active and have wide connections with government, farmers, residents, academia and businesses within or outside region and will serve as effective coordinators.

Appointing a non-government personnel to a permanent position of a GIAHS Regional Coordinator will also help nurture leadership and ensure ownership of the conservation activities. Working groups can also be formed for each criterion or thematic issue of the M\&E so that more stakeholders can help participate in implementing the conservation actions and monitoring the outcomes.

Utilization of M\&E results to enhance GIAHS value and generate resources

The results of M\&E, including the data and information gathered on the KPls, can be effectively used to enhance value of the GIAHS and generate resources for the M\&E. For instance, the results can be used as evidence and reporting of conservation outcomes for GIAHS certification systems, where consumers can access and validate the purposes of GIAHS certified products. A part of the proceeds from sales of these GIAHS certified products could then be contributed to the GIAHS conservation funds. The results of the M\&E will reveal the challenges faced by the GIAHS region, but these challenges can also be taken as business opportunities or identified as potential areas for external aid. It is thereby important to plan and establish a virtuous cycle for the financing of the M\&E based on the M\&E results.

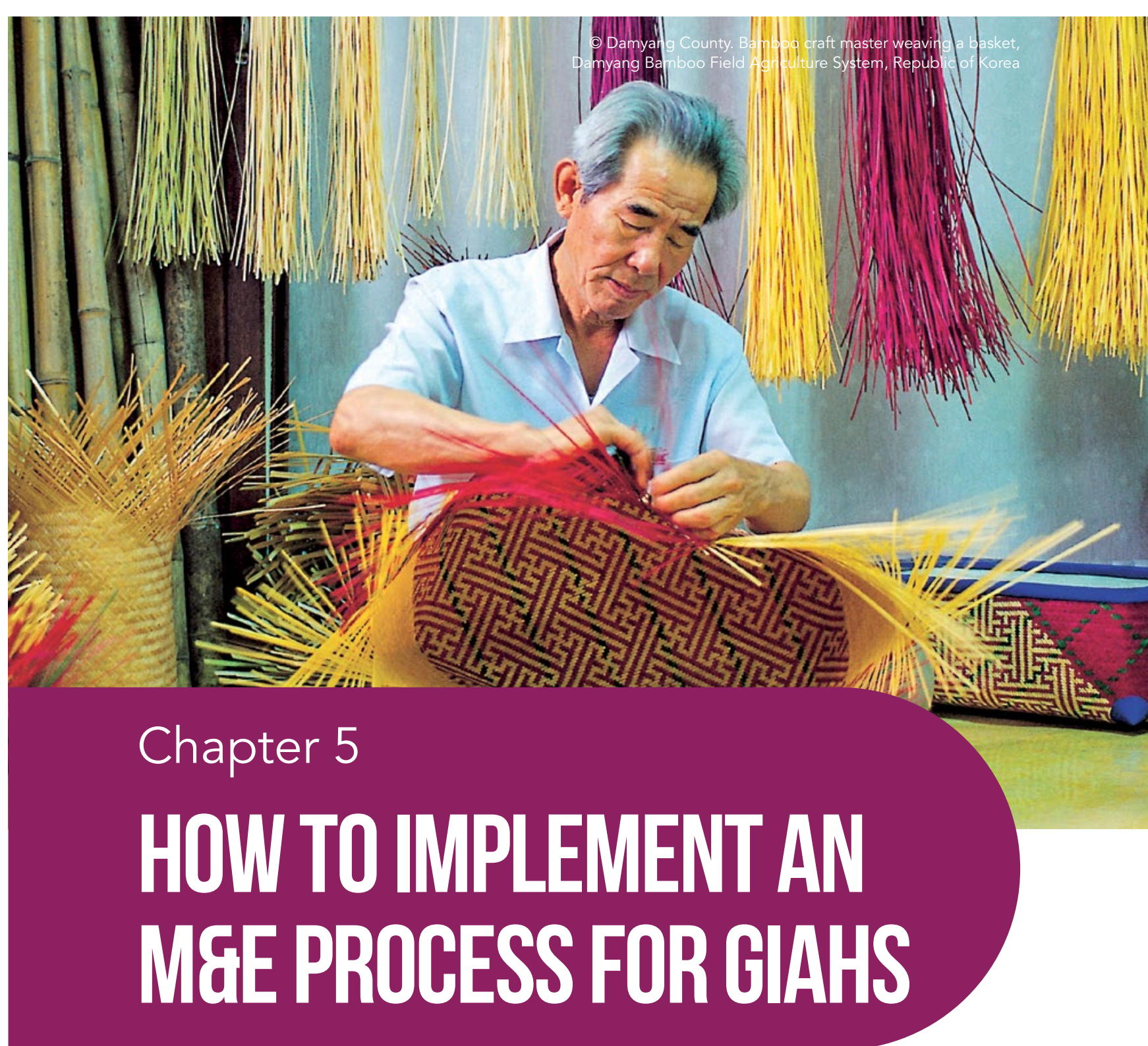


This chapter elaborates on the steps of implementing a M\&E process for GIAHS. It is intended to evaluate the outcomes of the actions taken under the GIAHS Action Plan, measured using the M\&E elements selected in the design phase (see Chapter 4).

Launching an M\&E process and data collection for GIAHS are similar to M\&E processes practiced by the international development community, including those that coordinate with and/or are supported by FAO. The steps that follow should aligned with governments' internal protocols, under which the GIAHS regions consulted for this Manual operate. Although they may be unique to GIAHS, the purpose of conducting monitoring and using the information to improve the lives of its beneficiaries mirror the spirit of M\&E

Figure 5-1 | Monitoring and Evaluation process flowchart

\begin{tabular}{|ll}
\hline Step 1. Start of M\&E process & Commencement \\
Step 2. Monitoring data collection and synthesis of results & Milestone in the process \\
Point of decision-making
\end{tabular}

Step 3. Self-assessment report

$\downarrow$

Step 4. Evaluation of monitoring results by a third party

Step 5. Feedback and reflections

$\downarrow$

Step 6. Future scenarios planning for new Action Plan

Step 7. Development of new Action Plan $\downarrow$

Step 8. Completion of M\&E and start of new Action Plan
With the preparatory and design of the M\&E process in place as described in Chapter 4, the process begins with the M\&E team contacting all GIAHS managers in municwipalities of the GIAHS region and all stakeholders on the commence and duration of the process. The time to start the M\&E process could be in line with the timeline of the national process for $M \& E$ of GIAHS conducted by the ministry. If there is no national process for M\&E, GIAHS regions can launch the process as and when ready. However, it is recommended that the start of the M\&E process coincide with the Action Plan's commence. Therefore, both the Action Plan and M\&E process should ideally start concurrently.

The M\&E team leads the process of coordinating with stakeholders to confirm the targets, means of verification, and subsequent steps that will unfold once data collection is complete, including the revision of the GIAHS Action Plan. The M\&E team manages the operationalization and technical details that follow the launching of the M\&E process, reporting on progress and regularly consulting with the GIAHS Promotion Office.

Step 2. Monitoring data collection and synthesis of results

The data collection process may vary across GIAHS regions, contingent upon the scope of data collection (number of KPls, size of the region, etc.), in-house expertise in monitoring, access to means of verification (people, organizations, documents, etc.), and availability of resources for outsourcing and consultation of experts. The M\&E team may collect data annually or at the final year of M\&E directly from actors or knowledge holders responsible for each indicator to prepare the self-assessment report for thirdparty evaluation. It will also entail establishing a sampling framework for KPls that require them overseeing the recruitment and training of enumerators; streamlining expectations around data collection methods and quality, including establishing protocols for inability to access sites in the sample or missing unavailability; and fulfilling administrative needs, including for data collection, use of photos, etc. from participants.

If the M\&E team has the resources and decides to outsource data collection and reporting, the contractor should have the capacity to carry out these responsibilities, with the M\&E team providing orientation to the undertaking (such as a walk-through of the Action Plan) and regular and ad hoc technical guidance. It is within the purview of the M\&E team to monitor the monitoring process - that is, manage the data collection process by accompanying the data collection team and intermittently review the quality of data gathered to date (particularly during the early stages of monitoring for KPls that have been introduced for the first time and whose tools have been scaled for the first time) etc.

If the selection of KPIs for monitoring does not require primary data collection or extensive fieldwork (e.g., population statistics, information on training programmes, etc.), the data collection process may consist of requests for information from respective ministries, municipality governments of the GIAHS region, and other the organizations who own the information. The M\&E team should be responsible to establish relationships with these entities and provide them with specifications for data requests, such as the time range, types and levels of disaggregation, qualitative description of activities, and explanations for substantial changes. For instance, a data request specification could say "number of new, young farmers between January and December of 2021, disaggregated by gender 
and profession, types of agricultural labour they engage in, and notes for changes that exceed +/- 20 percent." Transparency and clarity in what you need, provided through definitions, tools, and screenshots that can serve as references, will be useful in this circumstance.

\section{Step 3. Self-assessment report}

In this step, the M\&E team and the GIAHS Promotion Office that has commissioned the data collection will review the monitoring results to assess the progress of its conservation actions under the GIAHS Action Plan. The monitoring data collected will be synthesized to produce a self-assessment report which has to be first reviewed by the GIAHS Promotion Association. It is a process through which the GIAHS region self-reflects and gathers key learnings, and then in writing, deliberates the outcomes of that exercise. The selfassessment report articulates at a high level how much of the Action Plan's commitment have been currently fulfilled, what is working and not working within that process, and their renewed commitment to the Action Plan by making reflections for the new Action Plan. The report is submitted to ministries and agencies that provide a third-party evaluation of the monitoring results based on the selfassessment report.

The self-assessment report is formally required for revising the Action Plan, which, as aforementioned, does not occur annually. Results from monitoring conducted outside of the last year of the Action Plan are used internally by the commissioning GIAHS governing body to document changes, build institutional knowledge, and respond to areas of immediate need.
Step 4. Evaluation of monitoring results by a third party

In this step, the M\&E team will submit the self-assessment report of the monitoring results to a third-party evaluation panel for an unbiased evaluation and technical advice on areas of improvement and ways to update the Action Plan that mirror their suggestions. The panel can be a dedicated entity, either commissioned by the leading ministry as part of its national programme for GIAHS or formed upon the request of the GIAHS region solely for the purpose of the M\&E. The evaluation may be conducted through document reviews, interviews with the responsible team, onsite inspections, or a combination of these approaches. While most of the discussion transpired in this process will focus on the progress that the GIAHS region has made and the challenges it faces, it is within the evaluation panel's purview to ask questions on the monitoring mechanism and process as well as provide feedback for improvement.

Chapter 6 elaborates on the evaluation step, as it is an important and one of the final steps that will inform the next iteration of the Action Plan.

\section{Step 5. Feedback and reflections}

Based on evaluation results and advice received from the third-party evaluation, the M\&E team should then set up dialogue opportunities with stakeholders and local residents to reflect and provide feedback. This stakeholder dialogue helps raise awareness and maintain interest in GIAHS by providing the opportunity to participate, share their feedback, and formulate the next Action Plan together. It is important to enabling open access to the Action Plan and the $M \& E$ results, and where possible, the $M \& E$ data collected to the public. The M\&E process should also be publicized through outreach efforts via news, magazines, social media, etc., for public awareness and engagement.
Step 6. Future scenarios planning for new Action Plan

The GIAHS Promotion Office, with support from the M\&E team, builds on the feedback and advice received from the evaluation panel and report to stakeholders and the public to start the process of revising the Action Plan. Although an Action Plan typically covers three to five years, it is advised that to have it updated with short-term, mid-term, and longterm goals in its strategic vision of the GIAHS region. The future scenario planning matrix (see Table 5-1) from the M\&E process planning phase can be reutilized at this stage.

It can be used to facilitate selection of KPIs to track collective progress through M\&E towards common goals. It is recommended to envision in agreement among GIAHS stakeholders what outcomes are desired and possible short-, mid-, and long-term goals to achieve, whose windows of time should be determined by the GIAHS; what indicators would best speak to those outcomes; and what those indicators mean to the' various GIAHS stakeholders. Also refer to Annex 2 for the template.

\section{Step 7. Development of new Action Plan}

Steps 1-6 culminate into making key decisions for the future of GIAHS and articulating those decisions in the next Action Plan. While it is not obligatory for GIAHS to submit to FAO the updated Action Plan (only initial Action Plan is required at the GIAHS designation application stage), the Action Plan needs to be coordinated with the broader strategy within the country and municipality level, and accordingly, the GIAHS Promotion Office must submit it to the respective government agency for review and approval.

This by no means limits the value of the revised Action Plan and the M\&E process that contributed to it to a mere administrative responsibility or isolated community action within the GIAHS region. As a representation of the renewed commitments of everyone engaged in the M\&E process to the GIAHS' short-, mid- and long-term goals, the revised Action Plan carries the potential to influence future agricultural strategies and policy dialogue that in turn can generate positive changes to GIAHS.

\section{Step 8. Completion of M\&E and start of} new Action Plan

The completion of a full cycle of the M\&E process - from the initial kick-off and data collection to the third-party evaluation and revision of the Action Plan - is marked by the launching of the new Action Plan. It is a cycle that repeats to continue to benefit the GIAHS community by reminding it of the commitments to the 'GIAHS programme' and guiding it through the process of transforming the GIAHS of today into the GIAHS of their envisioned tomorrow.

Subsequent case study on the launching of PM\&E in Korea illustrates an example of implementation of a GIAHS M\&E process. 


\begin{tabular}{|c|c|c|c|}
\hline & $\begin{array}{l}\text { SHORT-TERM GOALS } \\
\text { (Duration: e.g., } 3 \text { years) } \\
\end{array}$ & $\begin{array}{l}\text { MID-TERM GOALS } \\
\text { (Duration: e.g., } 5 \text { years) }\end{array}$ & $\begin{array}{l}\text { LONG-TERM GOALS } \\
\text { (Duration: e.g., } 10 \text { years) }\end{array}$ \\
\hline \multicolumn{4}{|l|}{ Vision } \\
\hline $\begin{array}{l}\text { Societal changes (population, technology, climate, policy, } \\
\text { etc.) }\end{array}$ & $\begin{array}{l}\text { Align GIAHS conservation efforts with local/national } \\
\text { strategies and agricultural and rural development } \\
\text { policies, SDGs, UN Decade on Family Farming, etc. }\end{array}$ & $\begin{array}{l}\text { Contribute to global goals such as SDGs, UN Decade } \\
\text { of Family Farming, Convention on Biodiversity (CBD), } \\
\text { Paris Agreement on Climate Change, etc. }\end{array}$ & $\begin{array}{l}\text { Amplify contributions to national and global goals to } \\
\text { bring about positive change for a better and more } \\
\text { sustainable planet }\end{array}$ \\
\hline \multicolumn{4}{|l|}{ All GIAHS } \\
\hline Outcome statement & $\begin{array}{l}\text { Implement actions in the Action Plan, realize early } \\
\text { effects of the conservation efforts }\end{array}$ & $\begin{array}{l}\text { Achieve Action Plan goals, realize the benefits of } \\
\text { GIAHS designation, and develop the next Action Plan } \\
\text { through M\&E }\end{array}$ & $\begin{array}{l}\text { Achieve goals of the new Action Plan, create a model } \\
\text { for sustainable rural development, and develop the next } \\
\text { Action Plan through M\&E }\end{array}$ \\
\hline \multicolumn{4}{|l|}{ Key stakeholders } \\
\hline GIAHS Promotion Office & $\begin{array}{l}\text { - } \quad \text { Conduct an interim review of Action Plan } \\
\text { Disseminate monitoring results with stakeholder } \\
\text { and hold dialogues regularly } \\
\text { - Align Action Plan to SDGs and other global } \\
\text { goals }\end{array}$ & $\begin{array}{l}\text { - } \quad \text { Design and implement M\&E process } \\
\text { Implement stakeholder workshops for } \\
\text { - } \quad \text { development of next Action Plan } \\
\text { - } \quad \text { recomch a system of evaluation and } \\
\text { - Organize a } 5^{\text {th }} \text { anniversary ever improvement }\end{array}$ & $\begin{array}{l}\text { - } \quad \text { Design and implement M\&E process } \\
\text { Establish a participatory system, create a cycle of } \\
\text { - Instituttation and feedback } \\
\text { - } \quad \text { recommendation of actions for for improvement } \\
\text { - Organize a } 10^{\text {th }} \text { anniversary event }\end{array}$ \\
\hline Primary industry & $\begin{array}{l}\text { - } \quad \text { Promote policies to recruit new farmers } \\
\text { - Adopt sustainable farming technologies }\end{array}$ & $\begin{array}{l}\text { - Increase number of new farmers } \\
\text { Incorporate sustainable farming technologies into } \\
\text { daily practice }\end{array}$ & $\begin{array}{l}\text { - Secure a stable number of new farmers every year } \\
\text { Increase production area using sustainable farming } \\
\text { technologies on a daily basis }\end{array}$ \\
\hline Related organizations (e.g., cooperatives) & $\begin{array}{l}\text { Promote branding and certification of GIAHS } \\
\text { products }\end{array}$ & $\begin{array}{l}\text { Increase awareness of GIAHS certification and } \\
\text { branding efforts }\end{array}$ & Gain recognition of GIAHS certified products overseas \\
\hline Constituent municipalities & Promote and implement actions in the Action Plan & $\begin{array}{l}\text { - Cooperate with the GIAHS Promotion Office on } \\
\text { M\&E and develop the next Action Plan } \\
\text { Exercise ownership and lead efforts of GIAHS } \\
\text { conservation }\end{array}$ & $\begin{array}{l}\text { - Cooperate with the GIAHS Promotion Office on } \\
\text { M\&E and develop the next Action Plan } \\
\text { - Refine management of and support to GIAHS }\end{array}$ \\
\hline Tourism groups & Increase awareness of GIAHS as a tourism destination & $\begin{array}{l}\text { Position GIAHS as a tourism destination and increase } \\
\text { annual number of visitors }\end{array}$ & $\begin{array}{l}\text { Steadily increase annual number of domestic and } \\
\text { international visitors }\end{array}$ \\
\hline Consumer groups (e.g., national, particularly urban) & Participate in GIAHS conservation actions & $\begin{array}{l}\text { Expand core consumer base, increase supporters and } \\
\text { their awareness of GIAHS }\end{array}$ & $\begin{array}{l}\text { Establish target consumer groups and pool of supporters } \\
\text { or support organizations }\end{array}$ \\
\hline NPOs & $\begin{array}{l}\text { Design and implement community outreach } \\
\text { programmes for conservation of agro-biodiversity }\end{array}$ & $\begin{array}{l}\text { Participate in third-party evaluation of outreach } \\
\text { activities and research on agro-biodiversity; results } \\
\text { show increase in agro-biodiversity }\end{array}$ & $\begin{array}{l}\text { Leverage evaluation and research data to increase } \\
\text { awareness in the linkage between agro-biodiversity and } \\
\text { wellbeing of residents, advocate for more resources for } \\
\text { agro-biodiversity conservation }\end{array}$ \\
\hline Women & $\begin{array}{l}\text { Participate in and initiate GIAHS-related activities, to } \\
\text { support increase in women's participation }\end{array}$ & $\begin{array}{l}\text { Lead GIAHS-related activities, establish pathways for } \\
\text { increased women's participation }\end{array}$ & $\begin{array}{l}\text { Continue to lead GIAHS-related activities, sustain women's } \\
\text { participation and ownership of conservation efforts }\end{array}$ \\
\hline Youth & $\begin{array}{l}\text { Participate in and initiate GIAHS-related activities, to } \\
\text { support increase in youth participation }\end{array}$ & $\begin{array}{l}\text { Lead GIAHS-related activities, establish pathways for } \\
\text { increased youth participation }\end{array}$ & $\begin{array}{l}\text { Continue to lead GIAHS-related activities, sustain youth } \\
\text { participation and ownership of conversation efforts }\end{array}$ \\
\hline Non-farmer residents & $\begin{array}{l}\text { Participate in and initiate GIAHS supporting } \\
\text { programmes, to support increase in non-farmer } \\
\text { participation }\end{array}$ & $\begin{array}{l}\text { Lead GIAHS supporting programmes, establish } \\
\text { pathways for increased non-farmer participation }\end{array}$ & $\begin{array}{l}\text { Continue to lead GIAHS supporting programmes, sustain } \\
\text { non-farmer participation and ownership of conversation } \\
\text { efforts }\end{array}$ \\
\hline Civil society or community development groups & $\begin{array}{l}\text { Activities to utilize GIAHS are progressing in multiple } \\
\text { municipalities }\end{array}$ & $\begin{array}{l}\text { Activities that utilize GIAHS are being extended and } \\
\text { established throughout the GIAHS region. }\end{array}$ & $\begin{array}{l}\text { A system to utilize GIAHS is well-established throughout } \\
\text { the GIAHS region and self-sustained. }\end{array}$ \\
\hline Corporates and businesses & $\begin{array}{l}\text { Identify and launch GIAHS supporting corporate } \\
\text { shared value (CSV) activities }\end{array}$ & $\begin{array}{l}\text { Expand the amount of financial and in-kind } \\
\text { commitment and resources (gifts, volunteers, } \\
\text { philanthropical grants) dedicated to GIAHS-supporting } \\
\text { CSV activities }\end{array}$ & $\begin{array}{l}\text { Establish GIAHS supporting CSV activities and funds } \\
\text { into regular programmes (volunteer programmes, } \\
\text { philanthropic activities, etc.) }\end{array}$ \\
\hline$\ldots$ & $\ldots$ & $\ldots$ & $\ldots$ \\
\hline
\end{tabular}




\begin{tabular}{|c|c|c|c|}
\hline & $\begin{array}{l}\text { SHORT-TERM GOALS } \\
\text { (Duration: e.g., } 3 \text { years) } \\
\end{array}$ & $\begin{array}{l}\text { MID-TERM GOALS } \\
\text { (Duration: e.g., } 5 \text { years) }\end{array}$ & $\begin{array}{l}\text { LONG-TERM GOALS } \\
\text { (Duration: e.g., } 10 \text { years) }\end{array}$ \\
\hline \multicolumn{4}{|l|}{ Criteria } \\
\hline \multicolumn{4}{|l|}{ Criterion 1. Food and livelihood security } \\
\hline SC1. Population statistics & $\begin{array}{l}\text { Define demographics of GIAHS producers, including } \\
\text { the status of family farming }\end{array}$ & $\begin{array}{l}\text { Increase the number of GIAHS producers and } \\
\text { implement measures to support family farming }\end{array}$ & $\begin{array}{l}\text { Increase the number of GIAHS producers and grow } \\
\text { measures to support family farming into standard } \\
\text { programmes and interventions }\end{array}$ \\
\hline & $\ldots$ & $\ldots$ & \\
\hline \multicolumn{4}{|l|}{ Criterion 2. Agro-biodiversity } \\
\hline SC4. Agro-biodiversity & $\begin{array}{l}\text { Empower residents with technical skills and } \\
\text { knowledge to conduct agro-biodiversity surveys and } \\
\text { collect relevant data on their own }\end{array}$ & $\begin{array}{l}\text { Monitor the health of agro-biodiversity; results of } \\
\text { surveys conducted in collaboration with researchers } \\
\text { reveal that agro-biodiversity has improved since five } \\
\text { years ago }\end{array}$ & $\begin{array}{l}\text { Commission a large-scale survey to assess agro- } \\
\text { biodiversity; the linkage between agro-biodiversity and } \\
\text { the wellbeing of residents is verified }\end{array}$ \\
\hline & $\ldots$ & $\ldots$ & $\ldots$ \\
\hline \multicolumn{4}{|l|}{ Criterion 3. Local and traditional knowledge system } \\
\hline SC7. Farming practices & $\begin{array}{l}\text { Conduct technical training on traditional practices of } \\
\text { agriculture, forestry, and fisheries }\end{array}$ & $\begin{array}{l}\text { Expand technical training on traditional practices of } \\
\text { agriculture, forestry, and fisheries to include overseas } \\
\text { trainees }\end{array}$ & $\begin{array}{l}\text { Establish technical training on traditional practices } \\
\text { of agriculture, forestry, and fisheries as a standard } \\
\text { programme and outreach to rural communities overseas }\end{array}$ \\
\hline & $\ldots$ & $\ldots$ & $\ldots$ \\
\hline \multicolumn{4}{|c|}{ Criterion 4. Culture, value systems, and social organizations } \\
\hline SC10. Preservation of culture & $\begin{array}{l}\text { Revive indigenous food culture, farming rituals, } \\
\text { festivals, and other cultural initiatives }\end{array}$ & $\begin{array}{l}\text { Increase awareness of and participation in indigenous } \\
\text { food culture, farming rituals, festivals, and other } \\
\text { cultural initiatives }\end{array}$ & $\begin{array}{l}\text { Support regular conduct and celebration of indigenous } \\
\text { food culture, farming rituals, festivals, and other cultural } \\
\text { initiatives }\end{array}$ \\
\hline & $\ldots$ & $\ldots$ & $\ldots$ \\
\hline \multicolumn{4}{|l|}{ Criterion 5. Landscapes and seascapes features } \\
\hline SC13. Landscapes and seascapes assessment & $\begin{array}{l}\text { Document more accurate maps of landscapes and } \\
\text { seascapes of GIAHS region }\end{array}$ & $\begin{array}{l}\text { Complete landscape design (landscape/land-use plan) } \\
\text { for crop cultivation }\end{array}$ & Develop land use plan for certified products \\
\hline & & & $\ldots$ \\
\hline \multicolumn{4}{|l|}{ Criterion 6. Governance } \\
\hline SC15. Management and monitoring & $\begin{array}{l}\text { - Keep track of Action Plan progress annually; } \\
\text { - Regularly hold participatory stakeholder Action } \\
\text { Plan workshops }\end{array}$ & $\begin{array}{l}\text { - Design and implement M\&E process } \\
\text { Implement stakeholder workshops for } \\
\text { development of next Action Plan }\end{array}$ & $\begin{array}{l}\text { - Design and implement M\&E process } \\
\text { Establish a system of participatory stakeholder } \\
\text { consultation, creating a cycle of sharing and } \\
\text { feedback }\end{array}$ \\
\hline$\ldots$ & $\ldots$ & $\ldots$ & $\ldots$ \\
\hline \multicolumn{4}{|l|}{ Criterion 7. Capacity development and research } \\
\hline SC17. Training on agricultural skills and technology & $\begin{array}{l}\text { Provide training on SMART farming technologies that } \\
\text { complement GIAHS production }\end{array}$ & $\begin{array}{l}\text { Increase the annual number of trainees on SMART } \\
\text { farming technologies that complement GIAHS } \\
\text { production }\end{array}$ & $\begin{array}{l}\text { Support wide adoption of SMART farming technologies } \\
\text { that complement GIAHS production }\end{array}$ \\
\hline$\ldots$ & $\ldots$ & $\ldots$ & $\ldots$ \\
\hline \multicolumn{4}{|l|}{ Criterion 8. Partnership and outreach } \\
\hline SC20. Public relations and outreach & Implement a publicity plan for GIAHS & $\begin{array}{l}\text { Implement the publicity plan for GIAHS and monitor } \\
\text { public's awareness and knowledge of GIAHS; data } \\
\text { demonstrates increased popularity of GIAHS }\end{array}$ & $\begin{array}{l}\text { Implement the publicity plan for GIAHS and monitor } \\
\text { public's awareness and knowledge of GIAHS; data } \\
\text { demonstrates increased recognition of GIAHS } \\
\text { domestically and overseas }\end{array}$ \\
\hline & & & \\
\hline
\end{tabular}




\section{Launching of PM\&E in Korea}

Two Korean Important Agricultural Heritage Systems (KIAHS), a prerequisite national designation to qualify for GIAHS designation application, are currently piloting PM\&E. RDA has supported the KIAHS through a series of consultations with stakeholders and experts in designing a PM\&E process and formative testing of indicators and tools. The process has resulted in 40 indicators and associated guidelines captured in RDA (2021) Guidebook on Community-based Participatory Monitoring and Activities for Sustainable GIAHS Conservation.

The RDA has specified four key principles of PM\&E:

1. Monitoring should be conducted directly by the residents of the region.

2. There is no set timeframe or cycle for PM\&E. Monitoring is a year-long activity that takes place on a regular and ad hoc basis, as and when opportunities and/or reasons arise (e.g., meetings, educational programmes, festivals, new research findings, changes in the environment).

3. PM\&E should not replace or be replaced by the standard monitoring conducted by experts every two years. The two approaches are meant to supplement and complement each other for accurate and comprehensive findings.

4. PM\&E should be administered in coordination with institutions (e.g., government and local formal bodies) in charge of managing the region. MAFRA allots these institutions financial resources to fund PM\&E activities as part of standard management and conservation efforts.

PM\&E engages stakeholders at multiple levels of the region, from MAFRA and local governments to resident bodies and individual residents. Roles and responsibilities for each stakeholder group have been defined as follows:

- MAFRA ensures that the resources required for PM\&E are provided to the respective local governments.

- Local governments specify monitoring as part of their conservation and management plans, formally commission resident bodies and groups to conduct PM\&E, and provide necessary technical support and guidance.

- Members of MAFRA, advisory committees, RDA, and expert groups participate in consultations, training, feedback workshops, and action plan revisions throughout the PM\&E process.

- Resident bodies and groups establish the necessary institutional structure (e.g., president, secretary-general, and resident representatives) to be able to conduct PM\&E on regular and ad hoc basis. They are responsible for systematically collecting and archiving monitoring data, findings, and related documentation.

The findings and learnings from the pilot PM\&E, scheduled to become available during the first half of 2022, will be reviewed and considered for updating the abovementioned Manual on PM\&E.

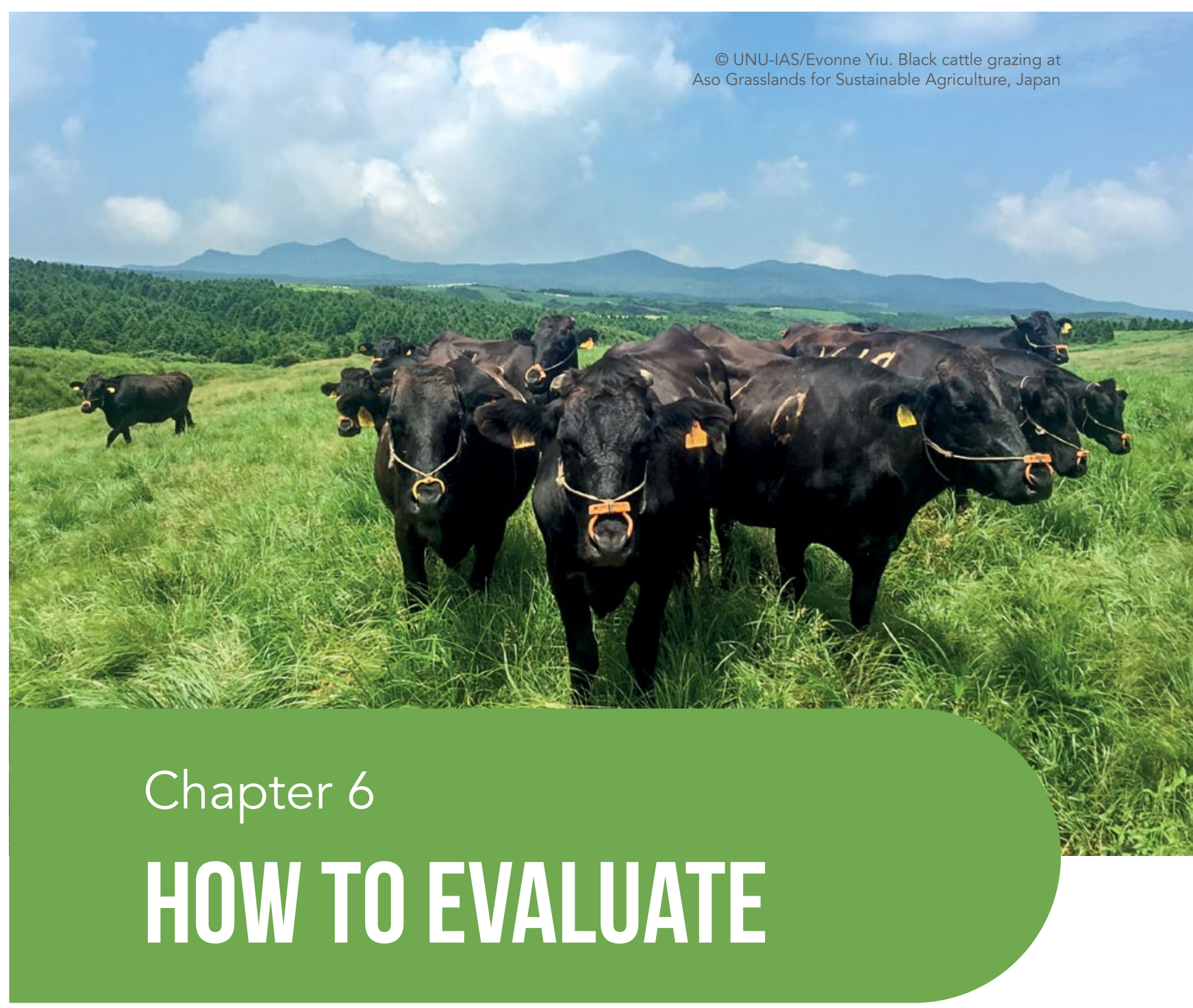


This chapter will discuss the linkage between monitoring and evaluation, perspectives for evaluation, and the strategic and meaningful use of M\&E process and data.

In the GIAHS context, evaluation is the assessment of the monitoring outcomes of the actions implemented under the GIAHS Action Plan, conducted as systematically and impartially as possible by a third-party evaluation panel.

\section{THE LINKAGE BETWEEN}

MONITORING AND EVALUATION

"Monitoring" and "evaluation" are often interchangeably used in the GIAHS community to refer to the process of tracking the progress of activities in the Action Plan and using that information to validate the effectiveness of the actions and identify areas of improvement. However, a clear difference exists between the two: monitoring is conducted by the GIAHS

Table 6-1 | Distinctions between "monitoring" and "evaluation" of GIAHS

\begin{tabular}{l|l|l|}
\multicolumn{1}{|c|}{ CRITERIA } & \multicolumn{1}{|c|}{ MONITORING } & \multicolumn{1}{|c|}{ EVALUATION } \\
\hline Interval & Continuous, annual data collection & Periodic, once in three to five years \\
\hline Operationalization & $\begin{array}{l}\text { Part of regular management, not } \\
\text { independent (internal) }\end{array}$ & $\begin{array}{l}\text { Independent from management, } \\
\text { independent (external) }\end{array}$ \\
\hline Timeframe & $\begin{array}{l}\text { Throughout implementation of actions } \\
\text { in the Action Plan }\end{array}$ & $\begin{array}{l}\text { After implementation of actions in the } \\
\text { Action Plan }\end{array}$ \\
\hline Measurement focus & $\begin{array}{l}\text { Process-oriented and focused on } \\
\text { progress achieved according to } \\
\text { implementation plans }\end{array}$ & $\begin{array}{l}\text { Impact-oriented, objectives assessed at } \\
\text { higher levels }\end{array}$ \\
\hline Purpose & $\begin{array}{l}\text { Data routinely collected, analysed, } \\
\text { interpreted and triangulated per } \\
\text { selected KPIs from multiple sources, } \\
\text { outcomes consolidated into a self- } \\
\text { assessment report }\end{array}$ & $\begin{array}{l}\text { Validation of performance of actions in } \\
\text { the Action Plan based on monitoring } \\
\text { data and the self-assessment report }\end{array}$ \\
\hline Output & $\begin{array}{l}\text { Causality and validity of the ToC are } \\
\text { raised as appropriate and needed }\end{array}$ & $\begin{array}{l}\text { Causality and validity of the ToC are } \\
\text { analysed and questioned to the extent } \\
\text { possible }\end{array}$ \\
\hline Analyse monitoring data to make self- & Make evaluation report and give advice \\
\hline assessment report
\end{tabular}

sector, operational area, or institutional performance (UNEG, 2016). It analyses the level of achievement of both expected and unexpected results by examining the results chain, processes, contextual factors, and causality using appropriate perspectives such as relevance, effectiveness, efficiency, impact, and sustainability. An evaluation should provide credible, useful evidence-based information that enables the timely incorporation of its findings, recommendations, and lessons into the decision-making processes of organizations and stakeholders.

In alignment with this purpose and spirit, GIAHS regions task a third-party evaluation panel to evaluate monitoring data and their self-assessment report for the primary purpose of providing guidance, technical advice, and feedback to inform the next Action Plan. Evaluative actions for GIAHS can be broadened to include more robust undertakings, such as commissioned expert studies, institutional performance reviews of selected programmes within the Action Plan, and sector-wide policy analyses.

Evaluation can strengthen learning and is essential for ensuring transparency and accountability to help in informed decisionmaking (UNDP, 2021). For instance, in the GIAHS context, evaluation can strengthen learning within the GIAHS Promotion Association and among stakeholders by informing them of the performance of training programs for farmers, exposure to promotional activities on social media, and early impacts of tourism initiatives. This way, stakeholders can make informed management decisions and plan strategically. Transparency of decisions and actions taken are ensured by undergoing impartial evaluation by a third-party evaluation panel. This evaluation process also helps strengthen the ability of GIAHS decision-makers and stakeholders and holds them accountable for their contributions. Moreover, through the generation of evidence and objective information, evaluations enable GIAHS decision-makers and other stakeholders to make informed management decisions and plan strategically.

\section{HOW TO CONDUCT AN}

\section{EVALUATION}

To conduct evaluation of the GIAHS monitoring outcomes, the GIAHS region needs to consider and have in place the following:

Evaluation pane

A third-party evaluation panel should be formed, comprised of professionals with expertise in GIAHS or the fields related to eight criteria of this Manual. In some instances, such as countries with GIAHS like China, Japan, and Korea, whereby there is already an independent expert committee on GIAHS appointed by the Ministry of Agriculture, the same expert committee can take the role of the evaluation panel. Otherwise, an evaluation panel comprised of at least three evaluators can be appointed by the GIAHS Promotion Association. Evaluators may be compensated for their service according to national or municipal government standards.

What to evaluate

As described in Chapter 5, the M\&E team should create a self-assessment report based on the monitoring data collected. The self-assessment report, along with the monitoring data, would then be the main document on which the evaluators will base their evaluation. The evaluation pane can have a review session with the monitoring team to validate the claims documented in the self-assessment report and ask other questions for a more comprehensive understanding of the progress. The evaluation can be made at the criteria, sub-criteria, or indicator level, as well as on the overall operational aspects and sustainability of the GIAHS conservation efforts under the Action Plan.

The evaluators should take into consideration the following perspectives in Figure 6-1: 


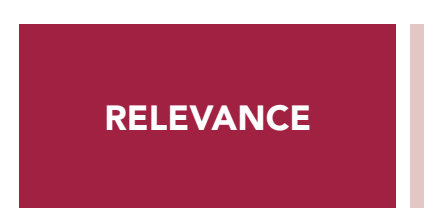

Is the action doing the right things?

The extent to which the action objectives and design respond to the GIAHS criteria it intends to conserve, and will continue to do so even circumstances change.

COHERENCE

How well does the action fit?

with other actions taken under the other policy interventions on national or local level.

EFFECTIVENESS

Is the action achieving its objectives?

The extent to which the action is achieved, or is expected to achieve, its objectives, and its targeted results.

EFFICIENCY

\section{How well are resources being used?}

The extent to which the action delivers, or is likely to deliver, results in an economic and timely way.

\section{SUSTAINABILITY}

\section{Will the outcomes last and the action be continued?}

The extent to which the net benefits of the action and the underaking of the action continue or are likely to continue.
Evaluation results

The evaluation results of the monitoring outcomes can be synthesized in the form of a grade, score, or normative assessment. It is not the intention of this Manual to propose a standardized evaluation template or methodology; Table 6-2 provides possible ways to synthesize evaluation results for reference.

- Grading : A grading scale of A (Excellent), $B$ (Good), C (Fair), and D (Poor) can be used to rate the action outcomes. There will not be a total or overall grade in this method, and it will be more readily accepted for those who may be averse to scoring systems or overall grade.
- Scoring : A numerical score on a scale from 0 to 10 can be used to rate the action outcomes. In this method, it will be possible to calculate the total score of all the action items and the average score of indicators.

For example, in a case where a total of 334 points out of 560 points for the 56 KPIs (35 Basic Indicators, 19 Advanced Indicators, where full points is 10 points for each indicator) is scored, the overall score will be 334/560 points equates to 59.6 points out of 100 points, or an average of 5.96 points per indicator.

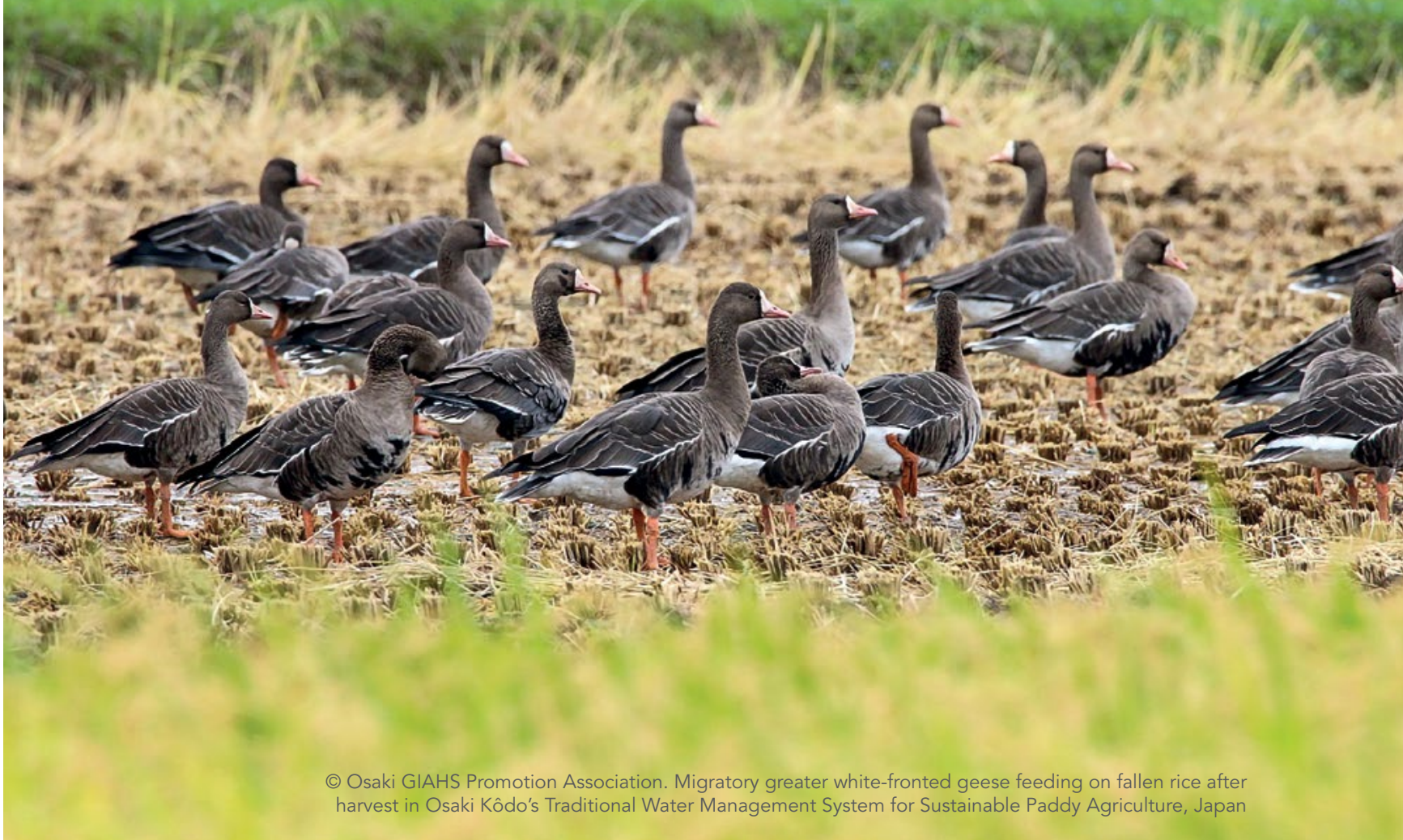

- Normative assessment : Unlike a grading or a scroing system, normative assessment is provided in the form of written text. In this approach, the evaluator can provide a more detailed observation, judgment, and insights on the outcomes of the actions implemented.

One of the above approaches can be used alone or in combination with one another, whichever is deemed more appropriate or informative for the GIAHS region.
Evaluation norms

Since GIAHS is a United Nations programme under the $\mathrm{FAO}$, evaluators should also take into account and adhere to the General Norms for Evaluation set out by the United Nations Evaluation Group (UNEG, 2016), which aims to ensure that United Nations evaluation functions provide credible and useful evidence to inform and strengthen the work of the United Nations system in pursuit of its goals. These General Norms include (1) internationally agreed principles, goals and targets; (2) utility; (3) credibility; (4) independence; (5) impartiality; (6)ethics; (7) transparency; (8) human rights and gender equality; (9) national evaluation capacities; and (10) professionalism.

\footnotetext{
6 Adapted from the OECD/DAC evaluation criteria (OECD, 2019) for application of GIAHS M\&E
} 


\begin{tabular}{|c|c|c|c|c|c|c|c|c|c|c|}
\hline \multicolumn{9}{|c|}{ MONITORING RESULTS } & \multicolumn{2}{|c|}{ EVALUATION RESULTS } \\
\hline Criteria & Sub-criteria & Indicator & $\begin{array}{c}\text { Means of } \\
\text { Verification }\end{array}$ & Baseline & $\begin{array}{c}\text { Target } \\
\text { (for outcome) }\end{array}$ & $\begin{array}{c}\text { Input } \\
\text { (Action in the } \\
\text { Action Plan) }\end{array}$ & Output & Outcome & $\begin{array}{c}\text { Grade } \\
\text { (e.g., A to D) } \\
\text { or } \\
\text { Score } \\
\text { (e.g., } 0 \text { to 10) }\end{array}$ & $\begin{array}{c}\text { Normative assessment } \\
\text { / notes }\end{array}$ \\
\hline $\begin{array}{l}\text { C1. Food and } \\
\text { livelihood security }\end{array}$ & $\begin{array}{l}\text { SC2.Agricultural } \\
\text { Income }\end{array}$ & $\begin{array}{l}\text { B6. Production } \\
\text { quantity (QS) }\end{array}$ & $\begin{array}{l}\text { Existing agricultural } \\
\text { statistics and// } \\
\text { or collecting } \\
\text { data from key } \\
\text { cooperatives and } \\
\text { producers }\end{array}$ & $\begin{array}{l}20 \text { tonnes of } \\
\text { grain, } 10 \text { tonnes } \\
\text { of vegetables, } 2 \\
\text { tonnes of livestock }\end{array}$ & $\begin{array}{l}\text { Maintain } \\
\text { production to at } \\
\text { least } 20 \text { tonnes of } \\
\text { grain, } 10 \text { tonnes } \\
\text { of vegetables, } 2 \\
\text { tonnes of livestock }\end{array}$ & $\begin{array}{l}\text { Maintain or increase } \\
\text { the production } \\
\text { quantity within } \\
\text { the GIAHS but } \\
\text { providing technical } \\
\text { assistance }\end{array}$ & $\begin{array}{l}\text { (QS) } 20 \text { tonnes of } \\
\text { grain, } 12 \text { tonnes of } \\
\text { vegetables, } 1.5 \text { tonnes of } \\
\text { livestock produced }\end{array}$ & $\begin{array}{l}\text { Production quantity } \\
\text { has been maintained } \\
\text { overall; no change in } \\
\text { grain, with an } 20 \% \\
\text { increase in vegetables, } \\
\text { but } 25 \% \text { reduction in } \\
\text { livestock production }\end{array}$ & $\begin{array}{l}\text { A } \\
\text { or } \\
9\end{array}$ & $\begin{array}{l}\text { Total production } \\
\text { quantity has increased; } \\
\text { Grain production was } \\
\text { maintained, Vegetables } \\
\text { (especially traditional } \\
\text { ones) increased, while } \\
\text { livestock has decreased } \\
\text { due to reducing } \\
\text { dependencies on } \\
\text { external feeds. }\end{array}$ \\
\hline $\begin{array}{l}\text { C2. Agro- } \\
\text { biodiversity }\end{array}$ & $\begin{array}{l}\text { SC4. Agro- } \\
\text { biodiversity }\end{array}$ & $\begin{array}{l}\text { A9. Genetic } \\
\text { diversity (QL) }\end{array}$ & $\begin{array}{l}\text { Survey of genetic } \\
\text { resources that } \\
\text { are produced } \\
\text { and harvested, } \\
\text { or kept by local } \\
\text { farmers, or request } \\
\text { information from } \\
\text { local seedbanks } \\
\text { or research } \\
\text { institutions }\end{array}$ & Nil & $\begin{array}{l}\text { Listing of } \\
\text { traditional and } \\
\text { indigenous } \\
\text { vegetables } \\
\text { produced for } \\
\text { sale or self } \\
\text { consumption }\end{array}$ & $\begin{array}{l}\text { Construct an } \\
\text { inventory list } \\
\text { of traditional } \\
\text { and indigenous } \\
\text { vegetables }\end{array}$ & $\begin{array}{l}\text { Survey of } 450 \\
\text { households have } \\
\text { identified } 18 \text { traditional } \\
\text { variety of crops, in } \\
\text { addition to the } 7 \\
\text { varieties kept as seeds } \\
\text { by local agricultural } \\
\text { department. }\end{array}$ & $\begin{array}{l}\text { A preliminary list } \\
\text { of traditional and } \\
\text { indigenous vegetables } \\
\text { have been identified } \\
\text { and recorded. }\end{array}$ & $\begin{array}{l}\text { B } \\
\text { or } \\
7\end{array}$ & $\begin{array}{l}\text { Data from only } 1 \text { out } \\
\text { of } 4 \text { municipalities in } \\
\text { the GIAHS region have } \\
\text { been obtained, but this } \\
\text { pilot effort can serve } \\
\text { as a demonstration to } \\
\text { other municipalities on } \\
\text { how to conduct data } \\
\text { collection to create the } \\
\text { list. }\end{array}$ \\
\hline $\begin{array}{l}\text { C3. Local and } \\
\text { traditional } \\
\text { knowledge systems }\end{array}$ & $\begin{array}{l}\text { SC8. Transfer of } \\
\text { traditional wisdom } \\
\text { and farming } \\
\text { techniques }\end{array}$ & $\begin{array}{l}\text { B15. Knowledge } \\
\text { recording and } \\
\text { documentation } \\
\text { (QL)/(QR) }\end{array}$ & $\begin{array}{l}\text { Written and } \\
\text { multi-media } \\
\text { materials, including } \\
\text { government } \\
\text { archives, library } \\
\text { collections, } \\
\text { storybooks, } \\
\text { research outputs, } \\
\text { and films }\end{array}$ & $\begin{array}{l}\text { Archival records in } \\
\text { the local museum } \\
\text { and national } \\
\text { government } \\
\text { database exist, } \\
\text { but there are no } \\
\text { teaching and } \\
\text { learning materials } \\
\text { for young children }\end{array}$ & $\begin{array}{l}\text { Content testing } \\
\text { indicate potential } \\
\text { to support } \\
\text { knowledge and } \\
\text { awareness increase } \\
\text { among the target } \\
\text { population. }\end{array}$ & $\begin{array}{l}\text { Promote } \\
\text { documentation } \\
\text { of LTK through } \\
\text { supporting projects } \\
\text { to develop } 5 \\
\text { storybooks, } \\
5 \text { posters, } 3 \\
\text { animated and/or } \\
\text { live action films, } \\
2 \text { public service } \\
\text { announcements } \\
\text { (PSAs) for education } \\
\text { of pre-primary and } \\
\text { primary school } \\
\text { children, to be } \\
\text { made accessible for } \\
\text { schools and public } \\
\text { libraries }\end{array}$ & $\begin{array}{l}\text { (QL) } 5 \text { posters and } \\
\text { corresponding } \\
5 \text { storybooks } \\
\text { documenting farming } \\
\text { practices, unique } \\
\text { features of the local } \\
\text { landscape, and local } \\
\text { produce and foods were } \\
\text { produced. The films } \\
\text { and PSAs are pending } \\
\text { production. } \\
\text { (QS) } 10 \text { educational } \\
\text { materials (5 posters, } 5 \\
\text { storybooks) produced }\end{array}$ & $\begin{array}{l}\text { Testing of the print } \\
\text { materials content } \\
\text { indicates potential to } \\
\text { support knowledge and } \\
\text { awareness increase of } \\
\text { LTK. Exposure to the } \\
\text { films and PSAs through } \\
\text { television is promising. } \\
\end{array}$ & $\begin{array}{l}\text { A (but noting the time } \\
\text { delay) } \\
\text { or } \\
8 \text { (due to time delay) }\end{array}$ & $\begin{array}{l}\text { Distribution strategy, } \\
\text { currently under } \\
\text { development, is key to } \\
\text { effective messaging. } \\
\text { The success of these } \\
\text { educational materials } \\
\text { should be shared } \\
\text { with other GIAHS for } \\
\text { knowledge exchange } \\
\text { and possible adaptation } \\
\text { by other GIAHS. }\end{array}$ \\
\hline $\begin{array}{l}\text { C4. Cultures, value } \\
\text { systems, and social } \\
\text { organizations }\end{array}$ & $\begin{array}{l}\text { SC12. Social } \\
\text { organizations }\end{array}$ & $\begin{array}{l}\text { A20. Participation } \\
\text { of women, youths, } \\
\text { indigenous } \\
\text { peoples, and other } \\
\text { vulnerable groups } \\
\text { (QL)/(QR) }\end{array}$ & $\begin{array}{l}\text { Existing agricultural } \\
\text { statistics and/ } \\
\text { or data from } \\
\text { cooperatives and } \\
\text { producers }\end{array}$ & $\begin{array}{l}\text { Participation of } \\
\text { women ages } \\
15 \text { and above } \\
\text { in agricultural } \\
\text { activities is } 52.4 \% \\
\text { as of 2019, but } \\
\text { their representation } \\
\text { in leadership } \\
\text { positions of social } \\
\text { organizations is } \\
\text { less than 20\%. }\end{array}$ & $\begin{array}{l}\text { Increase women's } \\
\text { representation } \\
\text { in leadership } \\
\text { positions of } \\
\text { cooperatives and } \\
\text { social organizations } \\
\text { to } 30 \% \text { in the by } \\
\text { the end of the } \\
\text { current Action } \\
\text { Plan. }\end{array}$ & $\begin{array}{l}\text { Maintain or } \\
\text { increase women's } \\
\text { participation in } \\
\text { agricultural activities } \\
\text { by promoting } \\
\text { recruitment of } \\
\text { female leadership } \\
\text { in cooperatives and } \\
\text { social organizations. } \\
\end{array}$ & $\begin{array}{l}\text { (QS) Women's } \\
\text { representation in } \\
\text { leadership positions in } \\
\text { cooperatives and social } \\
\text { organizations: } 21 \% \text {. } \\
\text { (QR) Efforts to raise } \\
\text { awareness and } \\
\text { facilitate promotion } \\
\text { of female leadership } \\
\text { and creation of a social } \\
\text { organization for women } \\
\text { are underway through } \\
\text { town hall meetings, } \\
\text { workshops, and group } \\
\text { communication. }\end{array}$ & $\begin{array}{l}\text { Women's representation } \\
\text { in leadership positions } \\
\text { of cooperatives and } \\
\text { social organizations has } \\
\text { increased from } 17 \% \text { to } \\
21 \% \text {. Women's support } \\
\text { group has yet to be } \\
\text { formed. }\end{array}$ & $\begin{array}{l}\text { A } \\
\text { or } \\
9\end{array}$ & $\begin{array}{l}\text { Women's representation } \\
\text { in leadership positions } \\
\text { now exceeds } 20 \% \text {. } \\
30 \% \text { may be difficult } \\
\text { to achieve by the end } \\
\text { of the Action Plan, but } \\
\text { is a reasonable aim to } \\
\text { target. }\end{array}$ \\
\hline
\end{tabular}




\begin{tabular}{|c|c|c|c|c|c|c|c|c|c|c|}
\hline \multicolumn{9}{|c|}{ MONITORING RESULTS } & \multicolumn{2}{|c|}{ EVALUATION RESULTS } \\
\hline Criteria & Sub-criteria & Indicator & $\begin{array}{l}\text { Means of } \\
\text { Verification }\end{array}$ & Baseline & $\begin{array}{c}\text { Target } \\
\text { (for outcome) }\end{array}$ & $\begin{array}{c}\text { Input } \\
\text { (Action in the } \\
\text { Action Plan) }\end{array}$ & Output & Outcome & $\begin{array}{c}\text { Grade } \\
\text { (e.g., A to D) } \\
\text { or } \\
\text { Score } \\
\text { (e.g., } 0 \text { to 10) }\end{array}$ & $\begin{array}{l}\text { Normative assessment } \\
\text { / notes }\end{array}$ \\
\hline $\begin{array}{l}\text { C5. Landscapes } \\
\text { and seascapes } \\
\text { features }\end{array}$ & SC14. Maintenance & $\begin{array}{l}\text { B25. Un-managed/ } \\
\text { poorly maintained } \\
\text { area and related } \\
\text { challenges (QS)/ } \\
\text { (QR) }\end{array}$ & $\begin{array}{l}\text { Existing agricultural } \\
\text { statistics and/or } \\
\text { initiating reporting } \\
\text { systems for data } \\
\text { collection }\end{array}$ & $\begin{array}{l}80 h a \text { of } \\
\text { unmanaged areas }\end{array}$ & $\begin{array}{l}\text { (QS): Manage at } \\
\text { least } 50 \% \text {, i.e. } 40 \text { ha } \\
\text { or } \\
\text { (QR): Make efforts } \\
\text { to manage these } \\
\text { areas }\end{array}$ & $\begin{array}{l}\text { Reviving abandoned } \\
\text { farmlands by } \\
\text { matching with new } \\
\text { entry farmers }\end{array}$ & $\begin{array}{l}\text { (QS): } 32 \text { ha or } 40 \% \\
\text { of abandoned land } \\
\text { managed now } \\
\text { or } \\
\text { (QR): } 8 \text { new entry } \\
\text { farmers are allowed } \\
\text { to use abandoned } \\
\text { farmlands for free for } 5 \\
\text { years. A total of } 32 \text { ha } \\
\text { unmanaged farmland } \\
\text { are now being utilized. }\end{array}$ & $\begin{array}{l}\text { Area of abandoned } \\
\text { farmlands have been } \\
\text { reduced, and attracted } \\
\text { new entry farmers. }\end{array}$ & $\begin{array}{l}\text { B } \\
\text { or } \\
8\end{array}$ & $\begin{array}{l}\text { While it did not reach } \\
\text { expected target } \\
\text { outcome, this is an } \\
\text { effective initiative to } \\
\text { reduce abandoned } \\
\text { farmlands and also } \\
\text { encourage new entry } \\
\text { farmers. }\end{array}$ \\
\hline C6. Governance & $\begin{array}{l}\text { SC15. } \\
\text { Management and } \\
\text { monitoring }\end{array}$ & $\begin{array}{l}\text { A24. Database } \\
\text { for GIAHS-related } \\
\text { information } \\
\text { gathering and } \\
\text { maintenance (QR) }\end{array}$ & $\begin{array}{l}\text { Report from M\&E } \\
\text { working groups or } \\
\text { entities assigned to } \\
\text { conduct M\&E }\end{array}$ & Nil & $\begin{array}{l}\text { Database(s), } \\
\text { roles, rules and } \\
\text { regulations } \\
\text { regarding its } \\
\text { maintenance } \\
\text { established }\end{array}$ & $\begin{array}{l}\text { Construct } \\
\text { database(s) for } \\
\text { the collection and } \\
\text { recording of M\&E } \\
\text { information and } \\
\text { data }\end{array}$ & $\begin{array}{l}\text { A preliminary database } \\
\text { maintained by the } \\
\text { GIAHS Promotion office } \\
\text { created }\end{array}$ & $\begin{array}{l}\text { A database for or the } \\
\text { collection and recording } \\
\text { of M\&E information and } \\
\text { data is created }\end{array}$ & $\begin{array}{l}\text { C } \\
\text { or } \\
6\end{array}$ & $\begin{array}{l}\text { Although a preliminary } \\
\text { database is created, } \\
\text { the data, its sources, } \\
\text { responsibilities } \\
\text { regarding reporting and } \\
\text { management, and ways } \\
\text { to utilize the database } \\
\text { have not been fully } \\
\text { agreed amongst the } \\
\text { stakeholders. }\end{array}$ \\
\hline $\begin{array}{l}\text { C7. Capacity } \\
\text { development and } \\
\text { research }\end{array}$ & $\begin{array}{l}\text { SC17. Training on } \\
\text { agricultural skills } \\
\text { and technology }\end{array}$ & $\begin{array}{l}\text { B32. People who } \\
\text { received training } \\
\text { in agricultural skills } \\
\text { and technology } \\
\text { (QS)/(QR) }\end{array}$ & $\begin{array}{l}\text { Registration } \\
\text { and attendance } \\
\text { information } \\
\text { from training } \\
\text { programme } \\
\text { working groups, } \\
\text { such as NGOs and } \\
\text { universities }\end{array}$ & $\begin{array}{l}0 \text { people ( } 52 \% \\
\text { male, } 48 \% \text { female) }\end{array}$ & 90 people & $\begin{array}{l}\text { Increase enrolment } \\
\text { in training } \\
\text { programs, and } \\
\text { promote services }\end{array}$ & $\begin{array}{l}\text { (QS) } 69 \text { people }(60 \% \\
\text { female, } 40 \% \text { male) have } \\
\text { enrolled and completed } \\
\text { all trainings. } \\
\text { (QR) Enrolment is lower } \\
\text { than anticipated due } \\
\text { to closure of two of the } \\
\text { existing seven courses. }\end{array}$ & $\begin{array}{l}\text { Enrolment in training } \\
\text { programs have } \\
\text { increased and all new } \\
\text { enrolees have obtained } \\
\text { training certification. }\end{array}$ & $\begin{array}{l}\text { B } \\
\text { or } \\
7\end{array}$ & $\begin{array}{l}\text { Although enrolment } \\
\text { has increased, the } \\
\text { target of } 90 \text { has yet to } \\
\text { be reached. Closure } \\
\text { of classes were } \\
\text { unexpected; recruitment } \\
\text { of quality instructors } \\
\text { is critical for ensuring } \\
\text { stability of courses. }\end{array}$ \\
\hline $\begin{array}{l}\text { C8. Partnerships } \\
\text { and outreach }\end{array}$ & $\begin{array}{l}\text { SC21. Exchange } \\
\text { and cooperation }\end{array}$ & $\begin{array}{l}\text { B39. Partnerships } \\
\text { within and/or } \\
\text { among GIAHS sites } \\
\text { and with different } \\
\text { sectors (QL)/(QR) }\end{array}$ & $\begin{array}{l}\text { Reports on } \\
\text { partnership } \\
\text { activities supported } \\
\text { by the GIAHS } \\
\text { Promotion Office }\end{array}$ & $\begin{array}{l}\text { Nil (There has not } \\
\text { been a formal } \\
\text { partnership with } \\
\text { other GIAHS } \\
\text { regions.) }\end{array}$ & $\begin{array}{l}\text { Hold at least } 3 \\
\text { M\&E experience } \\
\text { sharing workshops } \\
\text { with other GIAHS: } \\
1 \text { for M\&E } \\
\text { planning, } 1 \text { for } \\
\text { mid-term check-in } \\
\text { on progress, and } \\
1 \text { for reflection on } \\
\text { learnings }\end{array}$ & $\begin{array}{l}\text { Expand } \\
\text { coordination with } \\
\text { other GIAHS } \\
\text { regions in M\&E } \\
\text { by sharing data } \\
\text { collection tools and } \\
\text { key findings through } \\
\text { organizing the } \\
\text { experience sharing } \\
\text { workshops }\end{array}$ & $\begin{array}{l}\text { (QL) } 3 \text { M\&E workshops } \\
\text { held with [name] } \\
\text { GIAHS on [date] and } \\
\text { participated by [number] } \\
\text { participants } \\
\text { (QR) M\&E workshops } \\
\text { enabled coordination } \\
\text { and streamlining } \\
\text { of designing, tools } \\
\text { development, and } \\
\text { processes. Another } \\
\text { value-add of the shared } \\
\text { effort is the sense of } \\
\text { community and network } \\
\text { of practitioners that } \\
\text { enable free-flowing } \\
\text { sharing of ideas, } \\
\text { challenges, and possible } \\
\text { solutions. }\end{array}$ & $\begin{array}{l}3 \text { M\&E workshops were } \\
\text { conducted with [name] } \\
\text { GIAHS with great } \\
\text { success. Co-planning } \\
\text { the M\&E process } \\
\text { and co-development } \\
\text { of data collection } \\
\text { tools and reporting } \\
\text { templates enabled } \\
\text { streamilining processes } \\
\text { and information sharing. } \\
\text { During the reflection } \\
\text { meeting, the two GIAHS } \\
\text { regions identified } \\
\text { clear action points for } \\
\text { improvement for the } \\
\text { next M\&E cycle. }\end{array}$ & $\begin{array}{l}\text { A } \\
\text { or } \\
10\end{array}$ & $\begin{array}{l}\text { The output targets and } \\
\text { the objectives of those } \\
\text { targets have been met. } \\
\text { workshops were made } \\
\text { possible due to support } \\
\text { from municipal offices in } \\
\text { GIAHS and mobilization } \\
\text { of various stakeholders } \\
\text { to participate. }\end{array}$ \\
\hline
\end{tabular}


STRATEGIC AND MEANINGFUL USE OF M\&E DATA AND RESULTS

M\&E data and results can be put to strategic and meaningful use to contribute to the GIAHS conservation efforts. Some suggested ways could include the following:

Revision of Action Plan

The main purpose of the evaluation is to measure the performance and effectiveness of the actions set out in the GIAHS Action Plan, and check whether these actions are on track to achieve their expected outcomes and bring about the impacts envisioned under the ToC. Therefore, the evaluation results should be the core guidance for the revision of the next GIAHS Action Plan. The evaluation results should also be disclosed and made available to the public by reporting on the websites of the GIAHS or the respective government and agency. Making the results open to the public and keeping them informed of action outcomes will sustain their interests, commitment, and sense of ownership, and ensure transparency and accountability Office and the stakeholders involved.

It is important not to take unexpected and negative results of the evaluation as a deterrent to avoid including those challenging issues or indicators that seemed relatively difficult to achieve into the KPIs. GIAHS decision-makers should not be discouraged when results are not meeting expectations but take the results and recommendations positively as opportunities to revise and improve the Action Plan.

Management response

Management response is a formal mechanism to ensure that evaluation findings, conclusions, lessons learned, and recommendations will be used (UNDP, 2021). The GIAHS governing body should develop a management response for each recommendation or advice received from the evaluation results to ensure the effective use of evaluation findings. Essentially, it will entail followup actions, including identification of the agency, unit and stakeholders group that are responsible for each key milestone and the timeline. The management response should be executed immediately following the evaluation, so the decisions therein inform the next Action Plan.

Generating opportunities

Through the disclosure and enabling open access to the M\&E results, businesses and local groups interested in GIAHS conservation can find opportunities for participation. The results will also inform academic and research institutions of potential areas for research. In turn, their findings can feed into the M\&E process and GIAHS conservation. The M\&E results can also be evidence for certification schemes of GIAHS products, keeping consumers informed of both the challenges and positive changes in GIAHS, thereby motivating consumers for their continued support.

Exchange of experience

The M\&E process is highly contextual as the characteristics and social structure of each GIAHS differs, even amongst GIAHS regions located in the same country. An easily achievable indicator and data readily available in one GIAHS region may not necessarily be the same for another. The exchange of experience and knowledge around the M\&E process amongst GIAHS regions is essential and useful to improve learning and facilitate more effective implementation of M\&E. Therefore, GIAHS regions are encouraged to exchange knowledge on M\&E amongst themselves. National governments can also consider providing GIAHS regions with opportunities for capacity development or networking on M\&E-related topics. These experiences and learnings should also be then reported to FAO GIAHS Secretariat for their knowledge for wider dissemination.

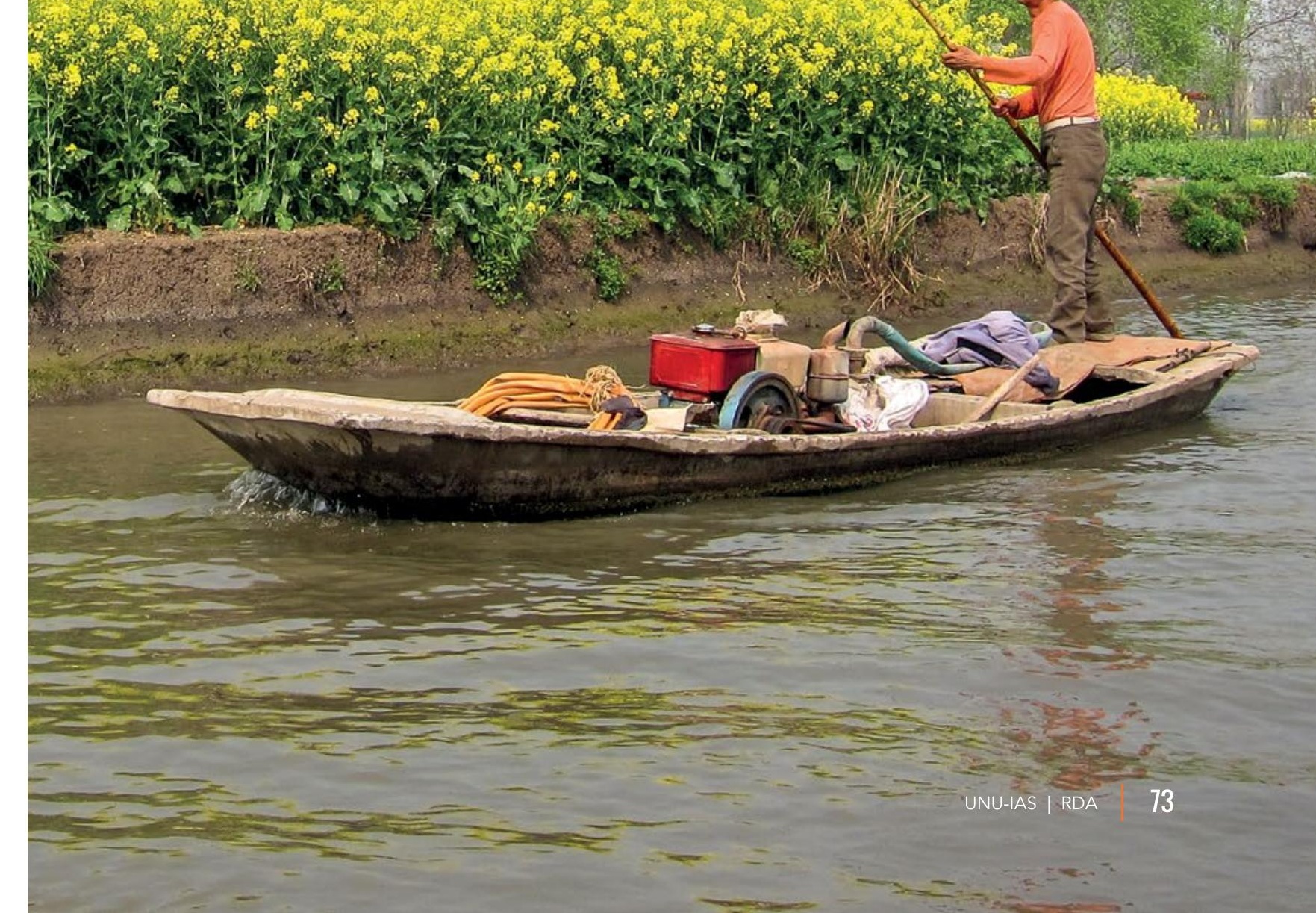




\section{WAY FORWARD}

While the Manual tries to balance comprehensiveness and practicality in articulating what an M\&E process for GIAHS can entail, we do not expect the GIAHS regions to implement every element suggested. We encourage GIAHS regions to use the Manual as a technical reference and not necessarily in its entirety, but select relevant aspects that strengthen their Action Plan and its M\&E process. This Manual aims to provide the necessary information for GIAHS regions to design and implement an effective M\&E process that helps them better understand their needs and build on their existing capacity to further improve the region.

However, GIAHS regions need not hastily conduct nor set high expectations for running an M\&E process. An M\&E process and its elements delineated by this Manual - including the criteria, sub-criteria, and indicators - can be added or removed, customized or improvised for contextualization, as deemed appropriate or necessary. M\&E is also not meant to take up more resources and effort, but quite the opposite; an effective M\&E can increase efficiency and cost-effectiveness by helping to streamline processes, avoid duplication of efforts, consolidate scattered activities, and mobilize the participation of a wide range of stakeholders. Participatory M\&E will help lighten the cost of managing GIAHS and the workload of GIAHS managers. It can also be leveraged as a tool and an opportunity to involve and engage the local stakeholders and the wider public to instill interest in GIAHS While the most opportune position for this positive mindset to be cultivated is likely the primary audience of this Manual — that is, the GIAHS managers and leaders of the important to recognize that $\mathrm{M} \& \mathrm{E}$ for enhancing the GIAHS conservation should be a collective commitment and effort of all actors.

As M\&E processes advance with practice, it is within a reachable future that a national government standardizes the M\&E process for all of its GIAHS. The learnings and experiences from a national M\&E process can then be shared with the global GIAHS community, FAO, and other regions aspiring to become GIAHS to deepen the knowledge and practice of GIAHS conservation activities. The research community can also benefit from M\&E efforts by building on existing research or exploring new areas to help enhance GIAHS conservation activities and policies, such as identifying typical trade-offs of KPI for synergies across $\mathrm{KPIs}$ and determining the contributions of GIAHS to achieving the SDGs, etc.

The dynamic conservation of GIAHS will require GIAHS managers and stakeholders at various levels to support GIAHS. This may require revisiting existing approaches and taking the initiative to break away from business-as-usual ways of management to bring about transformative changes to the GIAHS communities. The M\&E can serve as a catalyst to bridge one community with another and pave the way towards sustainable futures. We look forward to this Manual helping GIAHS regions in contributing to that vision of a shared future.

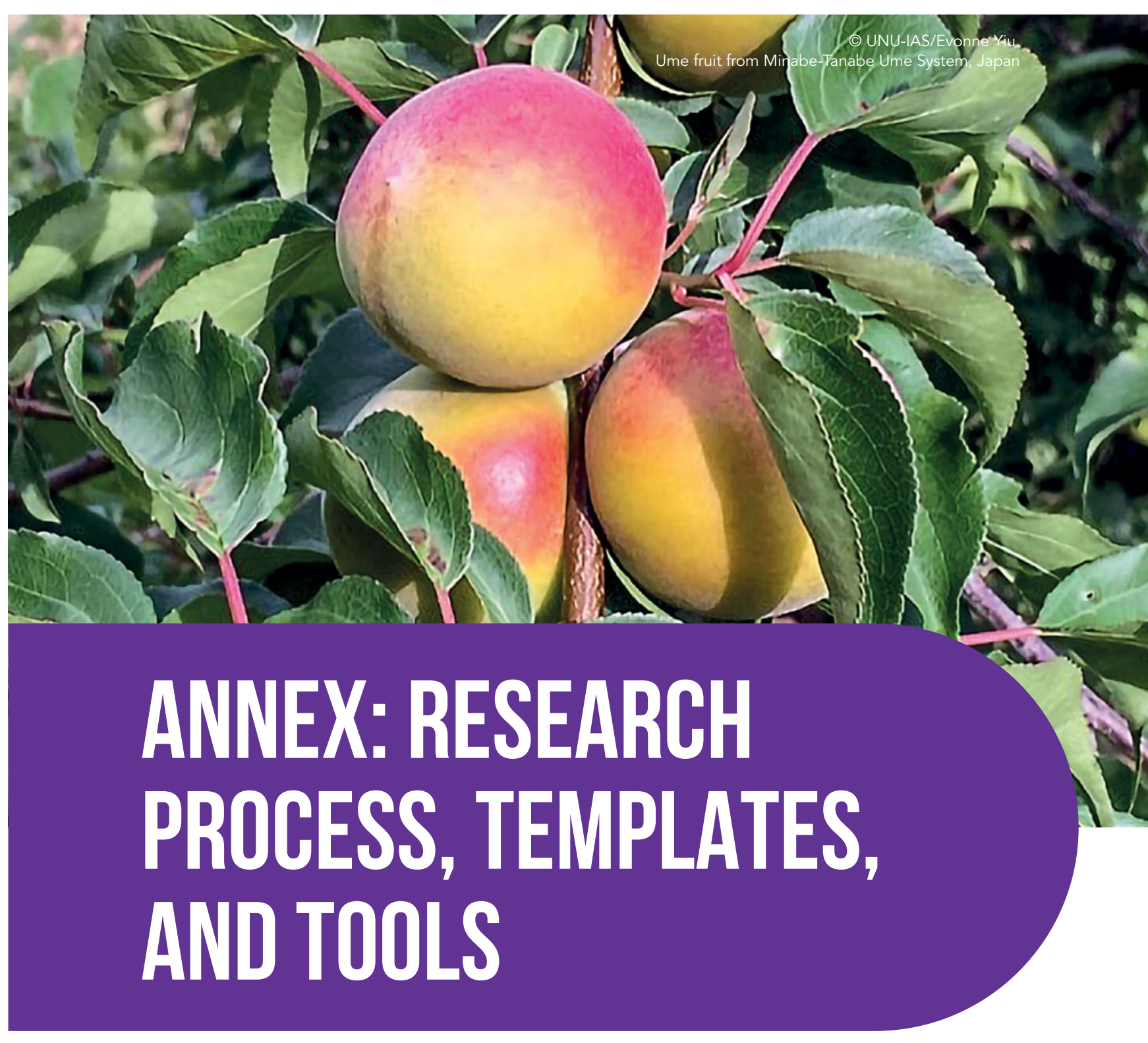




\section{ANNEX 1: RESEARCH PROCESS}

Development of criteria

sub-criteria, and indicators

A preliminary set of criteria, sub-criteria, and indicators developed through a review of literature, GIAHS proposals and Action Plans, as well as interviews and workshop discussions conducted from 2018 to 2021, including:

- Reyes, Sheryl R.C., et al. (2020). Enhancing Sustainability in Traditional Agriculture: Indicators for Monitoring the Conservation of Globally Important Agricultural Heritage Systems (GIAHS) in Japan. Sustainability 12, no. 14: 5656

- RDA. (2021). Guidebook on Communitybased Participatory Monitoring and Activities for Sustainable GIAHS Conservation.

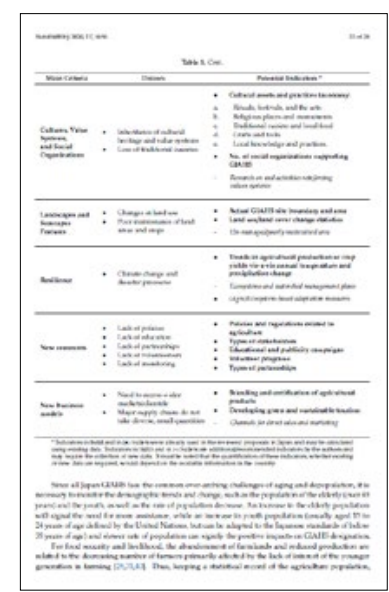

Reyes et al. (2020)

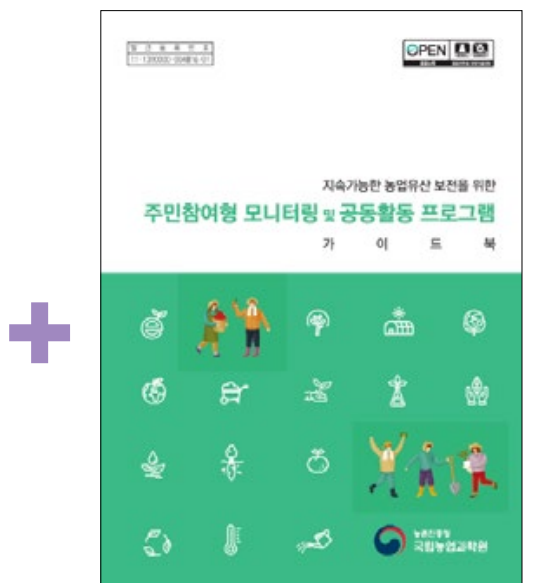

RDA (2021)
Verification of the feasibility of GIAHS monitoring indicators

A GIAHS monitoring indicators feasibility survey and two consultation workshops ${ }^{7}$ were conducted between September and October 2021 with GIAHS managers and researchers in Japan and Korea to assess the relevance and feasibility of the preliminary set of indicators. Subsequently, the preliminary set of indicators and the process of developing and validating them were presented for open feedback at the Symposium on Conserving and Strengthening the Value of Agricultural Heritage Systems in the New Normal Era in November 2021. ${ }^{8}$

The preliminary set consisted of 9 criteria, 34 sub-criteria, and 84 indicators.
Overall, respondents from both countries overlapped much in the indicators they identified to be 'too advanced'-i.e., perceived feasibility of below $50 \%$ — particularly around measuring changes in agro-biodiversity (part of Criteria 2), transfer of traditional technical knowledge (Criteria 3), economic support through policy (part of Criteria 6), adaptation measures against environmental crises (part of the original Criteria 8), and community-level initiatives (part of Criteria 9). During discussions that unfolded at the two aforementioned workshops and the symposium, the participants provided the reasoning behind their responses. They consisted of conceptual matters (e.g., understanding of the economic and social value of GIAHS), people-related matters (e.g., sensitivity among residents who must provide productivity and income detais), operational matters (e.g. lack of budget allocations and human resources capacity), technical matters (e.g., ability to disaggregate data or extract data applicable only to GIAHS or selected products, variations in standards (or lack thereof), and yet-to-be verified impact of natural disasters and climate change.
The validation process also confirmed that, although the awareness of SDGs deemed much higher and related activities more vibrant among Japan GIAHS, participants from both countries agreed that SDGs provide a viable platform for raising public awareness of GIAHS and its value to society.

Following the abovementioned processes and further consideration of the literature, the research team arrived at eight criteria, 22 sub-criteria, and 73 indicators (41 basic and 32 advanced). The basic indicators are derived from the preliminary set of indicators that had a perceived feasibility among an average of 50 percent and more respondents from Japan and Korea. The advanced indicators consist of those with an average response below 50 percent, but are retained for their importance and modified to increase feasibility and practicality of data collection. One of the original optional criteria was environmental resilience, whose indicators were then merged with Criteria 2. Agro-biodiversity.

The final list of criteria, sub-criteria, and indicators of this Manual reflect results of the external review process, which helped further refine them for practicality and feasibility.

\footnotetext{
For more details on the workshops, please see $h$ ttps://ouik.unu.edu/en/news/5024.
For more details on the symposium, please see $h$ ttps://ouik.unu.edu/en/events/5195.
} 
Design an M\&E process

\section{Action}

(1) Convene a dedicated M\&E team consisting of at least: 1. chairperson, 2 M\&E specialist, and 3. key stakeholder of the region aware of GIAHS regulations and its implications.

\section{(2) Define the scope of M\&E} process in consideration of the GIAHS' physical and demographic

characteristics, as well as its operational parameters and guidelines.

\section{Sub-actions}

$\square$ Extend the team with a resident expert on a particular topic or a working group for thematic actions, as needed.

b. $\square$ Establish a demographic balance across gender, age, race, ethnicity, and industry to ensure representation of the GIAHS population.

\section{Consider physical and demographic characteristics:}

a. $\square$ Geographic size

b. $\square$ Types of agricultural production

c. $\square$ Agro-biodiversity

d. $\square$ History and traditional culture

e. $\square$ Landscapes and seascapes features

f. $\square$ Demographics of population

g. $\square$ Core industries

Factor in operational parameters and guidelines:

h. $\square$ Theory of change (ToC)

$$
\text { (see Figure 1-2 or Template 2) }
$$

i. $\square$ Desired outputs and outcomes stipulated in the Action Plan

j. $\square$ Availability of and accessibility to existing information

k. $\square$ Efforts required to build relationships

I. $\square$ Realistic, clear expectations

m. $\square$ Level of coordination across GIAHS regions
(3) Decide M\&E elements to select KPIs, set targets and goals, and determine baselines and means of

verification.

(see Template 3)

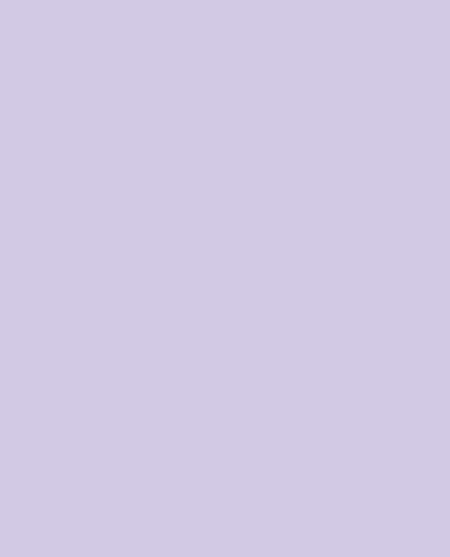

(4) Build a MIS or an agreedupon mechanism and process for centrally gathering and storing the information to maintain and build institutional knowledge.

\section{(5) Determine a full M\&E}

cycle, from data collectio to revision of new Action Plan.

\section{(6) Secure enabling factors} without which M\&E cannot be effectively implemented and its data meaningfully used. a. $\square$ Select KPIs: Select a combination of basic and advanced indicators that are important and relevant to the GIAHS, in linkage with other strategic visions, such as national agricultural policies, prefectural or provincial plans, and municipality goals.

b. $\square$ Set targets: Set targets for every action so that outcomes can be derived when outputs are matched against these pre-set targets.

c. $\square$ Set goals: Set short-term, mid-term, and longterm goals.

d. $\square$ Determine baselines: Set the baseline references to measure change.

e. $\square$ Determine means of verification: Identify sources of information or methods of data collection via which the desired information will be generated.

a. $\square$ Describe your MIS. For instance, is it a simple system with spreadsheets or a sophisticated database with interfaces for data entry, analysis, and extraction?

a. $\square$ Define the duration of the full M\&E cycle For instance, annual, biennial or triennial, etc. It is recommended that monitoring occurs annually in order for the data to be meaningful.

a. $\square$ The institutional structure that consists of a GIAHS Promotion Office, relevant government agencies, working groups, producers, local residents and other stakeholders as relevant is established, and their roles and responsibilities are clearly specified.

b. $\square$ A dedicated funding for $\mathbf{M} \& \mathbf{E}$ is secured.

c. $\square$ The necessary personnel are recruited, hired, and trained. 
Step

\section{Description}

(1) Start of M\&E process

The M\&E team contacts all GIAHS managers in municipalities of the GIAHS region and al stakeholders to commence. It leads the process of coordinating with stakeholders and manage the operationalization and technical details throughout implementation.

(2) Monitoring data collection and synthesis of results

The M\&E team may collect data directly in the field, through data requests to respective institutions, or outsource the effort to an external vendor.

\section{(3) Self-assessment report}

The M\&E team and the GIAHS Promotion Office review the monitoring results to assess the

progress of its conservation efforts against the Action Plan and compiles into a self-assessment report to be submitted for evaluation.

\section{(4) Evaluation of monitoring} results by a third party (see Table 6-2 or Template 3)

The GIAHS Promotion Office convenes a thirdparty expert panel for an unbiased review and technical advice on areas of improvement and ways to update the Action Plan.

\section{(5) Feedback and reflections}

The M\&E team set up dialogue opportunities with stakeholders and local residents to relay the evaluation results and reflect on them to identify concrete areas of improvement.

$\square \quad$ (6) Future scenarios planning for new Action Plan (see Table 6-1 or Template 4)

(7) Revision of new Action Plan

The GIAHS Promotion Office, with support from the M\&E team, plans the new Action Plan with stakeholders and residents.

The GIAHS Promotion Office makes decisions on the next strategic steps based on the monitoring findings, evaluation results, and feedback from stakeholders, and revises the Action Plan.

$\square \quad$ (8) Completion of M\&E and start of new Action Plan
The full cycle repeats regularly to continue to improve GIAHS.

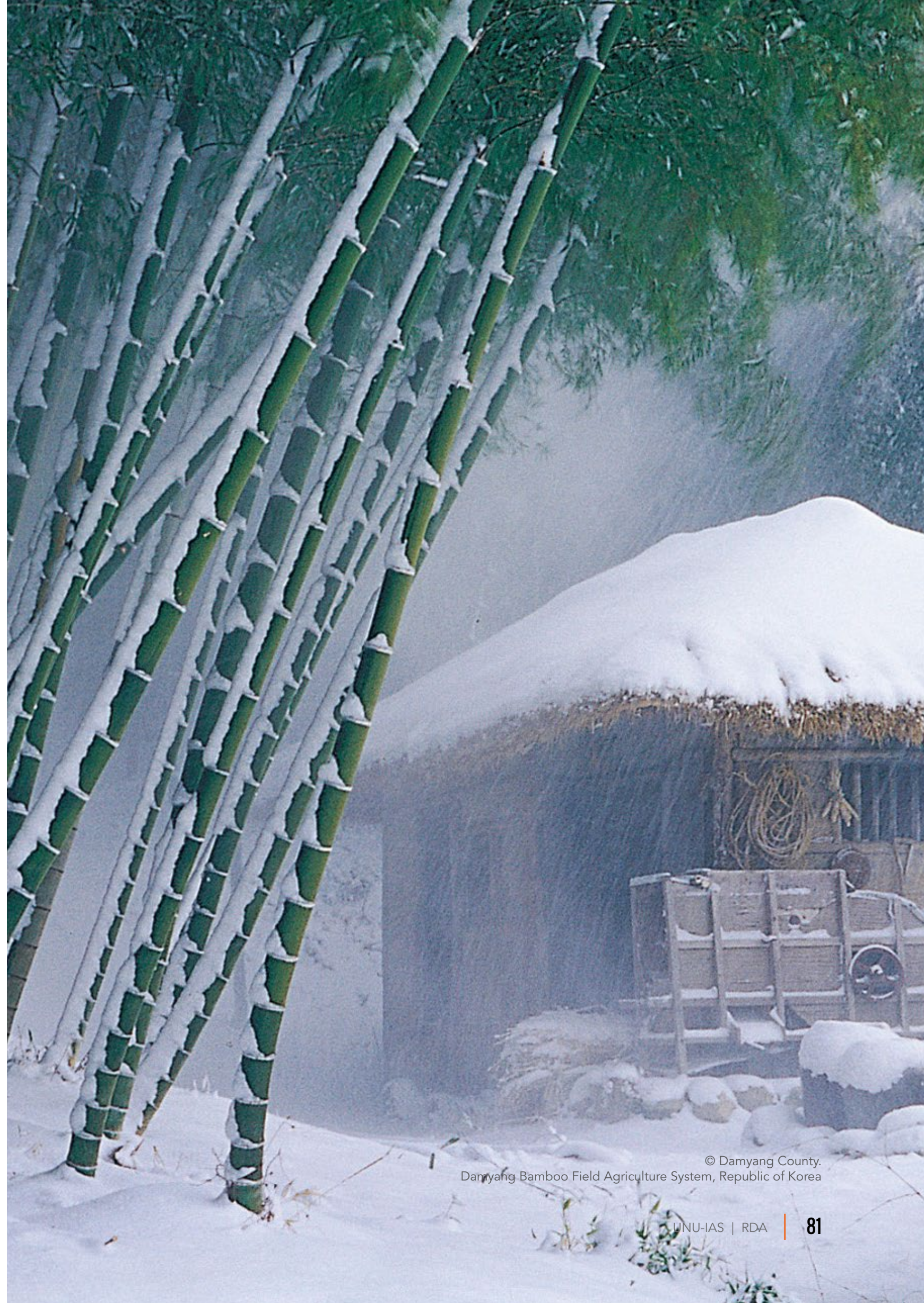


Template 2. | Theory of change template

RATIONALE/NEED FOR GIAHS

ASSUMPTIONS

INPUTS

(ACTIONS OF GIAHS ACTION PLAN)

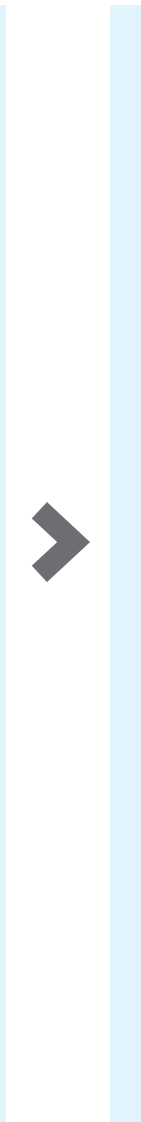

OUTPUTS

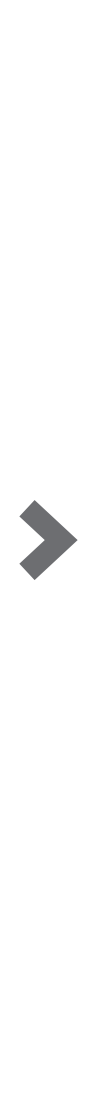

PRECONDITIONS

OUTCOMES

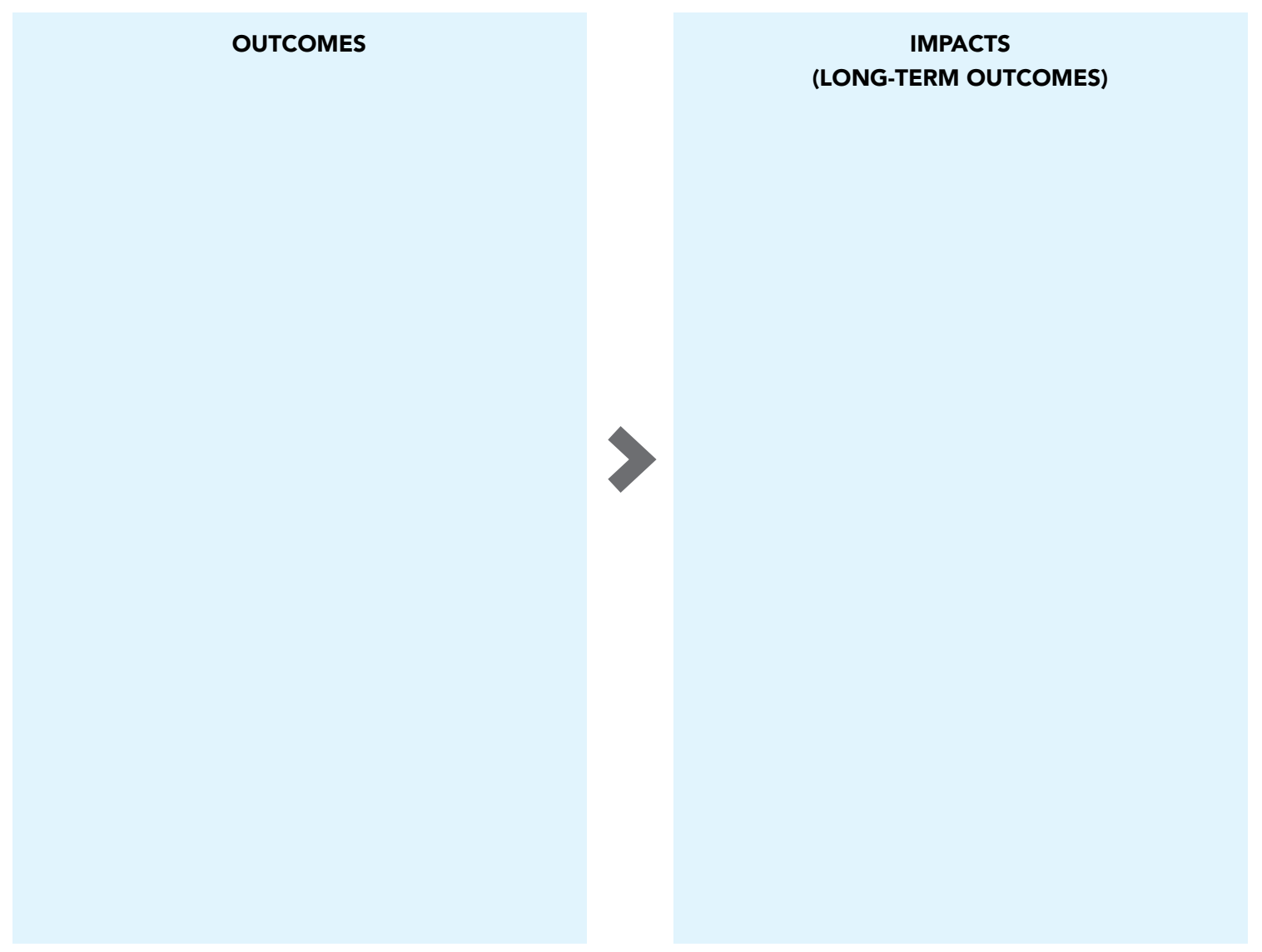

M\&E AND REVISION OF ACTION PLAN

82 GIAHS MONITORING AND EVALUATION MANUAL: A TECHNICAL REFERENCE 
Template 3. | Evaluation report template

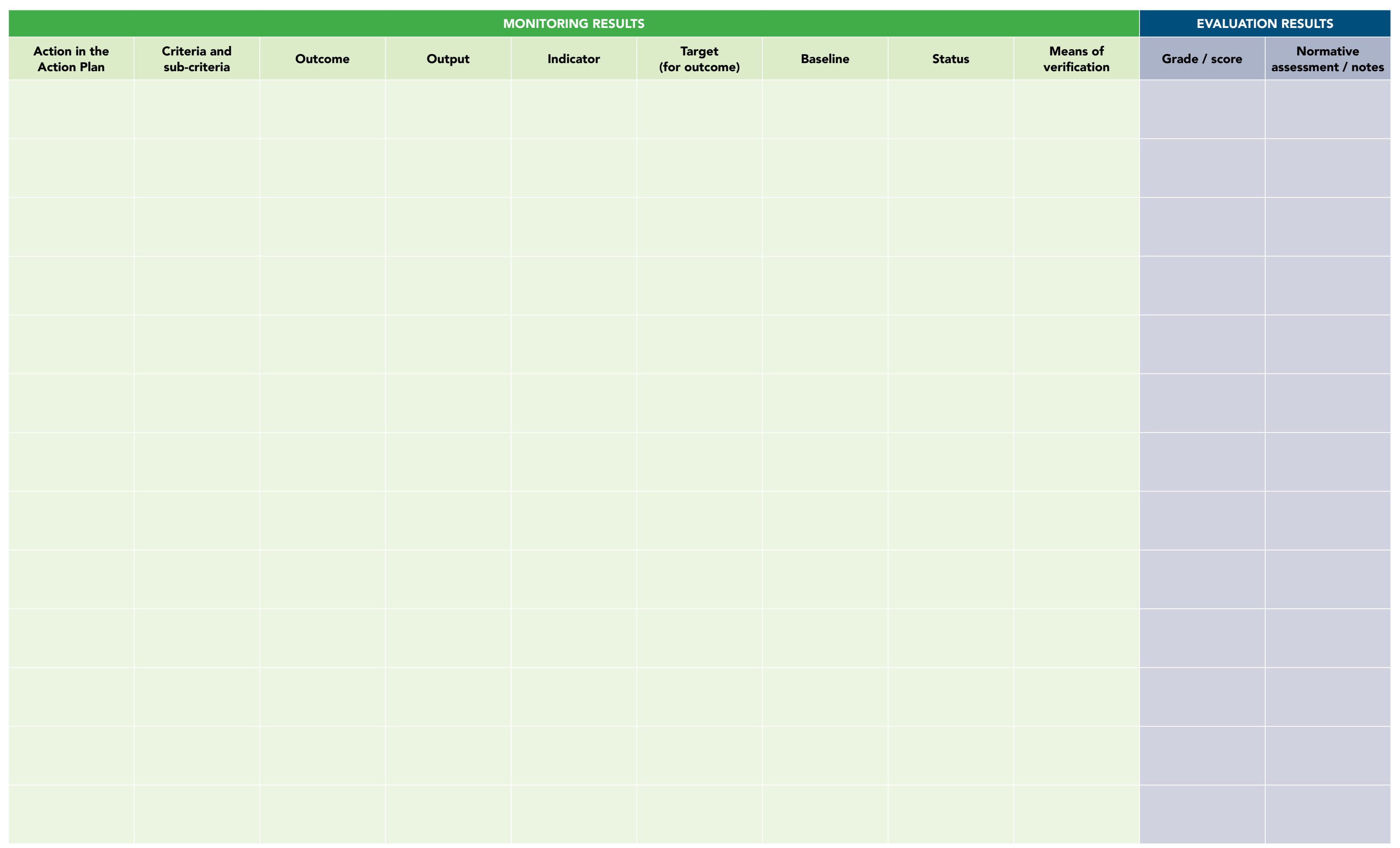


Template 4 | Future scenario planning tool

\begin{tabular}{|c|c|c|c|}
\hline & $\begin{array}{l}\text { SHORT-TERM GOALS } \\
\text { (Duration: }\end{array}$ & $\begin{array}{l}\text { MID-TERM GOALS } \\
\text { (Duration: }\end{array}$ & $\begin{array}{l}\text { LONG-TERM GOALS } \\
\text { (Duration: }\end{array}$ \\
\hline \multicolumn{4}{|l|}{ Vision } \\
\hline \multicolumn{4}{|c|}{ Societal changes } \\
\hline \multicolumn{4}{|c|}{ All GIAHS } \\
\hline \multicolumn{4}{|c|}{ Outcome statement } \\
\hline \multicolumn{4}{|c|}{ Key stakeholders } \\
\hline \multicolumn{4}{|c|}{ GIAHS Promotion Office } \\
\hline \multicolumn{4}{|c|}{ Primary industry } \\
\hline \multicolumn{4}{|c|}{ Related organizations } \\
\hline \multicolumn{4}{|c|}{ Constituent municipalities } \\
\hline \multirow{2}{*}{\multicolumn{4}{|c|}{ Tourism groups }} \\
\hline & & & Consumer groups \\
\hline \multicolumn{4}{|c|}{ NPOs } \\
\hline \multirow{2}{*}{\multicolumn{4}{|c|}{ Women }} \\
\hline Youth & & & \\
\hline \multicolumn{4}{|c|}{ Non-farmer residents } \\
\hline \multicolumn{4}{|c|}{ Civil society or community development groups } \\
\hline \multicolumn{4}{|c|}{ Corporates and businesses } \\
\hline \multirow{2}{*}{\multicolumn{4}{|c|}{$\begin{array}{l}\ldots \\
\text { Criteria }\end{array}$}} \\
\hline & & & \\
\hline \multicolumn{4}{|c|}{ Criterion 1. Food and livelihood security } \\
\hline \multicolumn{4}{|c|}{ Sub-criterion... } \\
\hline \multirow{2}{*}{\multicolumn{4}{|c|}{ Sub-criterion... }} \\
\hline \multirow{2}{*}{\multicolumn{4}{|c|}{$\begin{array}{l}\text { Criterion 2. Agro-biodiversity } \\
\text { Sub-criterion... }\end{array}$}} \\
\hline & & & \\
\hline \multicolumn{4}{|c|}{ Sub-criterion.... } \\
\hline \multicolumn{4}{|c|}{ Criterion 3. Local and traditional knowledge system } \\
\hline \multicolumn{4}{|c|}{ Sub-criterion... } \\
\hline Sub-criterion... & & & \\
\hline Criterion 4. $\mathrm{Cl}$ & & & \\
\hline Sub-criterion... & & & \\
\hline Sub-criterion... & & & \\
\hline Criterion 5. La & & & \\
\hline Sub-criterion... & & & \\
\hline Sub-criterion... & & & \\
\hline Criterion 6. Gc & & & \\
\hline Sub-criterion... & & & \\
\hline Sub-criterion... & & & \\
\hline Criterion 7. $\mathrm{C}_{\mathrm{a}}$ & & & \\
\hline Sub-criterion... & & & \\
\hline Sub-criterion... & & & \\
\hline Criterion 8. $\mathrm{Pa}$ & & & \\
\hline Sub-criterion... & & & \\
\hline Sub-criterion... & & & \\
\hline
\end{tabular}




\section{REEERENCES}

Chapter 1

Food and Agriculture Organization (FAO). (2005). Globally important Indigenous Agricultural Heritage Systems (GIAHS): Strategic framework. Rome: FAO. Accessed 15 December 2021 at https://www.fao.org/ fileadmin/user_upload/giahs/docs/GIAHS\%20Strategic\%20Framework.pdf.

Food and Agriculture Organization (FAO). (2012). Stocktaking of M\&E and Management Information Systems: Selected agricultural and rural development projects in South Asia. FAO, Rome, Italy. Accessed on 7 December 2021 at https://www.fao.org/3/i2883e/i2883e.pdf

Food and Agriculture Organization (FAO). (2021). Designation Process. Source accessed on 22 December 2021 at https://www.fao.org/giahs/become-a-giahs/designation-process/en/.

Vogel, I. (2012). Review of the use of 'Theory of Change' in international development: Review Report, UK Department for International Development (DFID). Source accessed on 22 December 2021 at https://www theoryofchange.org/pdf/DFID_ToC Review_VogelV7.pdf

van Es, M., Guijt, I., \& Vogel, I. (2015). Theory of Change Thinking in practice -Hivos ToC Guidelines - a stepwise approach. https://doi.org/10.1007/BF02562653

\section{Chapter 2}

Food and Agriculture Organization (FAO). (2005). Globally important Indigenous Agricultural Heritage Systems (GIAHS): Strategic framework. Rome: FAO. Accessed 15 December 2021 at https://www.fao.org/ fileadmin/user_upload/giahs/docs/GIAHS\%20Strategic\%20Framework.pdf.

Food and Agriculture Organization (FAO). (2009). Follow-up of recommendations from the 8th Session of the Permanent Forum on Indigenous Issues and highlights of activities undertaken by FAO during 2009. Accessed 15 December 2021 at http://www.un.org/esa/socdev/unpfii/documents/FAO\%20contribution\%20 PFIl\%202010\%20final.doc.

Food and Agriculture Organization (FAO). (2014). Training and Experience Sharing on Globally Importan Agricultural Heritage Systems (GIAHS) under the Framework of South-South Cooperation (SCC) - Think

Globally, Act Locally. Accessed 14 December 2021 at https://www.fao.org/3/bp904e/bp904e.pdf.

International Labour Organization (ILO). (2015). Basic principles of monitoring and evaluation. https://www. ilo.org/wcmsp5/groups/public/---ed_emp/documents/publication/wcms_546505.pdf.

Japan for Sustainability. (2019). "Future City" Initiative. Accessed on 15 December 2021: https://www. japanfs.org/en/projects/future_city/index.html.

Japan International Cooperation Agency (JICA) Research Institute. (1998). Participatory Development and Good Governance: Report of the Aid Study Committee. Tokyo: JICA. Accessed 15 December 2021 at https://www.jica.go.jp/jica-ri/FIC and_JBICl-Studies/english/publications/reports/study/topical/part/ part $5 . \mathrm{html}$.

Ministry of Agriculture, Food and Rural Affairs (MAFRA). (2016). A study on the development of monitoring and management techniques for KIAHS \& GIAHS sites. https://lib.mafra.go.kr/skyblueimage/25256.pdf.

Ministry of Agriculture, Forestry and Fisheries (MAFF). (2020). Effects of multi-functional payment grants and their relationship to SDGs. Source accessed on 15 December 2021 https://www.maff.go.jp/j/nousin/kanri/ tamen siharai/n sansya/pdf/r2 2 mat3.pdf and
Ministry of Foreign Affairs of Japan (MOFA). (2012). Speech by Foreign Minister Koichiro Gemba United Nations Conference on Sustainable Development (Rio +20$)$. Source accessed on 15 December 2021 https://www.mofa.go.jp/policy/environment/warm/cop/rio_20/fm_speech_en.html.

Regional Revitalization Promotion Office. (2021). Promotion of SDGs for the Creation of the Earth. Source accessed on 15 December 2021. https://future-city.go.jp/data/pdf/sdgs/sdgs_bk_210705.pdf.

Reyes S. R. C, Miyazaki, A., Yiu, E., \& Saito, O. (2020). Enhancing Sustainability in Traditional Agriculture: Indicators for Monitoring the Conservation of Globally Important Agricultural Heritage Systems (GIAHS) in Japan. Sustainability, 12(14), pp. 5656

Rural Development Administration. (2021). Guidebook on Community-based Monitoring and Activities for Sustainable GIAHS Conservation. Republic of Korea: RDA.

United Nations Evaluation Group (UNEG). (2014). Integrating Human Rights and Gender Equality in Evaluations. New York: UNEG. Accessed 14 December 2021 at http://www.uneval.org/document/ detail/980.

United States Agency for International Development (USAID). (2021). Discussion note: Complexityaware monitoring. https://usaidlearninglab.org/sites/default/files/resource/files/dn___complexity-aware monitoring_final2021_1.pe

Wagner, Daniel. (2004). Pro-equity approaches to monitoring and evaluation: Gender, marginalized groups and special needs populations. Washington, DC: World Bank. Accessed 14 December 2021 at https://www.infodev. org/sites/defaultffiles/resource/InfodevDocuments 288.pdf.

Wongtschowski, M., Oonk, L. and Mur, R. (2016). Monitoring and evaluation for accountability and learning. KIT Working Paper 2016:3. Accessed 15 December 2021 at https://www.kit.nl/wp-content/ uploads/2018/08/Monitoring-and-evaluation-for-accountability-and-learning.pdf.

\section{Chapter 3}

Amekawa, Y. (2010). Rethinking sustainable agriculture in Thailand: A governance perspective. Journal of Sustainable Agriculture, 34, pp. 389-416.

Food and Agricultural Organization (FAO). (2013). Indicators Definition, Training Material, Regional training on the new CountrySTAT for Anglophone countres, 28 November to 1 December, Dar-es-Salam, Tanzani

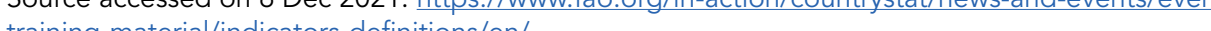
training-material/indicators-definitions/en/.

Food and Agricultural Organization (FAO). (2021). GIAHS Selection Criteria and Action Plan. https://www. fao.org/giahs/become-a-giahs/selection-criteria-and-action-plan/en/.

German International Development Cooperation (GIZ). (2011). Making adaptation count: concepts and options for monitoring and evaluation of climate change adaptation.

Helming, K., Daedlow, K., Hansjürgens, B., \& Koellner, T. (2018). Assessment and governance of sustainable soil management. Sustainability, 10(12), 4432.

Krister P. Andersson, K. P. \& Ostrom, E. (2008). Analyzing decentralized resource regimes from a polycentric perspective. Policy Sciences, 41(1), pp. 71-93.

Lin, B. B. (2011). Resilience in agriculture through crop diversification: Adaptive management for environmental change. BioScience, 61(3), pp. 183-193.

Manuel-Navarrete, D. \& Gallopín, G. (2011). Feeding the World Sustainably: Knowledge Governance and Sustainable Agriculture in the Argentine Pampas. Environment, Development and Sustainability. 14(3).

Min, Q., Zhang, Y., Jiao, W., \& Sun, X. (2016). Responding to common questions on the conservation of agricultural heritage systems in China. Journal of Geographical Sciences, 26(7), pp. 969-982.

Mori, A. S., Furukawa, T., \& Sasaki, T. (2013). Response diversity determines the resilience of ecosystems to environmental change. Biological Reviews, 88, pp. 349-364. 
Reyes S. R. C, Miyazaki, A., Yiu, E., \& Saito, O. (2020). Enhancing Sustainability in Traditional Agriculture: Indicators for Monitoring the Conservation of Globally Important Agricultural Heritage Systems (GIAHS) in Japan. Sustainability, 12(14), pp. 5656

United Nations Development Group (UNDP). (2017). Monitoring and Evaluation United Nations Development Assistance Framework (UNDAF) Companion Guidance. Source accessed on 6 Dec 2021: https://unsdg. un.org/ sites/defaut/fits UNDG-UNDAF-Companion-Pieces-6-Monitoring-And-Evaluation.pdf.

United Nations Development Programme (UNDP). (2009). Handbook on planning, monitoring and evaluating for development results. Source accessed on 6 Dec 2021: http://web.undp.org/evaluation/ handbook/documents/english/pme-handbook.pdf.

United Nations Development Programme (UNDP). (2011). Results-based Management (RBM) Handbook: Harmonizing RBM concepts and approaches for improved development results at country level. Source accessed on 6 Dec 2021: https://unsdg.un.org/sites/default/files/UNDG-RBM-Handbook-2012.pdf.

Volkov, A., Žičkienè, A., Morkunas, M., Baležentis, T., Ribašauskienė, E., \& Streimikiene, D. (2021). A multicriteria approach for assessing the economic resilience of agriculture: The case of Lithuania. Sustainability, 13(4), 2370.

World Bank. (2020). Water in Agriculture. Source accessed on 9 December 2021: https://www.worldbank. org/en/topic/water-in-agriculture\#1.

Yiu, E., Nagata, A., Takeuchi, K. (2016). Comparative study on conservation of agricultural heritage systems in China, Japan and Korea. Journal of Resources and Ecology, 7(3), pp. 170-179.

\section{Chapter 4}

Ishii, K. (2021). Toward the Realization of Sustainable Agriculture and Rural areas in GIAHS "Noto's 2021: https://www.fao.org/3/cb5304en/cb5304en.pdf.

Organisation for Economic Co-operation and Development (OECD). (2011). Compendium of OECD WellBeing Indicators. Source accessed on 17 December 2021. https://www.oecd.org/sdd/47917288.pdf

United Nations Development Group (UNDG). (2011). Results-based management handbook: Harmonizing RBM concepts and approaches for improved development results at country level.

\section{Chapter 5}

Rietbergen-McCracken, J. \& Narayan, D. (1998). Participation and Social Assessment: Tools and Techniques. Washington: The World Bank.

The World Bank. (2010). Participatory Monitoring and Evaluation, in Topics: Participation and Civic Engagement. Washington D.C.: The World Bank.

Chapter 6

Organisation for Economic Co-operation and Development (OECD). (2019). Better Criteria for Better Evaluations: Revised Evaluation Criteria Definitions and Principles for Use. http://www.oecd.org/dac/ evaluation/revised-evaluation-criteria-dec-2019.pdf

United Nations Development Programme (UNDP). (2021). UNDP Evaluation Guidelines, Independent UP Evaluation Office of UNDP, New York, June 2021. http://web.undp.org/evaluation/Manual/documents/PDF/
UNDP Evaluation_Manuals.pdf

United Nations Evaluation Group (UNEG). (2016). Norms and Standards for Evaluation. New York: UNEG. http://www.unevaluation.org/document/download/2787 


\section{UNU-IAS}

Institute for the Advanced Study of Sustainability

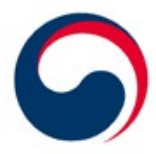

Rural Development Administration 